\title{
Cardiac purinergic signalling in health and disease
}

\author{
Geoffrey Burnstock • Amir Pelleg
}

Received: 24 November 2014 / Accepted: 25 November 2014 /Published online: 20 December 2014

(C) Springer Science+Business Media Dordrecht 2014

\begin{abstract}
This review is a historical account about purinergic signalling in the heart, for readers to see how ideas and understanding have changed as new experimental results were published. Initially, the focus is on the nervous control of the heart by ATP as a cotransmitter in sympathetic, parasympathetic, and sensory nerves, as well as in intracardiac neurons. Control of the heart by centers in the brain and vagal cardiovascular reflexes involving purines are also discussed. The actions of adenine nucleotides and nucleosides on cardiomyocytes, atrioventricular and sinoatrial nodes, cardiac fibroblasts, and coronary blood vessels are described. Cardiac release and degradation of ATP are also described. Finally, the involvement of purinergic signalling and its therapeutic potential in cardiac pathophysiology is reviewed, including acute and chronic heart failure, ischemia, infarction, arrhythmias, cardiomyopathy, syncope, hypertrophy, coronary artery disease, angina, diabetic cardiomyopathy, as well as heart transplantation and coronary bypass grafts.
\end{abstract}

Keywords ATP · Adenosine · Coronary vessels · Innervation · Cardiomyocytes · Pathophysiology

Electronic supplementary material The online version of this article (doi:10.1007/s11302-014-9436-1) contains supplementary material, which is available to authorized users.

G. Burnstock $(\bowtie)$

Autonomic Neuroscience Centre, University College Medical

School, Rowland Hill Street, London NW3 2PF, UK

e-mail: g.burnstock@ucl.ac.uk

G. Burnstock

Department of Pharmacology and Therapeutics, The University of

Melbourne, Melbourne, Australia

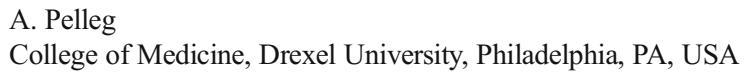

\section{Synopsis}

Introduction

Early history

\section{Cardiac innervation}

Sympathetic nerves

Parasympathetic non-adrenergic, non-cholinergic transmission

Sensory nerves

Intracardiac neurons

Central nervous system control of the heart

Vagal cardiovascular reflexes

\section{Actions of adenine nucleosides and nucleotides}

Cardiomyocytes 1979-1999

$$
P 1 \text { receptors }
$$

$P 2$ receptors

Cardiomyocytes 2000-2014

$P 1$ receptors

P2 receptors

Atrioventricular and sinoatrial nodes

$$
A V \text { node }
$$

SA node

Atria

His-Purkinje fibres

Papillary muscle

Endocardium

\section{Release and degradation of ATP}

Release of ATP

Degradation of ATP 


\section{Cardiac fibroblasts}

\section{Coronary blood vessels}

Pathophysiology and therapeutic potential

Acute and chronic heart failure
Ischaemia
Myocardial infarction
Arrhythmias
Paroxysmal supraventricular tachycardia
Ventricular arrhythmias
Atrial fibrillation
Cardiomyopathy
Syncope
Cardiac hypertrophy
Sick sinus syndrome
Coronary artery disease
Heart transplants and coronary bypass grafts
Heart transplantation
Coronary bypass grafts
Diabetic cardiomyopathy
Angina
Pulmonary hypertension

\section{Concluding comments}

\section{Introduction}

This review is a historical account of purinergic signalling research, which has led to our current understanding of its roles in the complex cardiac physiology and pathophysiology (comparable to retrospective art exhibitions). In 1978, Burnstock proposed that there were two families of receptors for purines, which he named P1 receptors (R) (receptors activated by adenosine) and P2R (receptors activated by adenosine 5'-triphosphate (ATP) and adenosine 5'-diphosphate (ADP)). Methylxanthines antagonised effects mediated by P1R, but not P2R [1]. When the actions of ATP were equipotent or less potent than that of adenosine, this suggested that ATP was acting via P1R after its enzymatic breakdown to adenosine. This could then be confirmed by antagonism with methylxanthines, such as theophylline or caffeine, non-selective P1R antagonists. The distribution of P1R and P2R in the guinea pig and frog hearts was described on the basis of pharmacology [2]. Current knowledge of receptor subtypes, based on cloning, pharmacological characterisation and second messenger systems published in the $1990 \mathrm{~s}$, is as follows: P1R are $\mathrm{G}$ protein-coupled receptors $(\mathrm{A} 1, \mathrm{~A} 2 \mathrm{~A}, \mathrm{~A} 2 \mathrm{~B}$ and $\mathrm{A} 3$ subtypes), $\mathrm{P} 2 \mathrm{XR}$ are cationic channels (P2X1-7) and $\mathrm{P} 2 \mathrm{Y}$ are $\mathrm{G}$ protein-coupled receptors (P2Y1, P2Y2, P2Y4,
P2Y6, P2Y11, P2Y12, P2Y13 and P2Y14) (see [3, 4]). The development of antibodies for P1R and P2R subtypes led to their localisation using immunohistochemistry and in situ hybridisation techniques, which led to subsequent advances in the field. The effects of adenosine and ATP acting on P1R and P2R on cardiomyocytes are summarised below. Thus, by definition, purinergic signalling means the actions of extracellular purine compounds mediated by cell surface receptors (i.e. P1R and $\mathrm{P} 2 \mathrm{R})$; moreover, the critical roles of intracellular purines in cellular energetics and metabolism are not discussed in this review.

Thousands of papers dealing with purines and the cardiovascular system in general and the heart in particular have been published since the first report on the effects of adenine compounds in the heart in 1929 [5], so it is inevitable that the coverage of the multiple areas of research in this field is limited and the citation of relevant papers is selective. Thus, we apologise if our selection does not include papers that others in the field feel should have been cited. The selection of papers published in the last decade about purinergic signalling in the heart is focused on pathophysiology. The vast majority of studies in this field deal with the two major purines: ATP and the product of its enzymatic degradation, adenosine.

Many reviews on various aspects of purinergic signalling in cardiac physiology and pathophysiology have been published over the years, including the following:

- Physiological roles of cardiac P2X and P2Y purinoceptors [6-16];

- Roles of adenosine in health and disease [17-35];

- Effects of ATP and adenosine on coronary myocytes [12, 36];

- Purine degradation pathways in the myocardium [18, 37];

- Myocardial nucleotide transport [38];

- Non-adrenergic, non-cholinergic (NANC) neural control of the atrial myocardium [39];

- Vagal cardiovascular reflexes [40];

- Genetic modulation of adenosine receptor function [41].

Pathophysiology

- Heart failure [16, 42];

- Coronary artery disease (CAD) [43];

- Congestive heart failure [44];

- Cardiac arrhythmia [45-47];

- Cardioprotection [48-54];

- Ischaemia $[55,56] ;$

- Myocardial transplantation [57];

- Adenosine and kidney function in heart failure $[58,59]$; 
- Paroxysmal supraventricular tachycardia (PSVT) and fibrillation [60-63].

Broad reviews about purinergic signalling have been published that include a section about the heart [64-78].

\section{Early history}

The seminal paper by Drury and Szent-Györgyi [5] reported that extracellular purine compounds, in particular adenosine 5 '-monophosphate (AMP), act on the coronary arteries of the guinea pig, cat, rabbit and dog. Later, it was shown in the perfused rabbit heart that adenosine is a powerful dilator of the coronary vessels [79]. The effects of adenosine on the human heart were also examined early on [80]. Honey et al. [81] concluded that adenosine was not useful for the treatment of heart disease. Intravenous administration of adenosine in patients led to paroxysmal tachycardia. A review summarising these early studies was published by Drury in 1936 [82]. He noted, in particular, unpublished observations that "ATP produces heart block in the guinea pig and appears to be more active than adenosine". Heart block by ATP in the rabbit was also reported [83], and Gaddum and Holtz [84] found that ATP was more than three times more potent than adenosine in this regard. An important book entitled Biological Actions of the Adenine Nucleotides was published in 1950 by Green and Stoner [85], which described seminal studies of the effect of ATP on the heart.

ATP injections were first used for the treatment of angina pectoris associated with coronary disease in the 1940s and AMP was also employed for the treatment of angina [86]. ATP was used early on for the treatment of patients with coronary insufficiency ([87-90]; and see references from an article published by RONA LABORATORIES Ltd. (1955) The influence of adenosine triphosphoric acid on coronary circulation and heart muscle, pp. 1-16). Senile myocardial fibrosis was treated with adenylic derivatives [91].

Since then until the early 1960s, relatively few publications dealt with the actions of extracellular nucleosides and nucleotides in the cardiovascular system. In 1963, Berne [92], and independently Gerlach [93], proposed that adenosine was the physiological regulator of reactive hyperaemia in the heart, what became known as Berne-Gerlach's Adenosine Hypothesis. In 1972, Burnstock's proposal of purinergic neurotransmission led to increased interest in this field [94]. He reported that ATP exerts negative inotropic and chronotropic effects on the mammalian heart and speculated that ATP could be released from vagal nerve terminals. At that time, it was shown in the isolated rat and guinea pig hearts that dipyridamole inhibits the uptake of adenosine [95]. Adenosine analogues were shown to be potent coronary dilators [96].
ATP and ADP were the only consistent releasers of prostaglandins from the isolated perfused rabbit heart, an action abolished by indomethacin [97]. ATP, ADP, AMP and adenosine injected into the left atrium of the guinea pig produced a period of heart block identical in both latency and duration, which raised the possibility that ecto-enzymes degrade extracellular nucleotides to adenosine, the active compound [98]. This was supported later by seminal studies by Schrader and Gerlach [99].

Adenosine produced cyclic AMP (cAMP) accumulation in guinea pig ventricular myocardium [100]. Another landmark paper showed the release of ATP from isolated adult heart cells in response to hypoxia [101]. Inosine, in addition to having cardiostimulatory effects, was reported to reverse $\beta$-adrenoceptor blockade [102]. AMP, as well as adenosine, was claimed to act via a receptor on cultured muscle cells and coronary myocytes [103]. This group also identified the important additional action of adenosine, i.e. the inhibition of the myocardial effect of catecholamines, what became known as the indirect anti- $\beta$-adrenergic action of adenosine [104].

The Adenosine Hypothesis was contested by Burnstock [105], who claimed that ATP, released during hypoxia from endothelial cells leading to the production of nitric oxide (NO), was the compound initially responsible for reactive hyperaemia. This role of ATP is supported by subsequent studies indicating that extracellular ATP can serve as a substrate for the extracellular production of adenosine (mainly by cell surfacelocalised enzymes CD39 and CD73) in addition to its role as a primary signalling molecule (see [106]).

\section{Cardiac innervation}

There are intrinsic cardiac neurons as well as sympathetic, parasympathetic, and sensory innervation of the heart.

Sympathetic nerves

Sympathetic nerve stimulation led to release of ATP and adenosine from the perfused rabbit heart [107]. Adenosine was shown to modulate sympathetic nerve stimulationinduced release of noradrenaline (NA) in the isolated rabbit heart [108]. Rat sympathetic neurons grown singly on small islands of cardiac myocytes were shown to release NA and acetylcholine (ACh) as well as an active compound that hyperpolarised and inhibited contraction of the cells; experimental evidence indicated that this compound was adenosine, the source of which could have been ATP [109]. ATP and NA were implicated as cotransmitters in sympathetic nerves supplying the sinus venosus of the toad [110]. Direct contact 
between sympathetic nerves and rat cardiac myocytes in vitro increased expression of functional calcium channels [111], although it was not recognised in this paper that ATP was a cotransmitter. Von Kügelgen et al. [112] presented, for the first time, evidence that prejunctional inhibition of NA release from sympathetic nerves involved $\mathrm{P} 2 \mathrm{R}$ as well as adenosine and P1R [112]. ATP was shown to be released by isoprenaline from sympathetic nerves in the guinea pig atrium [113]. P2XR on sympathetic nerve terminals in the guinea pig right atrium regulate release of NA [114]. Depressed cardiac contractility occurred during postnatal development in rats after clinical sympathectomy [115], perhaps due to ATP released as a cotransmitter from sympathetic nerves. Ectonucleoside triphosphate diphosphohydrolase (E-NTPDase) and ecto-5'-nucleotidase were shown to be present on nerve fibres only in the rat left ventricle, suggesting a different status of sympathetic nerves in left vs. right ventricles [116].

Parasympathetic non-adrenergic, non-cholinergic transmission

Non-adrenergic, non-cholinergic (NANC) neurotransmission has been identified in the mammalian heart. The transmitters involved were not identified initially, although calcitonin gene-related peptide appeared to be at least one of them [39, 117].

\section{Sensory nerves}

Inhibitory adenosine A1R were identified on cardiac sensory nerves and it was suggested that they may have a modulatory action on cardiac NANC neurotransmission [118, 119]. It was concluded that both A1R and A2R were present on ventricular epicardial sensory nerve endings of dorsal root ganglion (DRG) neurons [120]. Using in situ hybridisation, it was shown that P2X3R are localised on sensory nerves in the heart [121]. Using a canine model in vivo, it was found that $\mathrm{P} 2 \mathrm{X} 2 / 3 \mathrm{R}$ are localised on vagal sensory nerve terminals in the infero-posterior wall of the left ventricle [122].

\section{Intracardiac neurons}

The presence of quinacrine-positive intramural nerve cell bodies and nerve fibres in guinea pig atria suggested that a sub-population of intracardiac nerves could be purinergic (see Fig. 1) [6, 123]. Allen and Burnstock [124, 125] studied the actions of ATP on intracardiac neurons of two main types, AH and $\mathrm{M}$ cells in ganglia in the atria and in interatrial septum of newborn guinea pig heart. Three different responses to ATP were observed; initially, rapid transient depolarisations of about $40 \%$ of both $\mathrm{AH}$ and $\mathrm{M}$ cells with agonist potencies of ATP $>$ ADP, but with AMP and adenosine ineffective. In a further $30 \%$ of AH cells, ATP evoked an initial
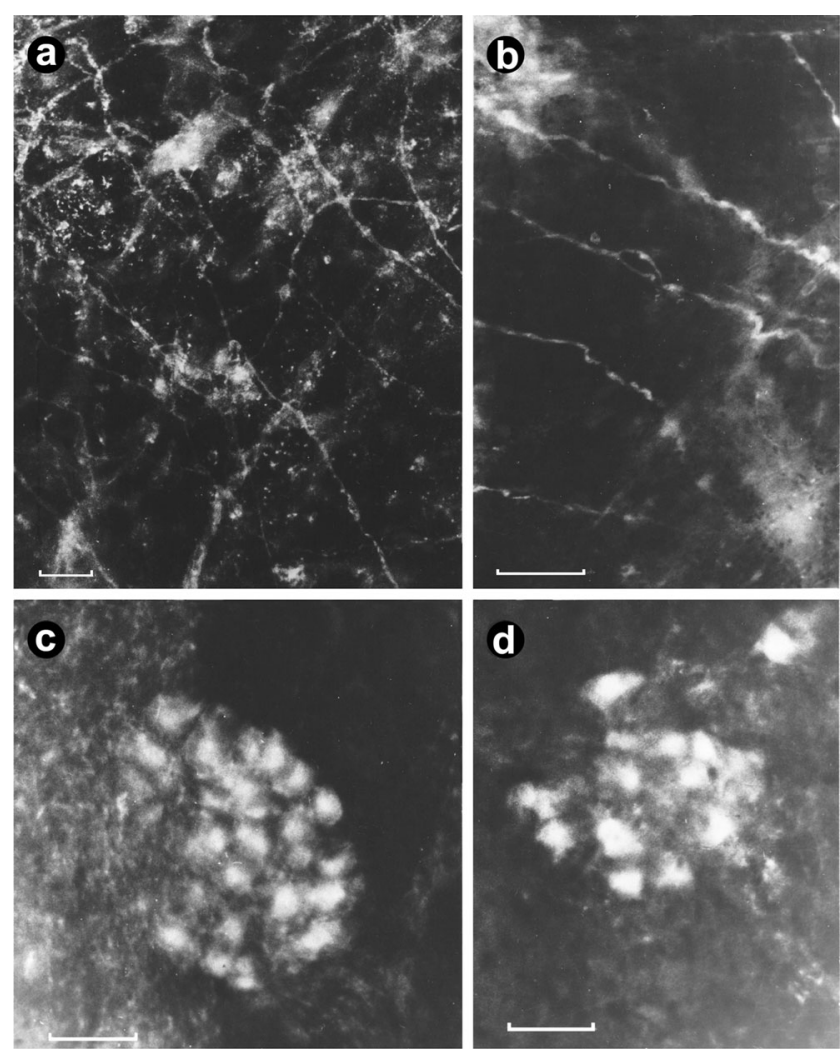

Fig. 1 Quinacrine fluorescent histochemistry showing quinacrinepositive intramural nerve cell bodies and varicose fibres in the guinea pig atrium. a A fine plexus of quinacrine-positive nerve fibres. b A similar preparation to a after treatment with 6-hydroxydopamine (one intraperitoneal injection, $250 \mathrm{mg} / \mathrm{kg}, 24 \mathrm{~h}$ prior to sacrifice). c A cardiac ganglion showing 20-30 quinacrine-positive nerve cell bodies; $\mathbf{d}$ Another ganglion, containing a smaller proportion of quinacrine-positive cell bodies. All bars represent $100 \mu \mathrm{m}$ (reproduced from [6], with permission)

depolarisation, followed by hyperpolarisation and a slow prolonged depolarisation. Finally, in about $2 \%$ of AH cells, ATP evoked a slow depolarisation [124, 125].

In a later study by another group, the actions of ATP on dissociated neurons from rat cardiac ganglia supported and extended these findings [126]. Huang et al. studied purinergic modulation of adult guinea pig cardiomyocytes in long-term cultures and co-cultures with extracardiac and intrinsic cardiac neurons $[127,128]$. They found that cardiac neurons expressing P2R could greatly enhance cardiac myocyte contractile rate when activated by ATP and also that some intracardiac neurons expressed adenosine receptors [127, 128]. Thus, intracardiac neurons are not all parasympathetic neurons controlled by nicotinic neurotransmission, but they may also contain sensory neurons playing a role in local reflex pathways [129]. Indeed, Armour and co-workers have shown that in situ canine nodose ganglion afferent neurons can be activated by adenosine and ATP $[127,130]$. A later study showed that in rat intracardiac neurons, ATP activated P2Y2R to transiently raise $\left[\mathrm{Ca}^{2+}\right]_{\mathrm{i}}$ and activate an inward current [131]. The ecto-nucleotidase CD39 localised in intrinsic neurons of 
human and porcine heart was shown to modulate ATPinduced NA exocytosis [132].

\section{Central nervous system control of the heart}

The increase in heart rate caused by activation of A1R appears to be mediated by its action on the central nervous system (CNS), while the decrease in blood pressure by activation of A2AR appears to be mediated in the periphery [133].

\section{Vagal cardiovascular reflexes}

There was an early hint about possible effects of purines in the heart mediated by a central vagal reflex [5]. In anaesthetised dogs, ATP, but not adenosine, was shown to trigger a vagal reflex, which appeared to mediate, in part, the transient negative chronotropic and dromotropic effects on the sinoatrial (SA) and atrioventricular (AV) nodes, respectively [134, 135]. The right vagus was identified to play a dominant role in carrying cardiopulmonary vagal afferent traffic [136] and subsequently the dominant role of the right vagus in the ATP-triggered vagal reflex in dogs was shown [137-139]. This reflex is the result of the activation of $\mathrm{P} 2 \mathrm{X} 2 / 3 \mathrm{R}$ localised on vagal sensory nerve terminals in the infero-posterior wall of the left ventricle (see Fig. 2) [122]. Thus, the actions of extracellular ATP in the heart are mediated by adenosine, the product of its rapid degradation by ecto-enzymes as well as a central vagal reflex. This explains the differential potency of

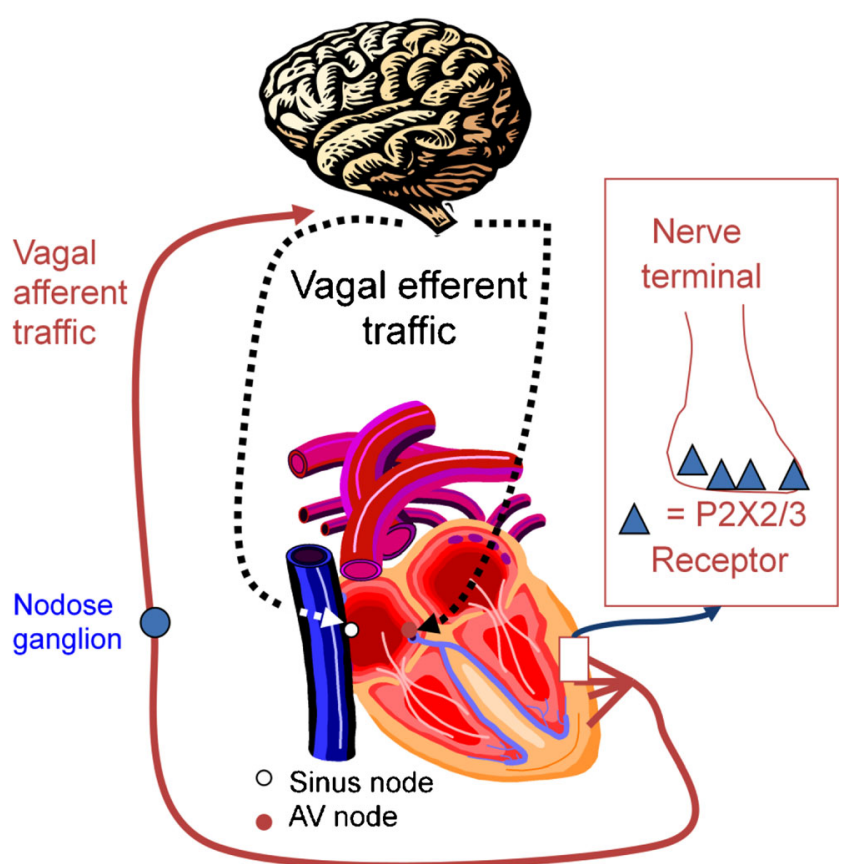

Fig. 2 Central vagal cardio-cardiac reflex triggered by ATP (modified and reproduced from [15])
ATP vs. adenosine for the suppression of sinus node automaticity and AV nodal conduction [15].

In view of the vagal component of the bradycardic action of ATP in the heart, Flammang et al. [140] hypothesised that patients with neurally mediated syncope might be hypersensitive to an intravenous bolus injection of ATP. They found that there was a cohort of patients with neurally mediated syncope or syncope of unknown origin that manifested an exaggerated response to ATP and that these patients could benefit from pacemaker therapy [141]. The negative chronotropic and dromotropic vagal effect of ATP in syncopal patients is reproducible [142] and thus, ATP is now an accepted diagnostic tool in this setting [143].

Evidence has been presented to suggest that ATP attenuates reflex increases in renal sympathetic nerve activity by stimulating left ventricular chemoreceptors with cardiac vagal afferents [144]. Adenosine is an endogenous modulator of cardiac excitatory afferent nerves and this has been suggested to play a mechanistic role in vasovagal syncope [145]. There is functional and immunohistochemical evidence that the cardiopulmonary chemoreflex pathways in the caudal nucleus of the solitary tract in the brainstem are directly inhibited by A1R activation and indirectly inhibited by A2AR via $\gamma$ aminobutyric acid release [146].

\section{Actions of adenine nucleosides and nucleotides}

Cardiomyocytes 1979-1999

\section{P1 receptors}

There is evidence that all four subtypes of P1R are expressed in cardiomyocytes [34]. A1R mediate the direct negative chronotropic and dromotropic actions of adenosine as well as indirect anti- $\beta$ adrenergic actions [28, 147, 148]. In addition, there is substantial evidence that the activation of all four adenosine receptors is cardioprotective [149].

$\mathrm{A} 1 \mathrm{R}$ were found in the guinea pig myocardium and adenylate cyclase was shown to be coupled to these receptors in the ventricular membranes [150]. A1R are also found in the guinea pig atrium [151] and rat ventricular myocytes [152]. It was suggested that cardiac A1R are critically dependent on temperature [153]. Evoniuk et al. [154] confirmed that A1R mediated the negative chronotropic effect of adenosine, while A2R mediated its vasodilatory-hypotensive effect.

A1R mediate the indirect anti-adrenergic action of adenosine, which is manifested in the attenuation of the electrophysiologic, metabolic and inotropic effects of catecholamines. For example, adenosine antagonised catecholamine-elicited glycogenolysis [155]. In addition, adenosine antagonised the positive inotropic action 
mediated by $\beta$-, but not $\alpha$-adrenoceptors in rabbit papillary muscle [156, 157]. Furthermore, adenosine abolished early after-depolarisations and triggered activity induced by isoproterenol in isolated guinea pig ventricular myocytes [158]. Under specific experimental settings, the actions of adenosine and catecholamines could be additive; e.g. stimulation of cAMP production produced by adenosine and isoproterenol combined was essentially the sum of the two individual responses [159]. Chronic dietary theophylline was shown to up-regulate cardiac A1R, without changing the anti-adrenergic or inhibitory inotropic and chronotropic actions of adenosine receptor agonists [160]. In addition to A1R-mediated inhibitory effects, activation of A2AR resulted in stimulation of contractility of cardiomyocytes [161] and attenuation of the anti-adrenergic actions of A1R activation [162]. Interestingly, a differential A1R reserve for the direct and indirect actions of adenosine in the guinea pig atrial myocytes has been documented [163].

Cardiac sympathetic neurotransmission was shown to be inhibited by adenosine [164-166]. Sympathetic nerve stimulation led to the formation and release of adenosine from the rabbit heart [167]. Presynaptic inhibitory action of adenosine on release of NA from sympathetic nerves supplying the guinea pig heart was reported [168].

Adenosine is transported into rat cardiac myocytes via a saturable process [169]. Potentiation of the effects of adenosine by diazepam as well as dipyridamole on cardiac muscle was suggested to be due to inhibition of adenosine uptake [170]. Coformycin, an inhibitor of adenosine deaminase (ADA), potentiated the concentration-dependent decrease in the action potential duration and contractile force of atrial preparations caused by adenosine [171].

Certain actions of adenosine manifest an age-dependency; e.g. young guinea pigs were sensitive to the positive inotropic effect of the A1R antagonist NPC 205. The sensitivity was lower in older animals and basal heart rate was also significantly lower [172]. A2R activation was shown to inhibit neutrophil adhesion and injury in isolated cardiac myocytes [173]. A decrease in A1R-mediated responses was reported in ageing rat heart $[174,175]$.

No evidence was found for the presence of $A 3 R$ in the atrium [176-178]. However, induction of apoptosis in cardiac myocytes from newborn rats by an A3R agonist was reported [179].

A1R stimulation activated $\delta$-protein kinase $(\mathrm{PK}) \mathrm{C}$ in rat ventricular myocytes [180]. Adenosine was shown to stimulate NO synthesis in rat cardiac myocytes [181]. Adenosine stimulated atrial natriuretic peptide (ANP) expression in cultured ventricular cardiomyocytes [182]. A1R over-expression can reverse the inotropic, but not the chronotropic, effects of adenosine in mouse heart [183]. A2AR activation enhances cardiomyocyte shortening [184].

\section{P2 receptors}

ATP elicited a triple response of the frog ventricle: an initial increase in contractility, followed by a period when the twitch amplitude fell, sometimes below the control level and thirdly, a slowly developing and longer-lasting increase in contractile force [185]. ATP was shown to facilitate the discharge of calcium from the sarcoplasmic reticulum in frog heart cells [186], in retrospect via P2YR. Evidence was presented to suggest that the inhibitory responses produced by ATP in the rat ventricle were mediated by P2R [187].

ATP, ADP and $\beta, \gamma$-methylene ATP had negative chronotropic and inotropic effects on guinea pig atrium, while $\alpha, \beta$-methylene ATP $(\alpha, \beta$-meATP) (which acts on P2XR) induced a stimulatory response [188]. ATP directly affected junctional conductance between paired ventricular myocytes from the heart of guinea pigs which could be explained by a specific ligand-receptor interaction between ATP and gap junctional channel proteins [189].

ATP is released from rat ventricular myocytes in response to hypoxia and acidosis $[190,191]$ or adrenaline in the perfused heart [192]. ATP increased $\left[\mathrm{Ca}^{2+}\right]_{\mathrm{i}}$ and contractility of ventricular myocytes of rat [193-195] and atrial myocytes of guinea pig and rabbit [196]. $\mathrm{Ca}^{2+}$ mobilisation by ATP was claimed to be regulated by PKC and PKA [197]. ATP was shown to increase mechanical activity and inositol trisphosphate $\left(\mathrm{InsP}_{3}\right)$ production in rat heart $[198,199]$, in retrospect mediated by P2YR. When inhibitory adenosine receptors were blocked, ATP produced a positive inotropic effect, probably mediated by P2YR [200]. Purinergic stimulation of rat cardiomyocytes induced tyrosine phosphorylation, a major mechanism for $\operatorname{InsP}_{3}$ generation [201].

P2X1R were identified on cardiac myocytes [202], and both P2X3 and P2X4R mRNA were detected in the human heart [121, 203]. In addition, P2X1, P2X3, P2X4 and P2Y2, P2Y4 and P2Y6R were identified in the human foetal heart [204]. Furthermore, P2X1R were found in low density on myocytes of the rat heart, with occasional high density patches near nerve varicosities, while $\mathrm{P} 2 \mathrm{X} 2$ and $\mathrm{P} 2 \mathrm{X} 3 \mathrm{R}$ were confined to nerve fibres [205]. Photoaffinity labelling and functional assays of ATP receptors expressed by cardiac myocytes were first described by Giannattasio et al. [206, 207].

The mechanism underlying the positive inotropy induced by ATP in rat papillary muscle in vitro was determined to be mediated, in part, by increased $\mathrm{Ca}^{2+}$ inward current [208]. While in bovine atrial cells, dual control of inwardly rectifying $\mathrm{K}^{+}$channels by ATP and ACh was reported [209]. Activation of chloride currents by purinergic stimulation of guinea pig atrial myocytes was described by Matsuura and Ehara [210] and later in rat and mouse ventricular myocytes [211, 212]. ATP-induced increase in $\left[\mathrm{Ca}^{2+}\right]_{\mathrm{i}}$ was attenuated in cardiomyocytes from vitamin $\mathrm{B}_{6}$-deficient rats [213]. The activation of $\mathrm{Cl}^{-}$ 
channels in mouse atrial and ventricular myocytes is due to activation of cystic fibrosis transmembrane conductance regulator (CFTR) $\mathrm{Cl}^{-}$channels through a novel intracellular signalling pathway involving purinergic activation of PKC and PKA [214]. L-type calcium channel activity was modulated by ATP and adenosine-5'-( $\gamma$-thio)-triphosphate in ferret and rat ventricular cells $[215,216]$ and sinoatrial nodal cells [217]. Increase in L-type calcium current amplitude induced by ATP was shown to be mediated by P2YR [218]. A later study confirmed that P2R as well as P1R contribute to the ATP-induced inhibition of L-type $\mathrm{Ca}^{2+}$ current in rabbit atrial myocytes $[219,220]$.

Experiments with electrically driven rat atria suggested that P2YR, as well as P1R (since 2-methylthio ATP (2-MeSATP) was effective) mediated rapid decrease in contractility, while P2XR (since $\alpha, \beta$-meATP was effective) mediated the increase in contractility [221], in retrospect probably by $\mathrm{P} 2 \mathrm{X} 1$ and/or P2X3R

Molecular cloning and functional expression of a novel rat heart P2XR was reported [203]. Both P2XR and P2YR were cloned and characterised from the human foetal heart, but their role in developmental processes and physiological activation of the foetal heart remains to be determined [204]. Activation of P2R in guinea pig atrial cells was shown to increase the delayed rectifier $\mathrm{K}^{+}$current through intracellular mechanisms independent of PKA, PKC or intracellular free $\mathrm{Ca}^{2+}$ [222]. Subsequently, it was claimed that P2YR were involved in this action [223]. Diadenosine polyphosphates activated guinea pig left atrium via P1R and P2R [224].

Activation of rat ventricular myocytes by ATP triggered oscillatory contractions and potentiated the amplitude of electrically triggered contractions [225]. ATP activated the muscarinic $\mathrm{K}^{+}$channel via pertussis toxin-sensitive $\mathrm{G}$ proteins in guinea pig [226, 227] and dog atrial myocytes [228]. Uridine 5'-triphosphate (UTP) also activated muscarinic $\mathrm{K}^{+}$channels, suggesting mediation by P2U (P2Y2 and/or P2Y4) receptors [229].

\section{Cardiomyocytes 2000-2014}

\section{P1 receptors}

A1R stimulation inhibited $\alpha_{1}$-adrenergic activation of the cardiac sarcolemmal $\mathrm{Na}^{+} / \mathrm{H}^{+}$exchanger [230]; it was also associated with increased production of $\mathrm{NO}$ and cyclic GMP [231], which prevents mitochondrial oxidant damage in rat cardiomyocytes [232]. Chronic caffeine treatment increased heart rate and resting blood pressure, which was concurrent with changes in P1R function [233]. A1R over-expression reverses, at least in part, the interaction of $\beta$-adrenergic and A1R stimulation suggesting that the receptor/effector coupling is dependent on receptor density at least in this experimental model [234]. Adenosine protects against apoptosis induced by angiotensin II in rat cardiomyocyte cultures [235].

A2AR activation increased contractility of isolated perfused hearts [236]. A2BR-mediated NO release in the mouse heart was blunted by knockout of the A2AR gene [237].

Diadenosine polyphosphates activated coronary vessels via P1R and P2R [238]. Diadenosine pentaphosphate $\left(\mathrm{Ap}_{5} \mathrm{~A}\right)$ was shown to produce A1R-mediated pro-arrhythmic effects in rabbit atrial myocardium [239]. Diadenosine monophosphate exerts indirect and direct negative inotropic effects in isolated human cardiac atrial preparations through A1R [240]. Adenosine $5^{\prime}$-tetraphosphate $\left(\mathrm{Ap}_{4} \mathrm{~A}\right)$ has been identified and characterised in human myocardial tissue [241] as well as $\mathrm{Ap}_{5} \mathrm{~A}$ and diadenosine hexaphosphate $\left(\mathrm{Ap}_{6} \mathrm{~A}\right)$ [242]. In human and guinea pig hearts, $A p_{5} \mathrm{~A}$ had positive inotropic and sustained anti- $\beta$-adrenergic effects, acting via P1R [243]. $\mathrm{Ap}_{5} \mathrm{~A}$ was identified as a potent activator of the sheep cardiac ryanodine receptors [244].

Free radicals potentiated the negative dromotropic effect of adenosine in guinea pig heart [245]. p38 Mitogen-activated protein kinase (MAPK) plays a mechanistic role in A1Rmediated anti-adrenergic action of adenosine in rat ventricular myocytes [246], while ERK1/2 signalling pathway activation by adenosine in cardiomyocytes resulted from an additive stimulation of A1R, A2AR and A3R, which involved $\mathrm{G}_{\mathrm{i} / \mathrm{o}}$ proteins, $P K C$, and tyrosine kinase for $A 1 R$ and $A 3 R$, and $G_{s}$ and PKA for A2AR; moreover, the A3R response also involved a cAMP/PKA pathway via PKC activation [247].

A3R stimulation reversed myocardial stunning of isolated atrial and papillary muscles [248]. An age-related reduction in expression of both $\mathrm{A} 1 \mathrm{R}$ and $\mathrm{A} 2 \mathrm{R}$ was found in the rat heart [249] in agreement with previous studies [174, 175]. The negative inotropic and chronotropic effects of fluoxetine, a selective serotonin re-uptake inhibitor antidepressant, on isolated guinea pig atria were suggested to be mediated by inhibition of re-uptake of adenosine or by the activation of A1R [250]. While the A1R is involved in the regulation of heart rate in the mouse, the magnitude of its involvement is more pronounced in males vs. females [251]. Inhibition of ADA enhanced the inotropic response mediated by A1R in hyperthyroid guinea pig atrium [252].

Several studies using genetic models of A1R knockout confirmed findings of previous studies, that the negative chronotropic action of adenosine is mediated by A1R. Thus, using A1R and A2AR knockout male mice, it was found that heart rate was higher in A1R knockout mice, but lower in A2AR knockout mice [253]. Also, the negative chronotropic effect of bolus injections of adenosine in vivo were abolished in A1R knockout mice [254].

It was reported that multivalent dendrimeric and monomeric adenosine receptor agonists attenuated cell death in HL-1 mouse cardiomyocytes expressing A3R [255]. Also, 
adenosine attenuated cardiomyocyte hypertrophy; adenosine kinase is an important mediator of this effect [256].

Differential effects of A2AR and A2BR on cardiac contractility were described [257]. A2BR mediated direct contractile effects without altering $\beta$-adrenergic or A1R-mediated anti-adrenergic effects, while A2AR mediated increase in cardiac contractility indirectly by modulating the A1Rmediated anti-adrenergic effect. Caffeine disrupted embryonic cardiac function and its response to hypoxia through blockade of A1R that raises concern regarding caffeine exposure during embryogenesis, particularly in pregnancies with increased risk of embryonic hypoxia [258]. NA release and stress-induced heart rate increase was selectively attenuated by partial A1R agonists, most likely due to a presynaptic attenuation of NA release [259].

There is reduced adenosine release from the heart of aged mammals, probably due to reduced mitochondrial purine synthesis [260]. A2BR mediate the release of interleukin (IL)-6 and IL-8 and vascular endothelial growth factor from cardiac stromal cells [261]. CD73, nucleoside transporters and inosine provoke arrhythmia mediated by $\mathrm{A} 1 \mathrm{R}$ and $\mathrm{A} 2 \mathrm{AR}$ in the developing heart [262]. The elevated plasma concentration of adenosine was probably the cause of bradycardia during experimental breath-hold diving [263]. A1R antagonists prevented the electrophysiological effects of amitriptyline, a tricyclic antidepressant, on atrial action potentials; it was suggested therefore, that A1R activation could mediate the cardiovascular toxic effects produced by amitriptyline [264]. Caffeine was shown to act via A1R in mouse embryos to alter adult cardiac function and DNA methylation [265].

\section{P2 receptors}

In concert with previous studies in animal models, it was found that ATP and adenosine also shorten action potential duration in atrial but not ventricular myocytes [266]. Regulation of muscarinic $\mathrm{K}^{+}$channels, which mediate action potential shortening by ATP in guinea pig atrial myocytes was found to be mediated by the activation of phospholipase $\mathrm{C}$ (PLC) and subsequent cell membrane depletion of phosphatidylinositol 4,5-bisphosphate [267]. It was reported that P2X4R and P2X7R are expressed in the t-tubular network of rat ventricular cells [268]. Longitudinal stretch of rat atrial myocytes induced the activation of non-selective cation channels [269], which, in retrospect, may be due to release of ATP acting on P2XR. The involvement of death receptor signalling in mechanical stretch-induced cardiomyocyte apoptosis [270] might be mediated by P2X7R after release of ATP. P2XR activation enhanced cardiac contractility in isolated rat and mouse hearts [271]. Indeed, using transgenic mice with cardiac-specific over-expression of the human P2X4R [272], it was found that $\mathrm{P} 2 \mathrm{X} 4 \mathrm{R}$ mediate the increase in myocyte contractility in response to ATP [273]. In another study, an increase in ATP-induced inward current was observed in mouse cardiac myocytes over-expressing P2X4R [274]. Activation of cardiac P2XR was shown to augment the $\mathrm{Ca}^{2+}$ content of sarcoplasmic reticulum independent of cAMP and therefore likely to contribute to P2XR-mediated myocyte contractility [275]. In mouse cardiomyocytes, the positive inotropic effects of ATP were reported to be mediated by P2Y11R [276]. It was tentatively suggested that the positive inotropic effects of ATP might be mediated by P2X4-like receptors [277]. Interactions between purinergic and adrenergic receptors in the regulation of rat myocardial contractility in postnatal development was reported [278]. P2Y2/4R were involved in the regulation of myocardial contractility in growing rats [279].

It was suggested that ATP and UTP had opposite effects on the regulation of ANP secretion; ATP via adenosine and P1R increased secretion, while UTP via P2YR decreased secretion [280]. In a later paper, stimulation of ANP secretion was shown to be mediated by A3R [281].

P2YR were shown to mediate the regulation of CFTR chloride channels in mouse cardiac myocytes [282]. Regulation of UTP-activated $\mathrm{Cl}^{-}$current involves P2YR, PLC-PKC signalling and ATP hydrolysis in mouse ventricular myocytes [283]. Outwardly rectifying chloride channel activity was upregulated by intracellular ATP, but inhibited by extracellular nucleotides [284]. A study using guinea pig ventricular myocytes has indicated that extracellular ATP modulates the activity of $\mathrm{K}_{\text {ATP }}$ channels via P2YR coupled to phosphatidylinositol 4,5-bisphosphate [285]. P2X1R in human myocardium were found to be densely localised in gap junctions at intercalated discs between myocytes, closely associated with connexin 43 in some regions of some gap junctions, but spatially separate in others regions (Fig. 3) [286].

P2R-mediated signalling appears to be involved in the intercellular synchronisation of intracellular $\mathrm{Ca}^{2+}$ oscillations in cultured cardiac myocytes [287]. It was shown that maxianion channels expressed by neonatal cardiomyocytes were involved in ATP release [288].

Valvular myofibroblasts, together with endothelial cells, cardiac myocytes and smooth muscle from the cardiac valves were shown to be activated by P2Y2R-mediated $\mathrm{Ca}^{2+}$ release [289]. ATP and UTP activation of P2Y2R via a G protein and stimulation of PLC $\beta$ induces the opening of heteromeric TRPC3/7 channels, leading to a sustained, non-specific cationic current [290]. P2Y1R, P2Y2R, P2Y4R and P2Y6R as well as P2Y11-like receptors were co-expressed and induced function through $\mathrm{G}_{\mathrm{q} / 11}$ protein coupling in neonatal rat cardiac myofibroblasts (see Fig. 4) [291].

Increased P2X7R expression was shown in atrial cardiomyocytes of caveolin-1-deficient mice [292]. Stretch of atrial myocytes stimulates recruitment of macrophages via ATP released through gap-junction channels [293]. 

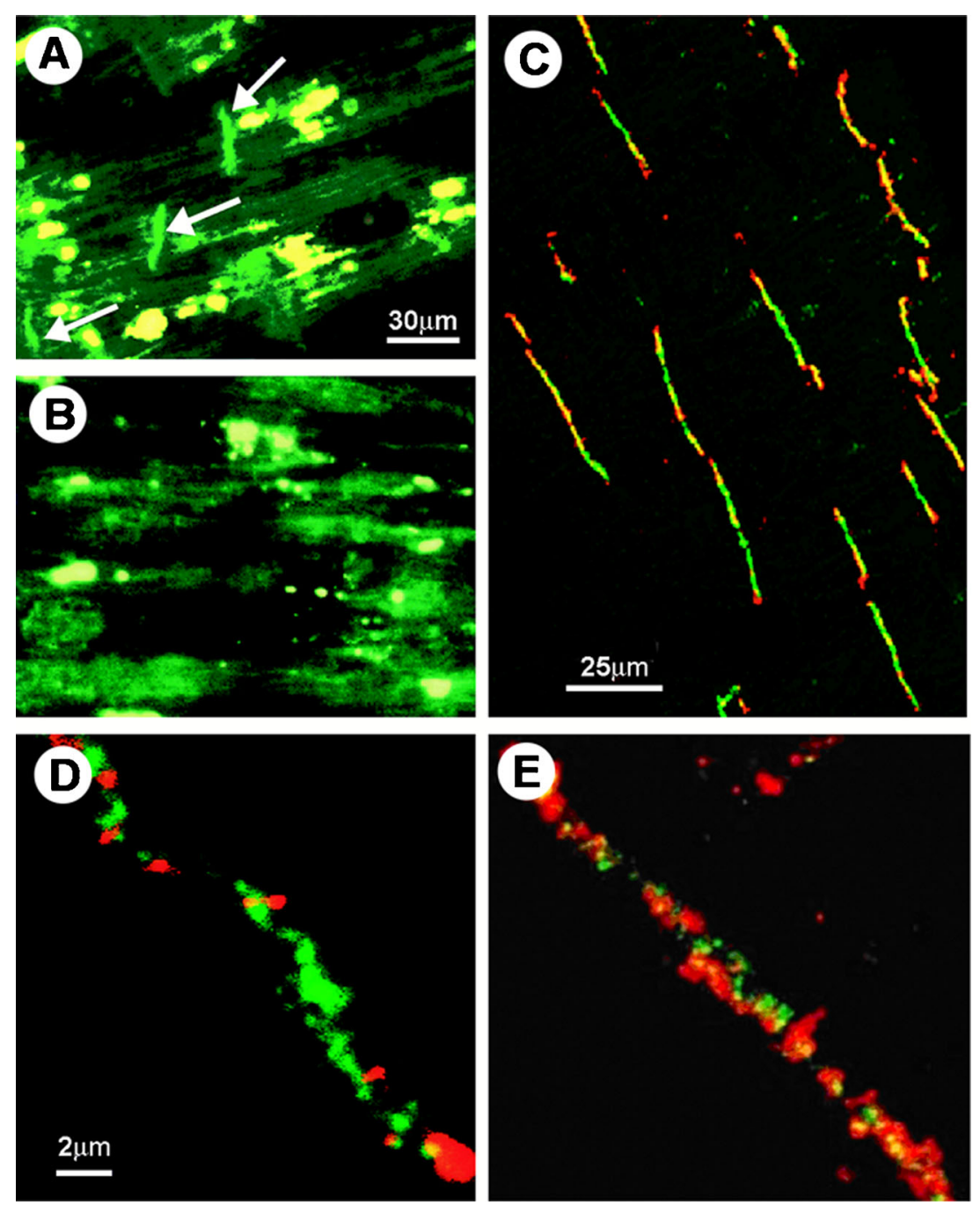

Fig. 3 Immunohistochemical staining of P2X1 receptors in human left ventricle and co-localisation with connexin43. a P2X1 staining is shown (green, FITC) with arrows indicating the intercalated discs. Scale bar= $30 \mu \mathrm{m}$. b After pre-incubation of the antibody with epitope peptide, positive P2X1 staining at intercalated discs preferentially disappears, although some green and yellow auto-fluorescence remains (probably due to the highly fluorescent protein lipofuscin). Scale bar as in a. c Double labelling of $\mathrm{P} 2 \mathrm{X} 1$ receptor and connexin43 in human left ventricle. Sections were double-labelled with anti-P2X1 (green, FITC)

Atrioventricular and sinoatrial nodes

AV node

Both adenosine and ATP suppress atrioventricular (AV) nodal conduction. In 1949, Wayne et al. [294] showed that the depressant effects of ATP and adenosine were dominant on the $\mathrm{AV}$ node. $\mathrm{AV}$ nodal conduction block associated with myocardial ischaemia is mediated by adenosine [295, 296]. A subsequent study showed that endogenous adenosine, via $\mathrm{A} 1 \mathrm{R}$ and a pertussis toxin-sensitive $\mathrm{G}$ protein, mediates hypoxia-induced AV nodal conduction block in guinea pig heart in vivo [297]. In the isolated guinea pig heart, the action

and anti-connexin43 (red, Cy3). The images were obtained by confocal microscopy. Both P2X1 and the gap junction protein connexin 43 are localised in the intercalated discs. Note the variable degree of double labelling (yellow) in different discs. Scale bar $25 \mu \mathrm{m}$. d and e are higher magnification micrographs showing the variable amount of double labelling of P2X1 receptors and connexin43 in two different gap junctions. Scale bar in d and e $2 \mu \mathrm{m}$ (reproduced from [286], with permission)

of ATP was shown to be mediated by adenosine [295]. The suppression of $\mathrm{AV}$ nodal conduction by adenosine, manifested in the prolongation of the AH interval, is mediated by A1R [298]. The potency of the bradycardic effects of adenosine manifests species variability among guinea pig, rat and rabbit [299]. Chronic administration of R-phenyl isopropyl adenosine to guinea pigs desensitised the AV node to the negative dromotropic effect of adenosine in a homologous but not a heterologous manner and desensitisation of the AV node response to adenosine was associated with down-regulation of A1R, a decrease in the fraction of A1R in the high-affinity state and a decrease in the contents of $G_{i}$ and $G_{o}$ proteins [300]. 

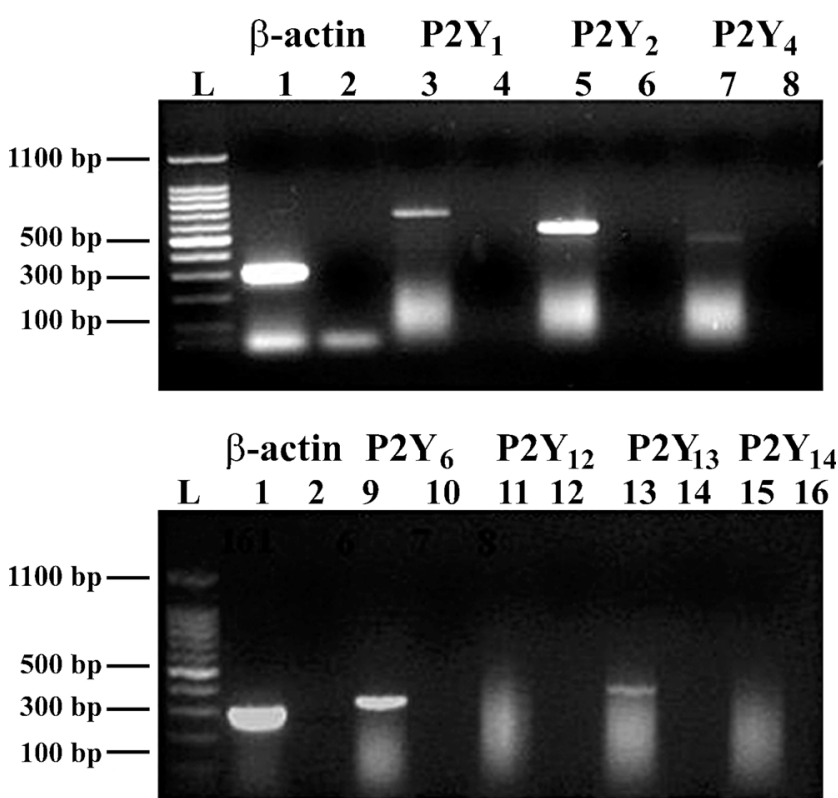

Fig. 4 Expression of P2Y receptor mRNA obtained from neonatal rat cardiac myofibroblasts. Total RNA was prepared and reverse transcription-polymerase chain reaction was carried out; $1.5 \%$ agarose gel electrophoresis represent $m R N A$ coding for $\beta$-actin (lanes 1-2), $\mathrm{P} 2 \mathrm{Y}_{1}$ (lanes 3-4), $\mathrm{P} 2 \mathrm{Y}_{2}$ (lanes 5-6), $\mathrm{P} 2 \mathrm{Y}_{4}$ (lanes 7-8), $\mathrm{P} 2 \mathrm{Y}_{6}$ (lanes 9-10), $\mathrm{P}_{2} \mathrm{Y}_{12}$ (lanes 11-12), $\mathrm{P} 2 \mathrm{Y}_{13}$ (lanes 13-14) and $\mathrm{P} 2 \mathrm{Y}_{14}$ (lanes 15-16). Lanes 2, 4, 6, 8, 10,12,14, 16 correspond to the primer control without cDNA and lane $L$ to the ladder. Gel images presented are from one experiment and representative of seven independent experiments (reproduced from [291], with permission from The British Pharmacological Society)

At all concentrations tested, the negative chronotropic and dromotropic effects of ATP on canine AV and sinoatrial (SA) nodes in vivo were more pronounced than those of adenosine [301]. This differential potency was due to a vagal component in the chronotropic and dromotropic actions of ATP but not adenosine [301]. In human patients, intravenously administered adenosine and ATP were equally effective in producing AV block that was antagonised by aminophylline but not by atropine [302]. However, other studies in human subjects have shown a vagal component in the suppression of AV nodal conduction by ATP (see [303]).

In the isolated perfused rat heart, ATP induced arrhythmias, prolonged the PR interval and suppressed SA nodal activity and induced partial block of AV conduction [8]. AV node (and SA node) electrophysiological responses to ATP appeared to be different [304]. Freely moving mice with over-expression of A1R exhibited AV (and SA) nodal dysfunction and supraventricular arrhythmias [305].

\section{SA node}

Both adenosine and ATP suppress pacemaker activity of the sinus node, as well as junctional, His and Purkinje fibres automaticity $[166,306]$. ATP (probably via adenosine) produced hyperpolarisation of cells in frog sinus venosus [307] and adenosine suppressed rabbit SA node automaticity [308]. The action of adenosine on the SA node was found to be mediated by the activation of a $\mathrm{K}^{+}$outward current [309]. In the isolated perfused guinea pig heart, adenosine potentiated ventricular overdrive suppression probably by direct activation of $\mathrm{K}^{+}$outward currents [310]. ATP increased sinus cycle length and SA conduction time in isolated blood-perfused dog atrium [311], and prolonged sinus cycle length in the canine heart in vivo [301].

mRNAs for P2X1R, P2X4R and P2Y1,2,4,6,12 and 14 receptors were expressed in human SA node, with P2Y14R manifesting the highest level (see Fig. 5) [312]. However, one study concluded that the electrophysiological effects of ATP on rabbit SA node pacemaker cells were via P1R, since no functional P2X1R or P2Y2R were found [313]. ATP is required to support the basal SA cell firing rate via the $\mathrm{Ca}^{2+}$, adenylate cyclise, and protein kinase pathways [314].

\section{Atria}

Adenosine is also a modulator of L-type calcium channels in the atrial myocardium of guinea pigs [315]. In anaesthetised, open-chest cats, adenosine infusion significantly decreased atrial fibrillation (AF) threshold; this effect was associated with reduced contractility [316]. A similar action of adenosine in the canine atria was shown to be mediated by pertussis toxin-sensitive guanine nucleotide binding proteins ( $\mathrm{G}$ proteins) coupled to adenosine receptors [228].

\section{His-Purkinje fibres}

Purkinje fibres are modified heart muscle fibres travelling from the AV node forward into the septum between the ventricles where they divide into right and left bundles. The initial portion of the bundle below the AV node is called the His bundle. The Purkinje fibres transmit the wave of depolarisation originating under physiological conditions in the sinus node and travelling from the atria, via the AV node to the ventricles. Under pathophysiological conditions, characterised by lack of depolarisation propagating from the AV junction, the His and Purkinje fibres can act as pacemakers. Both adenosine and ATP suppress the pacemaker activity of His and Purkinje fibres [166, 317, 318]. In guinea pig and dog, ventricular pacemakers were shown to be more sensitive to adenosine than the sinus node $[166,306]$. Adenosine and ATP modulate the electrophysiological effects of catecholamines in Purkinje and ventricular tissue [319, 320]. The effects of ATP and adenosine on action potentials evoked in sheep Purkinje fibres under normal and simulated ischaemic conditions have been described [321]. Rosen et al. [318] have shown that attenuation by adenosine of the effects of epinephrine on canine Purkinje fibre automaticity was membrane potential-dependent. However, a later study has found 
Fig. 5 Relative abundance, as measured by quantitative PCR, of $\mathrm{P} 2 \mathrm{X}$ and $\mathrm{P} 2 \mathrm{Y}$ transcripts in the human right atrium and sinoatrial node. Means $\pm \operatorname{SEM}(n=4)$ shown (reproduced from [312], with permission from Springer)

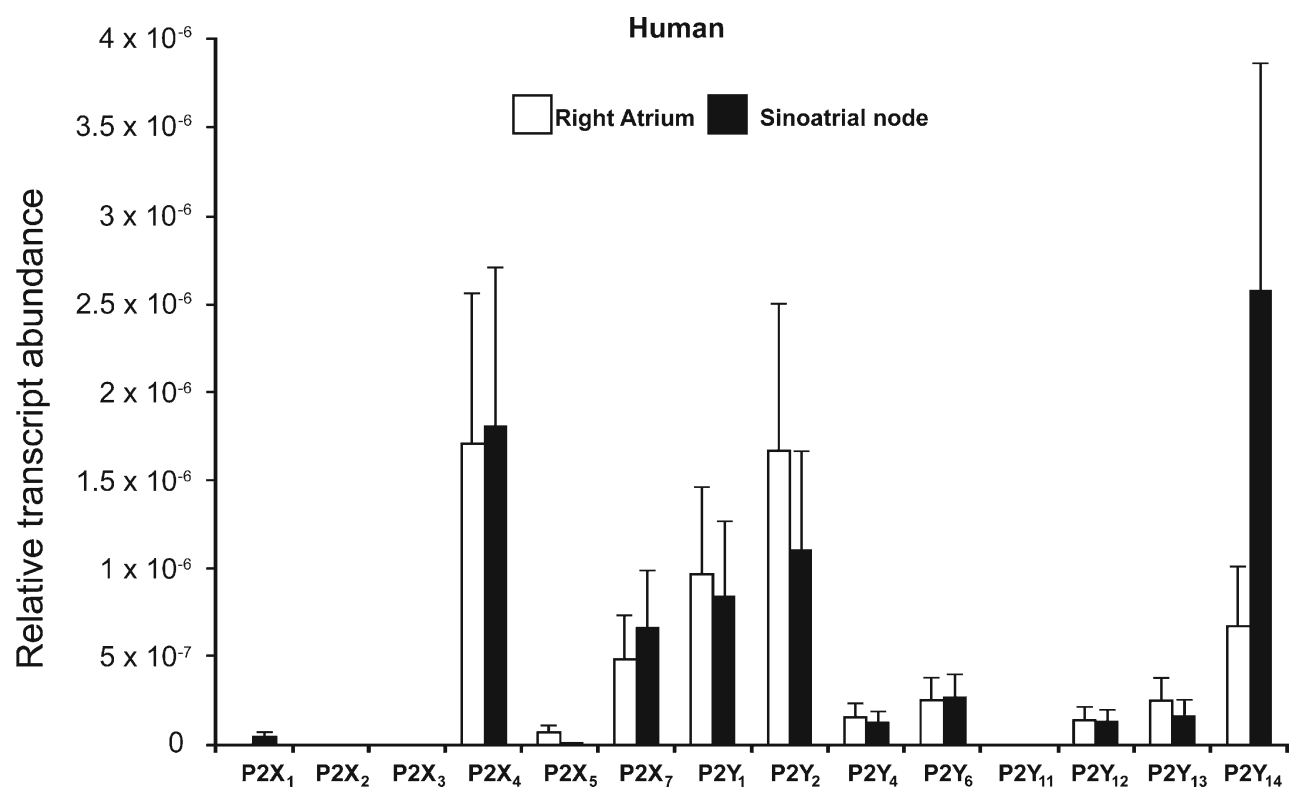

that adenosine did not alter the NA-induced effects on automaticity of sheep Purkinje fibres under physiological or ischaemic-acidotic conditions in vitro (i.e. modified medium) [321]. But, both adenosine and ATP attenuated the reduction in the rate of rise of the upstroke and the amplitude of the action potential caused by ischaemic-acidotic conditions [321].

\section{Papillary muscle}

Papillary muscles are located in the lumen of the ventricles; they are attached to the cusps of the AV valves (i.e. the mitral and tricuspid valves). UTP prolonged the action potential duration in guinea pig papillary muscles via P2Y2R [322].

\section{Endocardium}

ATP, ADP, AMP and adenosine hyperpolarised in guinea pig endocardial endothelium-like cells studied either as small tissue preparation or freshly isolated cells [323].

In summary, adenosine and ATP exert negative chronotropic and dromotropic effects on cardiac pacemakers and AV nodal conduction, respectively. In addition, adenosine exerts a negative inotropic effect, while ATP may exert a positive inotropic effect on cardiac myocyte contractility. Both adenosine and ATP interact with the autonomic neural control of the heart via localised actions as well as central reflexes.

Both P1R and P2R are localised in the heart. mRNA and protein for all $\mathrm{P} 2 \mathrm{XR}$ subtypes have been identified on cardiac myocytes [14, 205, 324]. mRNA for P2Y1, P2Y2, P2Y4,
$\mathrm{P} 2 \mathrm{Y} 6$ and $\mathrm{P} 2 \mathrm{Y} 11$ receptors is also expressed in cardiac muscle [14, 324-326].

\section{Release and degradation of ATP}

\section{Release of ATP}

Adenine nucleotides are present in variable amounts in the extracellular space of the heart; ATP is released from endothelial cells [327-329], from red blood cells (RBC) and activated platelets [14, 330]. The level of ATP in the coronary effluent of saline perfused hearts was in the range of $1 \mathrm{nM}$ [331]. However, this low value reflects the rapid degradation of ATP by ecto-enzymes and indeed high quantities of adenosine have been detected in the perfusates. With the use of microdialysis, interstitial levels of ATP were established to be in the range of $40 \mathrm{nM}$ [332]. The levels increased markedly during hypoxia and ischaemia [92, 101, 190, 192, 333]. ATP is released into the extracellular space during increased blood flow [334, 335], probably due to release of ATP from endothelial cells in response to shear stress (see [78]). ATP is also released as a cotransmitter from perivascular sympathetic nerves [336, 337]. ATP was also shown to be released from rat and mouse cardiac fibroblasts by hypotonic (mechanical) stimulation via connexin hemichannels [338]. A major source of extracellular ATP are RBC, which release ATP when tissue oxygen demand exceeds supply and/or under deformation and thereby, participate in vascular signalling and control the systemic circulation [339]. Other sources of ATP in the heart appear to be ischaemic myocytes, activated platelets, inflammatory cells and smooth muscle cells (see [14]). The 
mechanisms of ATP release involve vesicular exocytosis from both nerve terminals and vascular endothelial cells (see [328]) and there is more recent evidence for mediation of ATP release via connexin and pannexin hemichannels (see [340]). RBC are a major source of ATP, which participates in vascular signalling and control of the systemic circulation [330].

\section{Degradation of ATP}

The breakdown of ATP and ADP to adenosine and hypoxanthine was first reported by Jorgensen in 1956 [341]. Most of the ATP perfused into the heart is dephosphorylated during a single passage through the coronary vasculature $[295,333$, 342]. The catabolism is likely to be due mostly to endothelial ecto-nucleotidase. 5'-Nucleotidase activity was also described in isolated mature rat cardiac myocytes [343]. The relative activities of 5'-nucleotidase and ADA in atrial and ventricular myocardium were determined by Choong and Armiger [344]. ADA degrades adenosine to inosine [345, 346]. ADA was localised by immunocytochemistry to the extracellular surface of endothelial cells of small coronary arteries [347]. ADA was also localised in mid-myocardium of all chambers of the rabbit heart [348].

Characterisation of a $\mathrm{Ca}^{2+} / \mathrm{Mg}^{2+}$ ecto-ATPase from rat heart sarcolemma was reported by Tuana and Dhalla [349]. Using immunogold methodology, 5'-nucleotidase was found in the cytoplasm of cardiac myocytes and coronary endothelium [350]. Heavy exercise training was shown to increase the activity of 5'-nucleotidase and ADA in the left ventricle of the rat heart [351]. In addition, 5'-nucleotidase of neonatal rat ventricular myocytes was shown to be stimulated by thyroid hormone [352].

Regulation of adenosine production by ecto-nucleotidases on adult rat ventricular myocytes was such that at the cell surface the level of nucleotides (especially ATP and ADP) was low, and the level of adenosine was high during periods of extracellular nucleotides supply [353]. Ectonucleoside triphosphate diphosphohydrolases (E-NTPDase or apyrase), ecto-nucleotidase pyrophosphatase (E-NPPs), ecto-5'-nucleotidase (CD73) and alkaline phosphatases are likely to be involved in the degradation of ecto-nucleotides (see [354]). ATPdiphosphohydrolase (apyrase) activity was reported in rat heart tissue [355-357]. Ecto-ATPases were localised histochemically on the plasma membranes of cardiac myocytes, capillary endothelial cells and nerve fibres in rat heart [358]. ENTPDase1 was identified on cardiac sympathetic nerve endings modulating ATP-mediated feedback of NA release [359].

\section{Cardiac fibroblasts}

Adenosine, acting through A2BR, inhibits collagen and protein synthesis in cardiac fibroblasts; accordingly, it was suggested that A2BR agonists may protect against cardiac fibrosis [360]. In a later paper from this group, it was suggested that A2BR on proliferating cardiac fibroblasts play a role in regulating cardiac remodelling associated with myocardial infarction (MI) and ischaemic injury [361]. Overexpression of A2BR led to a decrease in basal levels of collagen and protein synthesis, while under-expression of A2BR yielded an increase in protein and collagen synthesis [362]. Elevated glucose increased the expression of A1R and A2AR, decreased expression of A3R and had no effect on A2BR, while insulin suppressed the expression of A1R and A2BR, but had no effect on A2AR and A3R expression [363]. Studies using RT-PCR revealed that mRNA for all four P1R subtypes, A1, A2A, A2B and A3, were expressed in rat cardiac fibroblasts, with $\mathrm{A} 2 \mathrm{R}$ dominant, acting via cAMP second messenger [364]. In primary cultures of adult rat cardiac fibroblasts, adenosine activated the $A 2 R-G_{s}$-adenylyl cyclase pathway; the resultant cAMP reduced collagen synthesis via a PKA-independent, Epac-dependent pathway that feeds through PI3K [365]. In a recent abstract, it was shown that $\mathrm{A} 2 \mathrm{AR}$ and $\mathrm{A} 2 \mathrm{BR}$ mediate differential modulation of signal transduction and collagen production in murine cardiac fibroblasts; both A2AR and A2BR stimulation increased ERK phosphorylation, but only A2BR modulated collagen production [366].

P2YR mediate activation of c-fos gene expression and inhibition of DNA synthesis in cultured rat cardiac fibroblasts [367]. UTP, acting via P2Y2R, induced pro-fibrotic responses in rat and mouse cardiac fibroblasts and it was suggested that P2Y2R antagonists may provide a means to reduce cardiac fibrosis [368]. Thickening and scaring of connective tissue occurs, most often as a consequence of inflammation or injury. Purinergic signalling via P2Y6R in cardiomyocytes triggers pressure overload-induced cardiac fibrosis [369]. ATP was shown to up-regulate proliferation and migration of human cardiac fibroblasts, probably via P2Y2R, but also via P2X4R and/or P2X7R [370]. Recently, Lu and Insel [371] suggested that the fibrotic response in rat cardiac fibroblasts involves the integration of purinergic signalling that is pro-fibrotic by ATP, and anti-fibrotic by adenosine, the product of ATP degradation by ENTPDs.

\section{Coronary blood vessels}

AMP has been known to be a potent dilator of coronary vessels since 1929 [5] and later, adenosine, ATP and ADP were also shown to dilate coronary vessels [85, 92, 372].

The hypothesis by Berne [92] and independently by Gerlach [93] that adenosine was the physiological regulator of blood flow during reactive hyperaemia (what became known as the Adenosine Hypothesis) dominated the field for the next decade, even though conclusive supporting evidence 
was lacking (see [373, 374]; and see later section on "Ischaemia").

ATP is released from coronary endothelial and RBC in response to shear stress, resulting from changes in blood flow and hypoxia (see [78, 330]). Release of ATP from cardiac endothelial cells has also been shown in response to ACh, bradykinin, 5-hydroxytryptamine and ADP [375]. ATP released from aggregating platelets and $\mathrm{RBC}$ also caused endothelium-dependent relaxation of canine coronary arteries [376, 377]. Intracoronary ATP [378], and also adenosine [379], produced maximal coronary vasodilatation in humans.

Large increases in myocardial blood flow were associated with ATP infusion in rat heart [380]. Intracoronary adenosine, ATP and ADP dilate these vessels largely via the endothelium [345], implying that P2R are expressed by coronary endothelial cells. ATP and adenosine hyperpolarised guinea pig cultured coronary endothelial cells; the adenosine-induced hyperpolarisation, but not that by ATP, was antagonised by theophylline [381], indicating that both $\mathrm{P} 1 \mathrm{R}$ and $\mathrm{P} 2 \mathrm{R}$ are present on these cells. A later study presented evidence for the presence of P2YR on endothelial cells mediating hyperpolarisation, and vascular relaxation via both P1R and P2R localised on smooth muscle cells, in guinea pig and rabbit coronary arteries [382]. It was suggested that ATP may be a more significant relaxant of canine large coronary arteries than adenosine, but that adenosine may be a more significant relaxant than ATP in small coronary arteries [383]. ATP also evoked endothelium-dependent vasodilation in human isolated coronary arteries [378, 384]. Direct smooth muscle (endothelium-independent) relaxation by ATP and UTP of human epicardial coronary arteries has also been reported [385], as well as hyperpolarisation of smooth muscle cells of the guinea pig coronary artery by ATP [386].

Vasodilatation by ATP in perfused guinea pig heart involves NO [387, 388], although in another study it was concluded that ATP-induced vasodilation of guinea pig heart did not depend on NO production, but may have been partly dependent on the production of prostaglandins [389]. Adenosine contributed little to the coronary vasodilation in guinea pig hearts resulting from bolus injection of ATP and ADP $[389,390]$. The receptors involved in purinergic endotheliumdependent vasodilation were identified as P2Y1R and P1R subtypes in the rat [391, 392] and dog [393] heart microvessels. P2Y1R and P2Y2R were described in cultures of rat cardiac microvascular endothelial cells [394]. UTPsensitive P2UR (P2Y2 and/or P2Y4), as well as P2Y1R, on human, canine and guinea pig cardiac endothelial cells have also been reported [388, 395, 396]. ATP and adenosine exerted opposing effects (stabilising and disrupting, respectively) on the barrier function (i.e. macromolecule permeability of microvascular endothelial cells and microvessels) of the rat coronary microvasculature [397].
In addition to vasorelaxation, predominantly via endothelial P2YR and P1R, P2XR and P2YR that mediate vasoconstriction are expressed on the coronary artery smooth muscle cells of human, porcine, rabbit and rat hearts [398-402]. Human coronary artery smooth muscle cells express P2YR and P2UR (P2Y2R and/or P2Y4R) leading to increases in $\left[\mathrm{Ca}^{2+}\right]_{\mathrm{i}}$ by 2-MeSATP and UTP, respectively [403]. RT-PCR studies of $\mathrm{P} 2 \mathrm{R}$ in human coronary arteries showed pronounced expression of P2X1R and P2Y2R mRNA, while weaker expression of P2Y1, P2Y4 and P2Y6R mRNA [401]. This study also showed that contractile responses of human coronary arteries to $\alpha, \beta$-meATP and the stable pyrimidine analogue, uridine 5 '-O-3-thiotriphosphate, were consistent with activation of P2X1R and P2Y2R, respectively. UTPevoked contractions of porcine coronary artery smooth muscle cells also appear to be mediated predominantly by P2Y2R [402]. Coexpression of mRNA for P2X1, P2X2 and P2X4R was found in smooth muscle cells of rat coronary arteries [404]. UTP elicited depolarisation of rat coronary artery smooth muscle [405]. $\mathrm{Ap}_{5} \mathrm{~A}$ and $\mathrm{Ap}_{6} \mathrm{~A}$ dinucleoside polyphosphates dilate or constrict rat coronary vessels via P2Y1R and P2XR on endothelial cells and smooth muscle, respectively [406]; adenosine 5'-tetraphosphate also dilated rat coronary vessels [241]. ATP can constrict human epicardial coronary veins [385]. Uridine adenosine-tetraphosphate is a novel vasodilator of the coronary microcirculation of swine hearts, acting via P1R [407]. ATP acting via P2YR seems to mediate NANC inhibitory transmission in lamb coronary small arteries [408]. One of the factors controlling coronary blood flow during exercise appears to be ATP [409-411].

Proliferation of porcine cultured coronary artery smooth muscle cells was promoted by ATP, via P2YR, and insulin acting synergistically [412]. A recent study indicates that P2X1R-mediated inhibition of the proliferation of human coronary smooth muscle cells involved the transcription factor $\mathrm{NR}_{4} \mathrm{~A}_{1}$ [413].

Nicotinamide adenine dinucleotide was reported to be a coronary vasodilator in 1971 [414] and adenosine is a potent coronary dilator in all mammalian species studied, including humans [415-417]. The vasodilator actions of adenosine are mediated by A2R [36, 418-420] since A2R-mediated coronary vasodilation was antagonised by methylxanthines [421], located on endothelial cells [422-426]. The adenosine may be released directly from cardiomyocytes and endothelial cells after intra- and extracellular breakdown of ATP, respectively [427].

Adenosine receptor-mediated hyperpolarisation of bovine and porcine coronary artery smooth muscle was reported [428, 429]. Adenosine was found also to hyperpolarise cultured guinea pig coronary endothelial cells; this finding supports the hypothesis that the hyperpolarisation of the endothelium induced by adenosine released into the perivascular space of the capillaries may be conducted electrotonically to 
the terminal arterioles and may cause vasodilation via current flow through myoendothelial gap junctions [430].

It was proposed that there was another P1R subtype, in addition to A2R, located on smooth muscle [431] since $N^{6}$ cyclopentyladenosine, an A1R-selective agonist, had vasorelaxant activity in porcine and canine coronary arteries $[432,433]$ and A1R are expressed by smooth muscle cells isolated from the porcine coronary artery [434], which also express A2R [435]. Adenosine-mediated relaxation in human small coronary arteries via A2BR, which was independent of the endothelium and NO [436]. However, in a later paper, it was claimed that in human coronary arteriolar smooth muscle, the A2AR mediated vasodilation [437]. A2AR and A2BR mediate production of $\mathrm{NO}$ in cultured porcine coronary artery endothelial cells [438] and it was suggested that while A2AR are predominant, A2BR may also play a role in adenosineinduced vasodilation, possibly through the p38 MAPK pathway [439]. A later study showed that the A2AR mediated relaxation via the smooth muscle [440]. Endotheliumdependent coronary vasodilation in the guinea pig heart was shown to be due to multiple P1R subtypes; A1R mediated the release of both $\mathrm{NO}$ and prostaglandin $\mathrm{I}_{2}$, and A2AR and A3R acted mainly via NO [441]. The presence of A3R in the rat coronary circulation has also been claimed [442]. A2AR and A2BR also mediate coronary vasodilation in mice [443, 444] and up-regulation of A2BR in A2AR knockout mouse coronary artery has been reported [237, 445]; an involvement of $\mathrm{K}_{\mathrm{ATP}}$ channels in this action was also demonstrated [445].

Inosine transiently decreased coronary flow in the rat, but potentiated vasodilation by adenosine [446]. Porcine coronary vasodilation was produced by $\mathrm{Ap}_{4} \mathrm{~A}$, probably via P1R [447]. Diadenosine polyphosphates are potent vasoconstrictors of human coronary artery, radial artery and saphenous vein bypass grafts and it was suggested that they may play a role in post-operative contraction of these grafts [448]. The role of adenosine in the dilation of human coronary vessels was reviewed by Heusch [449]. The P2Y12R antagonist, ticagrelor, enhanced adenosine-induced coronary vasodilatory responses in humans [450].

A period of maturation of the rabbit heart after birth was required before an adult level of coronary responsiveness to exogenous adenosine was demonstrated [451]. It was proposed that different adenosine receptor subtypes mediate coronary vasodilation in mature rats, but that there is a reduction in the response to adenosine with age that may be due to changes in the high-affinity receptor site [452], by a reduction in adenosine receptor transduction [453] and/or by a reduction of A3R-mediated activity [442, 454]. In vasculogenesis, longterm signalling by adenosine in cardiac microvascular cells has been described [455].

In male endurance athletes, myocardial blood flow during adenosine-mediated hyperaemia was reduced compared to untrained men and the fitter the athlete, the lower was the adenosine-induced myocardial blood flow, although A2AR density was unchanged [456]. Sexual dimorphism in the permeability response of coronary microvessels to adenosine was described [457].

More recently, a selective A2AR agonist has been introduced into the clinical setting to induce coronary vasodilation as a pharmacological stress agent in conjunction with radionuclide myocardial perfusion imaging in patients unable to undergo adequate exercise stress test, commonly used to diagnose coronary artery stenosis [458].

\section{Pathophysiology and therapeutic potential}

Acute and chronic heart failure

About one half of patients with chronic heart failure (CHF) and about two thirds of patients with acute heart failure have concomitant renal dysfunction, termed the cardiorenal syndrome.

There is endogenous adenosine accumulation in patients with CHF [459]. It was suggested that selective A1R blockade may be a useful adjunctive diuretic in heart failure. Long-term oral administration of dipyridamole, leading to high extracellular levels of adenosine, improved cardiac status of patients with mild to moderate heart failure [460]. A1R up-regulation accompanied decreasing myocardial adenosine levels in mice with left ventricular dysfunction [461]. Adenosine therapy was considered for its cardioprotective effect for CHF [462] mediated by A1R and A3R [463]. In contrast, impairment of adenosine action contributed to the pathophysiology of CHF [464] (see also the contradictory findings by [465]). A1R antagonists improved glomerular filtration, but simultaneously promoted natriuresis and diuresis in patients with heart failure [466-468]. A1R antagonists have been recommended for the treatment of cardiorenal syndrome [469]. Therefore, A1R antagonists are not recommended as a treatment for acute heart failure with renal dysfunction [470, 471], although rolofylline, a selective A1R antagonist, had some beneficial effects for high risk acute decompensated heart failure [472].

A2AR expression was decreased by chronic renal failure with or without left ventricular failure; this decrease was reduced in haemodialysed patients [473]. Intravenous infusion of adenosine improved left ventricular function in dogs with advanced heart failure [474]. A2BR mRNA was overexpressed in the left ventricle of minipigs with heart failure [475]. Adenosine release in CHF was found in the periphery and not in the myocardium [476]. In patients with CHF, following exercise the plasma levels of adenosine increased, while those of ammonia decreased and it was suggested that the enhanced cardioprotective actions of adenosine after exercise may be an adaptive response in patients with $\mathrm{CHF}$ 
[477]. The accumulation of adenosine in CHF was suggested to be due to the reduction of ADA gene expression [478].

Alterations in the expression of P2X1R in failing human atria were found [479]. P2X6R mRNA was reported to be upregulated in left myocardium of patients with CHF [480]. P2XR activation protected the heart in heart failure models [481, 482]. A beneficial effect of MRS2339, a P2XR agonist in heart failure was demonstrated; it was identical to that produced by cardiac myocyte-specific over-expression of the P2X4R [483]. The improvement was associated with the preservation of left ventricular wall thickness in both systole and diastole in post-infarct mice and calsequestrin (CSQ) over-expression mice with cardiac-specific P2X4R overexpression and decreased left ventricular chamber size in CSQ mice with heart failure and dogs with pacing-induced heart failure [483]. Increases in ecto-5'-nucleotidase in the plasma and myocardium in patients with CHF were thought likely to contribute to the increased levels of adenosine [484]. In the rat coronary artery ligation-induced heart failure model, P2X4R mRNA was up-regulated by $93 \%$ in cells of the SA node and in right atrial and left ventricular myocytes [312]. P2X7R are pro-thrombotic and knockout of the P2X7R gene was protective in a mouse model of coronary artery thrombosis [485].

Accumulation of blood within the heart, which is the result of back pressure in the veins, leads to congestive heart failure. There is congestion in the lungs and/or liver in heart failure, which may be associated with accumulation of fluid in tissues (oedema). Volume-overload congestive heart failure in dogs is associated with reduced myocardial inotropic responsiveness to the administration of $\beta$-adrenoceptor agonists. It was suggested that the elevated adenosine release in the failing myocardium contributed to these effects [486]. An A1R antagonist appeared to be beneficial for patients with congestive heart failure, but some side effects were noted [487].

An increase in cardiac P2X1R and P2Y2R mRNA was noted in congestive heart failure (Fig. 6) [488]. Enhanced P2YR-mediated dilatation by endothelium-derived hyperpolarising factor was also described in congestive heart failure [489]. However, in congestive heart failure, downregulation of P2X1R was induced in peripheral resistance arteries [490]. In a rat model of ischaemic congestive heart failure, there was a selective down-regulation of P2XRmediated pressor effects, while the hypotensive effects mediated by endothelial P2YR were unaffected and the adenosine-mediated inhibitory effects on heart rate were attenuated [491].

\section{Ischaemia}

Ischaemia leads to injury of the heart. Purine and pyrimidine nucleotides, released at the site of cell damage, generally contribute to injury, but adenosine is generally protective (see [492]).

As mentioned above, Berne [92] and Gerlach [93] put forward the adenosine hypothesis, according to which adenosine was the physiological regulator of blood flow during reactive hyperaemia following hypoxia. Although this hypothesis was supported by early papers [493, 494], data obtained in subsequent studies challenged this hypothesis. For example, theophylline, a non-selective adenosine receptor antagonist, blocked coronary vasodilation by perfused adenosine, but it did not block reactive hyperaemia [495-499]. Similarly, adenosine and ATP increased coronary blood flow, but after occlusion, reactive hyperaemia in the dog heart was not blocked by aminophylline, a non-selective adenosine receptor antagonist [500-503]. It was also shown that while reactive hyperaemia occurred about $10 \mathrm{~s}$ after resumption of blood flow, adenosine did not appear in the perfusate until about $90 \mathrm{~s}$ later. ATP, however, appeared early on in the coronary sinus effluent of the isolated working rat hearts in response to hypoxia [504]. Thus, Burnstock hypothesised [105] that the initial phase of vasodilation following hypoxia was due to ATP, released from endothelial cells [505] to cause vasodilation via NO [506], while adenosine, a breakdown product of ATP by ecto-enzymes, contributed only to the later stages of reactive hyperaemia by acting on P1R on the smooth muscle cells. The delay in appearance of adenosine in the perfusate was explained by the fact that ADP (derived from the rapid breakdown of ATP) inhibits 5 '-nucleotidase, the enzyme that metabolises AMP to adenosine [507]. Ectoenzymes involved in the breakdown of ATP by coronary microvascular endothelial cells from rat heart have been described [508].

An early study has found that a combination of suppression of contractility of right ventricular trabeculae and preservation of electrical stability could serve as a cardioprotective action by adenosine in ischaemia [509]. Adenosine decreased ischaemic damage and enhanced cardiac function during severe hypothermia [510]. Activation of adenosine receptors mimics the cardioprotective effect of pre-conditioning; intracoronary adenosine protects against reperfusion injury after coronary occlusion [511-514], an action mediated by A1R [515]. A reduced sensitivity to adenosine has been found in the ischaemic or hypoxic heart $[374,516]$. A2R binding in the heart was shown to be modified by ischaemia [517] and ischaemiareperfusion selectively attenuated coronary vasodilatation mediated by A2R, but not A1R agonists [432]. Attenuation of responsiveness would tend to counteract the cardioprotective effects of adenosine, but the importance of this is not yet clear.

Glycolysis inhibition and enhanced mechanical function of working rat hearts resulted from A1R stimulation during reperfusion following ischaemia [518]. Activation of adenosine receptors has been shown to reduce ischaemiareperfusion injury in the heart $[519,520]$. Transgenic A1R 

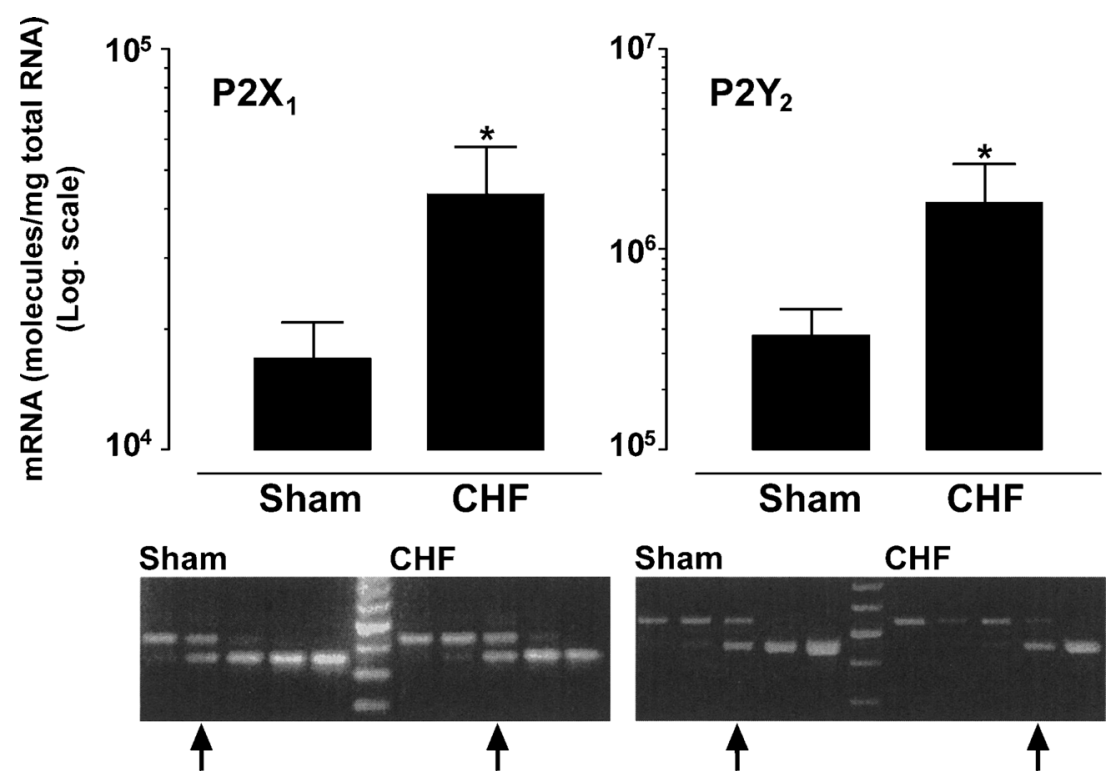

Fig. 6 Up-regulation of $\mathrm{P} 2 \mathrm{X} 1$ and $\mathrm{P} 2 \mathrm{Y}_{2}$ receptor mRNA levels in hearts from congestive heart failure $(C H F)$ rats. $\mathrm{P} 2 \mathrm{X} 1$ and $\mathrm{P} 2 \mathrm{Y}_{2}$ receptor mRNA molecule numbers $/ \mu \mathrm{g}$ total RNA in the myocardium from sham operated and CHF rats. Values are means+s.e.m., $n=7-8$. For each, receptor measurements were performed with the same concentration total RNA together with five increasing concentrations of competitor

standard. The upper band represents the wild-type product and the lower band represents the competitor product. The left set represents a sham operated rat and the right the CHF rat. There is a clear shift in the equivalence point (arrow) in the CHF rat towards the right (higher concentration) for both the $\mathrm{P} 2 \mathrm{X} 1$ and $\mathrm{P} 2 \mathrm{Y}_{2}$ receptor (reproduced from [488], with permission from Elsevier)

over-expression increased myocardial resistance to ischaemia [521]. A later study showed that the cardioprotective mechanism of A1R over-expression involved altered gene expression [522]. It was suggested that ischaemic stress-induced preconditioning is dependent on the concomitant stimulation of both adenosine and NA receptors and that P1R-mediated cardioprotection occured only if $\alpha_{1}$-adrenoceptor activation was intact [523]. Evidence that activation of both A1R and A2R during hypoxia can attenuate myocardial injury was presented [524-526]. There is an age-dependent decrease in the cardioprotection provided by adenosine in reperfusion injury in rats [527]. However, a stronger anti-adrenergic effect of adenosine was reported in the ageing ischaemic rat myocardium, possibly due to cross-talk between A1R and A2AR [528]. Selective A3R activation is cardioprotective in wildtype hearts and hearts over-expressing A1R, although A3R gene deletion generates an ischaemia-tolerant phenotype [529]. In a later study, it was shown that improved resistance of the heart to ischaemic damage can be achieved by increasing the expression of $\mathrm{A} 3 \mathrm{R}$, without detrimental side effects on heart rate or systolic function [530]. Reduced A3R transcription may contribute to improved ischaemia tolerance in aged hearts [531]. Reduction in post-ischaemic inflammation and infarct size was achieved by perfusion of the canine myocardium with a selective A2AR agonist [532]. One study concluded that cardioprotection by adenosine was dependent on $\mathrm{NO}$ and was blunted by the ganglion blocker hexamethonium indicating that it was mediated mainly by the activation of a neurogenic pathway [533]. Apyrase (CD39), which catalyses the hydrolysis of ATP to AMP, provided myocardial protection against cardiac ischaemia-reperfusion injury [534]. UTP was claimed to reduce infarct size and improve mouse heart function after myocardial infarct via P2Y2R [535].

The mechanism underlying cardioprotection by adenosine is not fully understood. Activation by adenosine of the reperfusion injury salvage kinase pathway, involving phosphorylation of Akt and/or ERK1/2, which leads to inhibition of mitochondrial permeability transition pore formation [536-538], may be involved. Genetic deletion of A1R limits myocardial ischaemic tolerance [539]. The cardioprotective effect of ischaemic pre-conditioning was shown to be dependent on activation of adenosine A1R in the first few minutes of reperfusion [540]. In contrast, the infarct size-limiting effect of myocardial ischaemic post-conditioning was shown to be mediated by the activation of adenosine A2AR at the time of reperfusion [541]. Indeed, targeted deletion of A2AR attenuated the protective effects of myocardial post-conditioning [541]. Low dose adenosine infusion reduced the ischaemic burden and improved left ventricular regional systolic function in the ischaemic walls of patients with exercise-induced myocardial ischaemia [542]. The infarct-sparing effect of A2AR activation has been suggested to be primarily due to inhibition of $\mathrm{CD}^{+} \mathrm{T}$ cell accumulation and activation in the reperfused heart [543]. Another study using H9c2 cardiomyoblasts showed that the cardioprotection afforded by adenosine was microtubules-dependent and involved the stimulation by adenosine of cytosolic $\mathrm{PKC} \varepsilon$ translocation to the nucleus and dephosphorylation at Ser729 [544]. 
It was first suggested that reflex responses mediated by cardiac sympathetic afferent nerves during myocardial ischaemia were caused by adenosine, released from the ischaemic myocardium, mediated by A1R [545], but later it was suggested that it was ATP that activated sympathetic afferents [546]. A brief intravenous infusion of ATL-146e, a selective adenosine A2AR agonist (added 30 min before reperfusion), reduced myocardial infarct size at $48 \mathrm{~h}$ after ischaemiareperfusion perturbation [547]. Endogenous adenosine is an important mediator of ischaemic preconditioning and postconditioning (see [548]). It has been claimed that A2AR and A2BR act in concert to induce strong protection against reperfusion injury in rat hearts [549] and co-operative activation of A1R and A2AR to produce cardioprotection in ischaemiareperfused mouse heart has also been reported [550]. Indeed, endogenous adenosine makes a significant contribution to A1R agonist-mediated prevention of necrosis in a cardiac cell model of ischaemia by co-operative interactions with both $\mathrm{A} 2 \mathrm{AR}$ and $\mathrm{A} 2 \mathrm{BR}$, but does not play a role in A3R agonistmediated protection $[551,552]$. Figure 7 shows a simplified depiction of the impact of adenosine receptors in protecting against myocardial injury following ischaemia or hypoxia.

It has been reported that $\mathrm{A} 1 \mathrm{R}$ and $\mathrm{A} 3 \mathrm{R}$ agonists reduce hypoxic injury through the involvement of p38 MAPK [553]. In situ ischaemic pre-conditioning conferred cardioprotection in A1R, A2AR and A3R, but not A2BR knockout mice, or in wild-type mice after inhibition of $\mathrm{A} 2 \mathrm{BR}$, and thus, it was suggested that 5 '-nucleotidase and A2BR agonists might be considered as therapeutic agents for myocardial ischaemia $[554,555]$. Activation of A3R protected against myocardial ischaemia-reperfusion injury in mice, an effect which disappeared in A3R knockout mice [529, 556, 557]. In male patients with stable angina, capadenoson, an oral A1R agonist, lowers heart rate during exercise, which was associated with prolongation of time to ischaemia [558]. CD73-derived adenosine promoted cardiac remodelling and recovery of ventricular performance after ischaemia-reperfusion, most likely by acting on T cells [559]. Adenosine was shown to stimulate the recruitment of endothelial progenitor cells to the ischaemic heart resulting in enhanced revascularisation [560]. Studies focusing on the attenuation of myocardial ischaemia by targeting A2BR have been reviewed recently [561]. Previous reviews discussed the role of adenosine in pre-conditioning and ischaemia-reperfusion injury $[65,562-570]$.

Although early on the focus was on the role of adenosine in ischaemic and reperfusion injuries, there is now increasing interest in the role of ATP in these settings. A possible role for nucleotides in cardiac ischaemia was first raised in 1948, with the emphasis on degradation of nucleotides which appears to take place within muscle cells during ischaemia [571]. Accordingly, local infusion of ATP was used to successfully delay the onset of irreversible ischaemic injury and the role of high energy phosphates in preservation of ischaemic myocardium was highlighted [572]. Delayed resynthesis of ATP following its depletion during myocardial ischaemia was proposed [573] and thus, ATP- $\mathrm{MgCl}_{2}$ was used for the treatment of ischaemia (see [574-576]). Extracellular ATP and adenosine appear to play complementary, protective roles in ischaemic pre-conditioning through $\mathrm{P} 2 \mathrm{YR}$ and $\mathrm{P} 1 \mathrm{R}$, respectively [577]. Pre-administration of UTP, by as much as $48 \mathrm{~h}$ before an ischaemic episode, had a cardioprotective effect $[326,578]$.

Ischaemia is accompanied by increased release of ATP from cardiac myocytes and sympathetic nerves [579-581]. Before its degradation to adenosine, ATP was shown to induce positive inotropy, but it may also depolarise cells and trigger
Fig. 7 Simplified depiction of the impact of adenosine receptors (AR) in ameliorating injury and promoting adaptation during and following myocardial insult. Responses may be modified in disease states. Receptor involvement (identified in either animal or human studies) is shown. *Support from human tissue studies; †supported from animal models; $\neq$ speculative/ debated (reproduced from [33], with permission)

\section{Cardiovascular Insult (eg. ischaemia, hypoxia)}

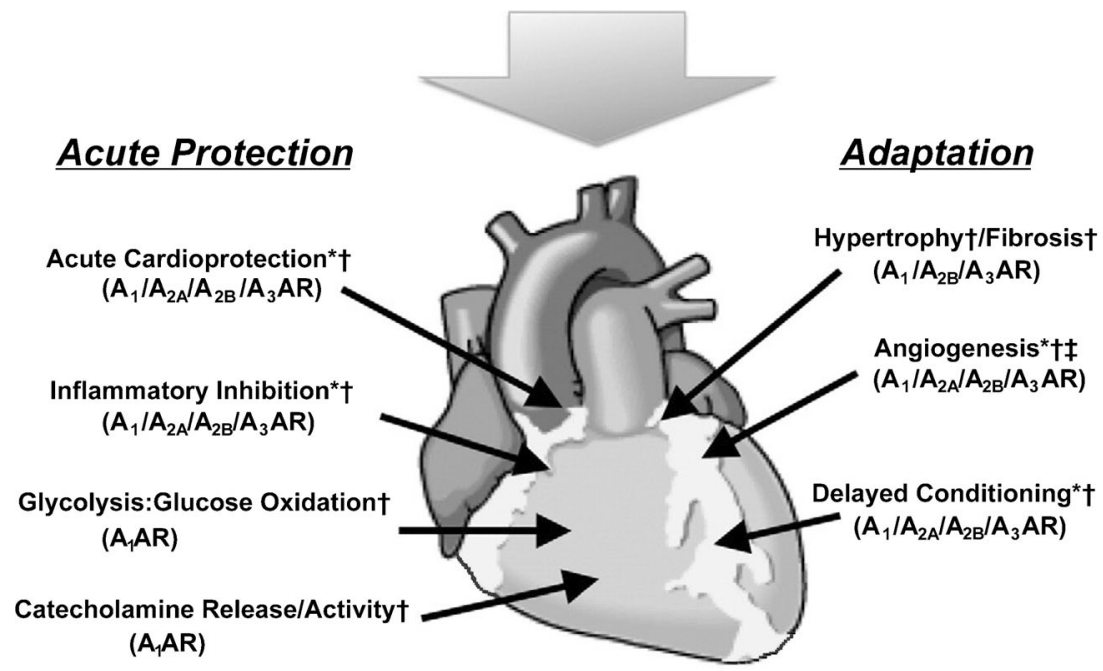


arrhythmias [582]. Release of ATP from cardiac myocytes in response to ischaemia was suggested to be via connexin hemichannels [581]. In a later study, it was proposed that ATP released in this way acts as a paracrine agent to cause fibroblast activation leading to the development of fibrosis in the heart following MI [583]. Blocking P2X7R or pannexin-1 channels prevented the protective effect of both ischaemic preand post-conditioning [584, 585].

It has been suggested that release of ATP from cardiomyocytes is strictly regulated during ischaemia by a negative feedback mechanism consisting of maxi-anion channel-derived ATP-induced suppression of ATP release via hemichannels in cardiomyocytes [586]. In a more recent study, it was shown that ischaemic/hypoxic stress induced rapid ATP release from cultured cardiomyocytes and that distinct P2R, perhaps P2X7R and P2Y2R, regulated cardiomyocyte death [587]. Ischaemia-induced accumulation of ATP in the extracellular space was suggested to trigger enhancement of $\left[\mathrm{Cl}^{-}\right]_{\mathrm{i}}$ in ventricular muscle during ischaemic conditions [579].

Tissue transglutaminase 2 protects cardiomyocytes against ischaemia-reperfusion injury by regulating ATP synthesis [588]. There is up-regulation of P2X7R in rat superior cervical ganglia (SCG) after myocardial ischaemic injury [589]. Sensory-sympathetic coupling in SCG after myocardial ischaemic injury facilitates sympathoexcitatory action via upregulated P2X7R [590]. The P2X7R antagonist brilliant blue $\mathrm{G}$ acting on stellate ganglia prevented the increased sympathoexcitatory reflex via sensory-sympathetic coupling induced by myocardial ischaemic injury [591]. It has been claimed that ATP post-conditioning provides a powerful protective effect in a rat model of ischaemia-reperfusion due partly to antioxidation and partly to inhibition of inflammation [592]. It has been claimed that puerarin, an active ingredient in the traditional Chinese medicine Ge-gen, blocked signalling transmission mediated by P2X3R in stellate ganglia and DRG and reduced myocardial ischaemic damage [593].

Extracellular purine nucleotides have been shown to be cardioprotective in various experimental models. Extracellular ATP protects against reperfusion-induced failure of the endothelial barrier in rat hearts [594]. Extracellular ATP also protects human cultured myocardial endothelial cells from apoptotic cell death during hypoxia, by activating P2Y2Rmediated MEK/ERK- and P13K/Akt-signalling pathways [595]. ATP administration, before or just after cardiac ischaemia, inhibited the development of ventricular muscle damage [584].

UTP, released during cardiac ischaemia, was claimed to act via P2Y2R and/or P2Y4R to play a substantial role in mediating cardioprotection from hypoxic damage $[325,326,596$, 597]. In isolated ischaemic rat hearts, ATP-loaded liposomes and ATP-loaded immunoliposomes effectively protected the myocardium from ischaemia-reperfusion damage as determined by systolic and diastolic function [598]. Moreover, in the rabbit heart in vivo with induced localised myocardial ischaemia, liposomal encapsulation of ATP significantly diminished the proportion of ventricular muscle at risk that was irreversibly damaged during reperfusion [598]. Thus, it was proposed that ATP-loaded liposomes could be developed as a treatment for myocardial ischaemia [598]. It has been suggested that P2Y6R and P2Y11R are involved in pyridoxal-5'phosphate-induced cardiac pre-conditioning in rat hearts [599]. ADP acting on endothelial P2Y1R plays a major role in coronary flow during post-ischaemic hyperaemia [600]. ADP, acting via P2Y1R, mediates the release of tissue plasminogen activator during ischaemia and post-ischaemic hyperaemia. Tissue plasminogen activator is involved in maintaining the endothelial wall of blood vessels free of thrombi formation and it was suggested that this action of ADP may counteract some of the platelet activating effects of ADP [601]. It has been suggested that the P2Y4R could be a therapeutic target to regulate cardiac remodelling and postischaemic revascularisation [602]. P2Y2R activation protects cardiomyocytes from hypoxia in vitro and reduces postischaemic myocardial damage in vivo [603].

Extracellular ATP augments cardiac contractility by elevating intracellular calcium in cardiac myocytes. Impairment of extracellular ATP-induced $\mathrm{Ca}^{2+}$ mobilisation in rat hearts after ischaemia-reperfusion has been described [604]. Cardiacspecific over-expression of human P2X4R confers a beneficial effect in the left anterior descending artery ligation model of ischaemic cardiomyopathy [605]. Transgenic overexpression of P2X4R in mouse heart led to enhanced cardiac contractile performance after ischaemic infarction and increased survival at 1 and 2 months after infarction; this suggested that enhanced contractile function via P2X4R of the non-infarcted areas was likely to be a rescuing mechanism [606]. A recent review discusses P2X4R as targets for cardiac ischaemia [607].

Myocardial ischaemic nociceptive signalling was shown to be mediated by P2X3R in rat stellate ganglion neurons [608]. $\mathrm{P} 2 \mathrm{X} 3 \mathrm{R}$ were up-regulated in rat stellate and nodose ganglia after myocardial ischaemic injury and may underlie ischaemic pain [609-611]. Myocardial ischaemic injury induced an increase in expression of P2X3R in SCG and DRG neurons, which led to aggravated sympathoexcitatory reflexes [612]. The authors also claimed that oxymatrine, a Chinese herbal remedy for ulcers and tumours, may decrease the expression of P2X3R and depress the aggravated sympathoexcitatory reflex induced by ischaemic injury.

AZD6140, a reversible oral P2Y12R antagonist, inhibits adenosine uptake into erythrocytes and enhances coronary blood flow after local ischaemia or intracoronary adenosine infusion [613]. After ischaemia-reperfusion injury, the coronary vasodilator effect of $\mathrm{Ap}_{4} \mathrm{~A}$ was shown to be impaired, probably due to reduced responsiveness of $\mathrm{P} 2 \mathrm{YR}$ to $\mathrm{Ap}_{4} \mathrm{~A}$ [614]. Extracellular tri- and di-phosphates 
were claimed to be responsible for cardioprotection against hypoxic damage, probably by preventing free radical formation [615]. Diadenosine triphosphate, a vasoactive mediator stored in platelet granules, induces coronary vasodilation, which is attenuated by ischaemia-reperfusion due to the functional impairment of P2YR [616]

A protective role of E-NTPDase 1/CD39 in ischaemiareperfusion injury has also been shown. Specifically, targeted deletion of E-NTPDase 1/CD39 led to enhanced myocardial ischaemia-reperfusion injury, which was corrected by infusion of AMP or apyrase (which degrades nucleotides) [534]. More recently, transgenic expression of human E-NTPDase 1/CD39 in pigs protected against myocardial ischaemia-reperfusion injury [617]. Interestingly, robust and selective induction of E-NTPDase 1/CD39 was shown after pre-conditioning in the mouse heart [534]. Ecto-nucleotidase on sympathetic nerve endings attenuates ATP and NA exocytosis in myocardial ischaemia by reducing ATP levels and consequently the prejunctional facilitatory effects of ATP [580]. Conversely, over-expression of E-NTPDase 1/CD39 resulted in enhanced removal of exogenous ATP [618] and protection against murine myocardial ischaemic injury [619]. Since ATP availability greatly increases in myocardial ischaemia, it has been suggested that recombinant E-NTPDase 1/CD39 may offer a novel therapeutic approach to the damage caused by ischaemia by reducing sympathetic activity [618]. E-NTPDase 1/CD39 deletion led to an attenuation of the activity of sympathetic pre- and post-synaptic P2XR (attributed to P2XR desensitisation) perhaps due to prolonged exposure to ATP that accompanies E-NTPDase 1/CD39 deletion, and it was suggested that E-NTPDase 1/CD39 can potentially prevent the transition from myocardial ischaemia to infarction [620]. A recent study showed that decreased ecto-nucleotidase activity produced by ischaemia in rat heart may exacerbate subsequent reperfusion injury [621]. These observations are in congruence with an earlier finding that ischaemic pre-conditioning increased 5 '-nucleotidase activity and adenosine release during myocardial ischaemia and reperfusion in dogs [622].

In summary, ATP is released from ischaemic cells and adenosine, the product of its degradation by ecto-enzymes, plays a major role in cardioprotection in the setting of myocardial ischaemia-reperfusion.

\section{Myocardial infarction}

Myocardial infarction (MI) is localised death of heart muscle in the setting of myocardial ischaemia (imbalance between oxygen supply and demand) caused by impaired coronary blood flow.

Protection against MI was mediated by $\mathrm{A} 1 \mathrm{R}$ and also probably A3R in the rabbit heart $[515,623]$. Activation of
A2AR at reperfusion was shown to reduce infarct size in dog heart [519]. Inhibition of NO synthesis reduced infarct size via release of adenosine [624]. Magnesium reduced infarct size also via enhancement of the action of adenosine in rabbits [625]. Over-expression of A1R protected mice against MI [626]. The use of intravenous adenosine after primary coronary stenting reduced the infarct size [627]. Clinical outcomes in patients with acute MI undergoing reperfusion therapy (thrombolysis) were not significantly improved with adenosine infusion (3-h infusion of 50 or $70 \mu \mathrm{g} / \mathrm{kg} / \mathrm{min}$ ) [628]. However, it was reported later that continuous infusion of adenosine for $3 \mathrm{~h}$ improved left ventricular function and reduced infarct size in patients with ST-segment elevation MI [629]. The role of adenosine as an adjunct therapy in the prevention and treatment of no-reflow phenomenon in MI with ST-segment elevation was recently reviewed [630].

Acute Myocardial Infarction Study of Adenosine (AMISTAD) clinical trials showed that infusion of adenosine for $3 \mathrm{~h}$ resulted in a striking reduction in infarct size [631]. However, long-term stimulation of A2BR commenced after MI prevented cardiac remodelling in rats [632] and contributed to post-infarction heart failure [633]. In a more recent study, it was found that the selective blockade of A2BR reduced cardiac remodelling following acute $\mathrm{MI}$ in mice [634]. It was suggested that stimulation of A2BR blocks apoptosis of cardiac myocytes and that this may explain the anti-remodelling effect of A2BR stimulation after MI [635]. It was shown that A2BR signalling is linked to up-regulation of pro-angiogenic factors in cardiac Sca- $1^{+} \mathrm{CD} 31^{-}$stromal cells, which is essential for overall improvement of cardiac recovery seen after their transplantation to the injured heart (post MI) [636]. Intracoronary adenosine improved myocardial microvascular perfusion in late reperfused MI [637].

Infarct size was reduced after a brief intravenous infusion of a selective A2AR agonist, ATL-146e [547]. In a clinical trial, a high dose of intracoronary adenosine given during percutaneous coronary intervention (PCI) did not reduce infarct size [638]. However, a later study provided evidence for contrasting beneficial effects of adenosine under similar conditions [639]. Intracoronary administration of adenosine, but not of nitroprusside, resulted in a significant improvement following acute MI [640].

Imidapril, an angiotensin-converting enzyme inhibitor, improved the attenuated inotropic responses to ATP in heart failure due to MI [641]. UTP reduced infarct size and improve heart function in rats after MI [578] and also in mice [535]. Positive inotropic effects in humans were elicited by UTP and uridine diphosphate via P2Y2R and P2Y6R, respectively [642]. Release of UTP from cardiomyocytes during MI was also claimed in this study. P2XR-mediated pressor reflex responses were augmented in animals with MI compared with healthy control animals, and congestive heart failure induced by MI was shown to up-regulate P2XR in the DRG [643]. 
There is increased risk of acute MI in carriers of the Thr- 87 polymorphic variant of the P2Y11R; since extracellular ATP acting on the P2Y11R regulates inflammatory cells, the increased risk was hypothesised to involve an inflammatory mechanism [644]. Intravenous administration of high doses of ATP during primary PCI reduced left ventricular improved wall motion within an area at risk for MI suggesting that ATP can prevent reperfusion injury [645]. In addition, intravenous ATP administration significantly extended ST-segment resolution, reduced the no-reflow ratio, preserved left ventricular systolic function and prevented left ventricular remodelling [646]. An association of the P2Y2R gene with MI in Japanese men has been reported [647]. Clopidogrel and ticlopidine, P2Y12R antagonists used for thrombosis, are also used for prevention and treatment of MI, acting via L-type calcium currents on cardiomyocytes [648].

ATP, released from astrocytes within the rostral ventrolateral medulla presympathetic circuits, induced increased sympathetic outflow contributing to the progression of heart failure following MI in rats [649]. These findings support the view that sympathetic overactivity in heart failure is detrimental, contributing to the progression of the disease. It was suggested that ATP metabolism is a target for protection against MI [650].

In summary, although there are conflicting reports regarding the actions of purine nucleosides and nucleotides during MI, it is clear that adenosine is effective in reducing MI size and is probably involved in post-infarct remodelling. Adenosine inhibits proliferation of cardiac fibroblasts and hypertrophy of cardiomyocytes, both of which play a role in cardiac remodelling after MI.

\section{Arrhythmias}

\section{Paroxysmal supraventricular tachycardia}

ATP was first used for the acute therapy of paroxysmal supraventricular tachycardia (PSVT) in the late 1940s [651] (and see reference to earlier studies therein) and later by others [652-658]. ATP was shown to evoke transient tachycardia at low doses and to induce AV block at high doses [659, 660]. Later, adenosine was also found to be effective in the acute termination of PSVT $[661,662]$ and was used effectively in children [663-666]. The mechanism of terminating the arrhythmias by either adenosine or ATP is the induction of transient complete AV nodal conduction block. Dipyridamole, which inhibits the uptake of adenosine and thereby increasing its extracellular levels, was found to reduce the amount of adenosine required for the termination of PSVT involving the AV node [667]. In contrast, it has been suggested that caffeine (a non-selective adenosine receptor antagonist) ingestion reduces adenosine efficacy in the treatment of PSVT [668], although, the methodology of the latter study was subsequently criticised [669].

Tachycardia can be induced by A2AR agonists and is mediated by direct stimulation of the sympathoexcitation system in awake rats [670]. Caffeine can also induce PSVT [669]. Slow infusion of calcium channel blockers are claimed to be a safe alternative to adenosine for the emergency treatment of PSVT [671]. The relative efficacy of adenosine and verapamil for the treatment of PSVT were found to be similar; adenosine had a higher rate of minor adverse effects, while verapamil had a higher rate of causing hypotension [672].

A comprehensive study of the clinical and electrophysiologic effects of ATP and verapamil on paroxysmal reciprocating junctional tachycardia was undertaken [673]. It was concluded that ATP was more effective and more rapid than verapamil, but with a higher incidence of cardiac and noncardiac side effects. ATP was shown to be a safe and effective drug at low dose for re-entrant tachycardias, involving the $\mathrm{AV}$ node [674]. ATP and adenosine were found to be equally effective for the diagnosis and treatment of PSVT and the incidence and severity of side effects were similar [675]. However, other studies have shown that ATP is more potent than adenosine, probably due to the central cardio-cardiac vagal reflex triggered by the nucleotide (see [15]).

ATP was effective against wide QRS tachycardia [676], and it can be used as a diagnostic tool in the non-invasive diagnosis of dual AV nodal pathway as the substrate for PSVT [677-679]. The effect of ATP on PSVT seems likely to be due to its degradation by ecto-nucleotidases to adenosine to act via P1R [680]. However, continuous perfusion of ATP in animal models where adenosine receptors were blocked showed both negative and positive chronotropic and inotropic effects of ATP, which were dose dependent [122, 681].

Several reviews discuss the treatment of PSVT by ATP and adenosine [15, 61, 682-687]. Adenosine was recommended for the diagnosis of wide complex tachycardia [688].

\section{Ventricular arrhythmias}

Evidence was presented to suggest that adenosine in low concentrations contributed to ventricular dysrhythmia, while ATP and ADP and high concentrations of adenosine have anti-arrhythmic effects [689]. Adenosine was recommended as a safe and effective agent in the evaluation and treatment of infants and children with arrhythmias [46, 690-692]. However, several rare cases of life-threatening ventricular arrhythmias induced by adenosine have been reported [693, 694]. When the activity of intrinsic cardiac neurons was modified by locally applied adenosine, ventricular arrhythmias were induced [695]. An A2BR antagonist, GS-6201, reduced left ventricular dysfunction and ventricular arrhythmias 1 week after MI in a rat model [696]. 
It has been shown that acute adenosine administration in the rat activates cardiac vagal nerve terminals and it was suggested that this could make an important contribution to the anti-arrhythmic action of adenosine [697]. However, in cat, dog and man, the actions of adenosine (given as a rapid intravenous bolus injection) on SA and $\mathrm{AV}$ nodes do not involve the vagus (for adenosine-vagus interaction, see [303, 698]). Valuable articles discussing the role of adenosine in atrial arrhythmias and fibrillation have been published [699, 700].

It was proposed that the release of ATP in pathological conditions could induce a depolarisation, which would generate ventricular arrhythmias [701]. In isolated guinea pig ventricular myocytes, ATP alone did not induce afterdepolarisations nor did it significantly alter the resting membrane potentials and action potentials. However, when it was applied with drugs known to increase intracellular $\mathrm{Ca}^{2+}$, ATP facilitated the induction of after-depolarisations and triggered activity in approximately $60 \%$ of the cells [702]. ATP triggers arrhythmias in electrically stimulated rat cardiac myocytes [703]. ATP prevents the run-down of gap junctional communication between ventricular myocytes in newborn rats by promoting protein phosphorylation [704]. In a later paper, P2X1R were shown to be closely associated with connexin 43 in gap junctions in the human ventricular myocardium [286] and the possibility that decreased expression of $\mathrm{P} 2 \mathrm{X} 1 \mathrm{R}$ is related to arrhythmias in the heart in Chagas disease and diabetes was considered [705]. In the perfused mouse heart, the addition of ATP to the perfusate induced ventricular tachycardia; this effect was mediated by P2R and increased diastolic level of $\left[\mathrm{Ca}^{2+}\right]_{i}[706]$.

\section{Atrial fibrillation}

Fibrillation is characterised by rapid unsynchronised beating of cardiac myocytes resulting in non-effective contractions of the atria or the ventricles. Transient episodes of atrial fibrillation (AF) occur in some patients after the administration of adenosine or ATP for the termination of PSVT; this is probably due to the shortening of action potential duration of atrial myocytes [228, 707, 708].

Abnormal calcium handling in AF was linked to upregulation of A2AR [709]. High endogenous adenosine plasma concentrations were associated with AF during cardiac surgery with cardiopulmonary bypass [710]. However, the use of adenosine, instead of hyperkalemia, in cold crystalloid cardioplegia for the induction of cardiac arrest during coronary artery bypass grafting surgery, was found to reduce the incidence of post-operative AF [711].

Adenosine and ATP have been used in conjunction with various AF ablation procedures to expose dormant conductions between an arrhythmogenic superior vena cava (SVC) and pulmonary vein (PV) and the right atrium (i.e. acute
adenosine/ATP-induced pulmonary vein reconnection may lead to a greater likelihood of recurrence of AF) [712-718].

\section{Cardiomyopathy}

Cardiomyopathy, or heart muscle disease, is a type of progressive chronic heart disease characterised by abnormally enlarged, thickened and/or stiffened myocardium. These pathological changes result in inadequate blood pumping and flow, causing heart failure and the backup of blood in the lungs or the rest of the body. Cardiomyopathy can also be associated with cardiac arrhythmias. It may be inherited, but can also be caused by other factors, including viral infections, alcoholism, vitamin B deficiency or amyloidosis.

In hereditary dystrophic cardiomyopathy in hamsters, adenosine reduced the force of contraction during $\beta$ adrenergic stimulation, but impaired adenosine feedback control of the heart did not play a role in the pathogenesis of this hereditary cardiomyopathy [719]. Pacing-induced regional differences in P1R mRNA expression were described in a swine model of dilated cardiomyopathy [720].

An increase in P2X1R expression in the atria of patients with dilated cardiomyopathy was reported [721]. A beneficial role for activation of cardiac P2X4R was described in a CSQ over-expression model of cardiomyopathy [722]. P2XRmediated action on cardiac myocytes was beneficial in the CSQ model of cardiomyopathy, reducing hypertrophy and increasing life span [723].

\section{Syncope}

Syncope or transient loss of consciousness can be due to many factors involving the cardiovascular system and its neural control. Syncope of cardiac origin can be due to sinus node malfunctioning, paroxysmal AV nodal conduction block, PSVT or self terminating ventricular tachycardia. Patients with syncope of unknown origin or suspected neurally mediated syncope, were more susceptible to intravenous injection of ATP than those without syncope [140, 724]; patients with hyper-sensitivity to ATP can benefit from pacemaker therapy [140, 141, 725].

Adenosine and ATP have been used in conjunction with the head-up tilt table test (HUT) to provoke vasovagal reaction in susceptible patients during the test [726, 727]. Higher plasma levels of adenosine and increased expression of A2AR was found in syncopal patients with a positive HUT [728]. Since syncopes occur suddenly and unexpectedly, it is difficult to see a mechanistic role for chronic changes of A2AR expression and adenosine level in the acute syncopal events. A study of highly symptomatic vasovagal patients using an implantable loop recorder found that the heart rhythm during a spontaneous syncope was identical to the recurrent syncope but not that during HUT or ATP-test [729]. However, 
the method used by this group to quantify the effects of ATP during the test and the interchangeable use of adenosine and ATP as the provocateur agent has been criticised [141].

\section{Cardiac hypertrophy}

Activation of A1R attenuates cardiac hypertrophy and prevents heart failure in a mouse left ventricular pressureoverload model [730]. Phenylephrine-induced cardiomyocyte hypertrophy in rats was inhibited by activation of multiple adenosine receptor subtypes [731]. In addition, hypertrophy induced by phenylephrine in cultured rat ventricular myocytes was associated with compensatory up-regulation of the adenosine system manifested in the significant increase in gene and protein expression of adenosine A1R, A2AR and A3R [732], furthermore, phenylephrine-induced cardiomyocyte hypertrophy and calcification were shown to be regulated by the interaction of CD73 and alkaline phosphatase and inhibited by adenosine receptor activation [733].

Extracellular ATP induces immediate-early gene expression but not cellular hypertrophy [734], and inhibited adrenergic agonist-induced cardiac hypertrophy in cultured neonatal cardiac myocytes [735]. UTP, but not ATP, caused hypertrophic growth in neonatal cardiomyocytes [736]. Overexpression of human P2X4R in ventricular myocytes of a transgenic mouse increased basal cardiac contractility without cardiac hypertrophy or failure [274] and activation with a P2X4R agonist had beneficial effects [483]. Deletion of the P2Y4R gene in mice lowered exercise capacity and reduced myocardial hypertrophy [737].

\section{Sick sinus syndrome}

Sick sinus syndrome (SSS) is defined as malfunction of the sinus node. Intravenous injection of adenosine or ATP can be used to assess sinus node dysfunction and thereby diagnose SSS [738-745].

\section{Coronary artery disease}

Atherosclerosis of coronary vessels is known as coronary artery disease (CAD). The pharmacologic stress test is a common diagnostic procedure aimed at determining the extent of $\mathrm{CAD}$ and the affected coronaries in patients unable to perform conventional exercise stress. In this test, a vasodilating agent is administered followed by a radioisotope (what is known as cardiac nuclear perfusion imaging). Affected coronaries fail to dilate properly resulting in a coronary steal phenomenon, manifested as a non-homogenous increase in coronary blood flow, which is reflected in the non-homogeneous distribution of the radio-isotope that can be mapped using a gamma-camera. Adenosine and ATP, and more recently a selective A2AR agonist (Lexiscan [458]), have been used as pharmacologic stressors in this setting [746-754]. The use of adenosine-cardiac magnetic resonance imaging for the detection of CAD has been recommended recently [755-757].

Administration of ATP into the left coronary artery has been used to treat patients with CAD in preference to papaverine [758]. ATP acts on endothelial P2YR to cause release of NO and subsequent vasodilation. Patients with CAD and patients with risk factors for the disease were shown to have reduced lymphocyte CD39 (NTPDase 1) ecto-nucleotidase activity compared to healthy controls [759].

Platelet adhesion and aggregation is a key step in the development of inflammation, thrombosis and atherosclerosis. Thus, platelet aggregation inhibitors, such as clopidogrel, prasugrel or cangrelor, antagonists of ADP-sensitive P2Y12R, have been used to prevent and treat CAD [760-763]. Several reviews discuss the use of anti-platelet drugs for the treatment and prevention of CAD [762, 764, 765]. It has been suggested that ADP-mediated migration of host smooth muscle-like cells and $\mathrm{CD} 45^{+}$leukocytes, via P2Y12R, may play a role in the development of transplant arteriosclerosis, partly by monocyte chemoattractant protein-1 [766]. Clinical trials with clopidogrel and ticlopidine in patients with CAD have shown significant benefit compared with aspirin. An association between the T744C polymorphism of the P2Y12R gene and the antiplatelet effect of clopidogrel was found in patients with CAD after coronary stenting [767]. ADP receptor antagonist discontinuation prior to coronary artery bypass surgery has been recommended [768, 769].

Continuous infusion and low-dose bolus injection of adenosine were early approaches to determine coronary vasodilator reserve in patients with CAD [770]. The safety of adenosine infusion during cardiac MRI was confirmed [771]. Coronary sinus adenosine was proposed to provide an index of myocardial ischaemia in patients with CAD [772]. Intravenous adenosine resulted in variable changes in systemic blood pressure, which can lead to alterations in fractional flow reserve lesion classification [773].

It was claimed that $\mathrm{ADA}$ played a key role in $\mathrm{CAD}$ [774]. Ischaemic pre-conditioning effects of adenosine were identified in patients with severe CAD that preserved coronary flow reserve [775]. It was reported that a high intracoronary bolus dose of adenosine was equal to or more effective than an intravenous infusion in assessing fractional flow reserve in patients with coronary heart disease [776].

Heart transplants and coronary bypass grafts

\section{Heart transplantation}

The responses to adenosine of the denervated donor sinus and AV nodes were of greater magnitude and duration than those 
of the innervated recipient and normal control hearts, suggesting supersensitivity to adenosine in the denervated human heart [777]. Cardioplegia is the technique used to stop the heart, either by injecting it with a salt solution, by hypothermia or by an electrical stimulus. This is used to enable complex cardiac surgery and transplantation to be performed safely. Adenosine injection prior to cardioplegia is used to protect against ischaemia-reperfusion injury during hypothermia [778-780]. ATP administered to pig hearts in cardioplegia and reperfusion had beneficial effects both on the myocardium and on peripheral vessels [781]. The introduction of ATP synthesis promoters did not improve the beneficial effects of adenosine in cardioplegia [782].

Selective up-regulation of P2X6R was observed in the myocardium of patients undergoing heart transplantation because of CHF [480]. The potential significance of this was studied in primary cardiac fibroblasts freshly isolated from young pigs. Tumour necrosis factor- $\alpha$ (TNF $\alpha)$, a proinflammatory cytokine implicated in CHF progression, increased cell death and similar effects were produced by ATP in a murine cardiomyocytic cell line. In cardiac fibroblasts, TNF $\alpha$ inhibited the down-regulation of P2X6R mRNA and may provide a basis for P2X6R up-regulation in CHF, which may contribute to CHF pathogenesis. There was significant reduction of ATP levels in 1-day-old blood compared to fresh blood, suggesting that fresh blood should be used for assessing $\mathrm{T}$ cell immune function in transplant patients [783]. A recent study found that P2X7R are specifically upregulated in graft-infiltrating lymphocytes in cardiactransplanted humans and mice [784]. Furthermore, a shortterm treatment with a P2XR antagonist prolonged cardiac transplant survival [784].

\section{Coronary bypass grafts}

The purinoceptor distribution on endothelial cells of blood vessels used for coronary artery bypass grafts was examined [785]. The level of P2Y2R was much the same in human internal mammary arteries (IMA) and radial arteries (RA) and on saphenous veins (SV), whereas levels of P2X4R were low in IMA and RA, but high in SV. The authors suggested that the high levels of P2X4R in SV may be the principal reason why these vessels are found to be more susceptible to atherosclerosis and exhibit a reduction in graft patency longevity. Since $\mathrm{P} 2 \mathrm{X} 4 \mathrm{R}$ appears to play a role in arteriosclerosis and restenosis, it is suggested that IMA and RA are preferable for coronary bypass grafts. In another study, it was shown that P2X1R and P2Y6R mediate more prominent contractions in the SV than in the IMA and they suggested that P2X1R and P2Y6R antagonists could be used to prevent vasospasm and restenosis in the SV during and after revascularisation surgery [786]. The robust vasoconstriction produced by diadenosine polyphosphates observed in human RA was compared to the low incidence of vasoconstriction in the IMA [448]. It was concluded that the selective activity of diadenosine polyphosphates in RA would implicate them as potential mediators of post-operative contraction of the graft, confirming again the preference for the use of IMA for coronary bypass grafts.

\section{Diabetic cardiomyopathy}

The coronary dilator action of adenosine was shown to be reduced in diabetes $[787,788]$. Activation of P1R was required for myocardial insulin responsiveness in vivo [789]. Atria from middle-aged diabetic rat models exhibited supersensitivity to the inotropic effect of adenosine [790]. Atria from 6-week streptozotocin (STZ)-induced diabetes in rats exhibited supersensitivity to the negative inotropic and chronotropic effects of adenosine [791]. A3R mRNA and protein levels were increased in whole heart from rats with STZ-induced diabetes [792]. The development of diabetes resulted in an increased uptake of adenosine by rat cardiac fibroblasts and reduction of their ability to release adenosine due to altered expression of nucleoside transporters [793]. The heart rate response to adenosine infusion was diminished in patients with diabetes mellitus, probably due to cardiovascular autonomic neuropathy [794]. Protective effects of adenosine on the diabetic myocardium against ischaemic-reperfusion injury were reported [795]. A predictor of adverse cardiac outcome in asymptomatic patients with type 2 diabetes is the heart rate response to adenosine [796].

Insulin improved the ATP decrease in the subendocardium of the left ventricle of STZ-induced diabetic, but not non-diabetic hearts [797]. The maximum response of $\left[\mathrm{Ca}^{2+}\right]_{\mathrm{i}}$ to exogenous ATP was increased in diabetic cardiomyocytes [798]. Modulation of purinergic neurotransmission via P2YR in isolated atria of STZ-induced diabetic rats has been reported [799].

\section{Angina}

Angina pectoris, pain in the centre of the chest, occurs when the demand for blood by the heart exceeds the supply by the coronary arteries that usually results from coronary artery atheroma. It can be treated with $\mathrm{NO}$ donors and $\beta$-blockers, but may need coronary angioplasty or coronary bypass grafts.

Adenosine was claimed to be a messenger between myocardial ischaemia and angina pectoris in a patient with a transplanted heart [800]. Intracoronary adenosine administration provoked anginal pain and aminophylline, a P1R antagonist, reduced both adenosine and exercise-induced chest pain [801]. Further, the severity of anginal pain produced by intravenous adenosine was milder in patients with silent ischaemia than in those with painful ischaemia. Adenosine infusion into both left and right coronary arteries also produced anginal pain [802]. It was shown later that adenosine, released during 
ischaemia, provoked anginal pain that was controlled by previous administration of theophylline, a non-selective P1R antagonist [803]. Another study found that intracoronary administration of adenosine produced anginal pain by a mechanism other than myocardial ischaemia [804]. Dipyridamole infusion, which inhibits adenosine uptake, increased anginal pain [805]. $\beta$-Endorphin counteracted adenosine-provoked anginal pain [806]. However, it was shown later that adenosine infusion provoked oscillation of chest pain without involvement of opioids [807]. Yet, A1R agonists were recommended for the treatment of neuropathic pain as well as cardioprotective agents [808].

Myocardial release of the breakdown products of ATP, inosine, hypoxanthine and lactate, during pacing-induced angina in humans with CAD was reported [809]. ATP was recommended as a sensitive and reliable method of detecting coronary lesions in patients with unstable angina pectoris [810].

\section{Pulmonary hypertension}

Several studies in animal models of pulmonary hypertension demonstrated the beneficial effects of ATP infusion in this setting [811-815]. Pulmonary hypertension is a serious problem in children with congenital heart defects. ATP- $\mathrm{MgCl}_{2}$ $(0.05,0.1$, and $0.2 \mathrm{mg}$ of ATP $/ \mathrm{kg} / \mathrm{min})$ was a safe and effective pulmonary vasodilator in children with pulmonary hypertension, secondary to congenital heart defects [816].

\section{Concluding comments}

What is clear from the voluminous literature about purinergic signalling in the heart is that:

(1) Nucleoside and nucleotide receptors, i.e. P1R and P2R, respectively, play multiple roles in cardiac physiology and pathophysiology.

(2) There are still important gaps in our knowledge and many questions still remain unanswered regarding purinergic signalling in the heart.

(3) Many of the therapeutic strategies for a number of heart disorders based on the manipulation of purinergic signalling are not well defined. The side effects of some of the treatments need to be considered and strategies to overcome them defined.

The newly developed stable, small molecules that act as selective agonists and antagonists at purinergic receptors, which can be taken orally, as well as novel nucleotidase inhibitors and ATP transport blockers could be a major step forward towards resolving these problems. Studies with inhibitors of ATP release may also enhance our understanding of the relevant mechanisms including the genetic variations in response to purinergic compounds. In this context, immunological factors should also be taken into account.

Acknowledgments We are greatly indebted to Dr Gill Knight for the superb editorial work in the preparation of this manuscript.

\section{References}

1. Burnstock G (1978) A basis for distinguishing two types of purinergic receptor. In: Straub RW, Bolis L (eds) Cell Membrane receptors for drugs and hormones: a multidisciplinary approach. Raven, New York, pp 107-118

2. Burnstock G, Meghji P (1981) Distribution of $P_{1}$ - and $P_{2-}$ purinoceptors in the guinea-pig and frog heart. $\mathrm{Br} \mathrm{J}$ Pharmacol 73: 879-885

3. Abbracchio MP, Burnstock G (1994) Purinoceptors: are there families of $\mathrm{P}_{2 \mathrm{X}}$ and $\mathrm{P}_{2 \mathrm{Y}}$ purinoceptors? Pharmacol Ther 64:445-475

4. Burnstock G (2007) Purine and pyrimidine receptors. Cell Mol Life Sci 64:1471-1483

5. Drury AN, Szent-Györgyi A (1929) The physiological activity of adenine compounds with special reference to their action upon the mammalian heart. J Physiol 68:213-237

6. Burnstock G (1980) Purinergic receptors in the heart. Circ Res 46: 175-182

7. Belhassen B, Pelleg A (1984) Electrophysiologic effects of adenosine triphosphate and adenosine on the mammalian heart: clinical and experimental aspects. J Am Coll Cardiol 4:414-424

8. Hohl CM, Hearse DJ (1985) Vascular and contractile responses to extracellular ATP: studies in the isolated rat heart. Can J Cardiol 1: 207-216

9. Pelleg A (1985) Cardiac cellular electrophysiologic actions of adenosine and adenosine triphosphate. Am Heart J 110:688-693

10. Pelleg A (1988) Cardiac electrophysiologic actions of adenosine and adenosine 5 '-triphosphate. In: Paton DM (ed) Adenosine and adenine nucleotides. Physiology and pharmacology. Taylor \& Francis, London, pp 143-155

11. Pelleg A, Katchanov G, Xu J (1997) Autonomic neural control of cardiac function: modulation by adenosine and adenosine $5^{\prime}$-triphosphate. Am J Cardiol 79:11-14

12. Pelleg A, Belardinelli L (1998) Effects of extracellular adenosine and ATP on cardiomyocytes. Landes, Austin, pp 1-225

13. Pelleg A, Vassort G (1998) Direct and indirect effects of extracellular ATP on cardiac myocytes. In: Pelleg A, Belardinelli L (eds) Effects of extracellular Adenosine and ATP on cardiomyocytes. Landes, Austin, pp 197-222

14. Vassort G (2001) Adenosine 5'-triphosphate: a P2-purinergic agonist in the myocardium. Physiol Rev 81:767-806

15. Pelleg A, Belhassen B (2010) The mechanism of the negative chronotropic and dromotropic actions of adenosine 5 '-triphosphate in the heart: an update. J Cardiovasc Pharmacol 56:106-109

16. Nishida M (2011) Roles of heterotrimeric GTP-binding proteins in the progression of heart failure. J Pharmacol Sci 117:1-5

17. Lubbe WF (1984) Cardiac actions of adenosine. Methods Find Exp Clin Pharmacol 6:171-177

18. Sparks HV Jr, Bardenheuer H (1986) Regulation of adenosine formation by the heart. Circ Res 58:193-201

19. Lerman BB, Belardinelli L (1991) Cardiac electrophysiology of adenosine. Basic and clinical concepts. Circulation 83:1499-1509

20. Belardinelli L, Shryock JC, Pelleg A (1992) Cardiac electrophysiologic properties of adenosine. Coron Artery Dis 3:1122-1126 
21. Pelleg A (1993) Adenosine in the heart: its emerging roles. Hosp Pract (Off Ed) 28:71-74

22. Tucker AL, Linden J (1993) Cloned receptors and cardiovascular responses to adenosine. Cardiovasc Res 27:62-67

23. Bertolet BD, Hill JA (1993) Adenosine: diagnostic and therapeutic uses in cardiovascular medicine. Chest 104:1860-1871

24. Pelleg A, Belardinelli L (1993) Cardiac electrophysiology and pharmacology of adenosine: basic and clinical aspects. Cardiovasc Res 27:54-61

25. Shen WK, Kurachi Y (1995) Mechanisms of adenosine-mediated actions on cellular and clinical cardiac electrophysiology. Mayo Clin Proc 70:274-291

26. Hernández J, Ribeiro JA (1995) Adenosine and ventricular automaticity. Life Sci 57:1393-1399

27. Mubagwa K, Mullane K, Flameng W (1996) Role of adenosine in the heart and circulation. Cardiovasc Res 32:797-813

28. Shryock JC, Belardinelli L (1997) Adenosine and adenosine receptors in the cardiovascular system: biochemistry, physiology, and pharmacology. Am J Cardiol 79:2-10

29. Cai G, Wang HY, Gao E, Horwitz J, Snyder DL, Pelleg A, Roberts J, Friedman E (1997) Reduced adenosine $A_{1}$ receptor and $G_{\alpha}$ protein coupling in rat ventricular myocardium during aging. Circ Res 81:1065-1071

30. Dobson JG, Jr., Fenton RA (1998) Cardiac physiology of adenosine. In: Burnstock G, Dobson JG, Jr., Liang BT, Linden J (eds) Cardiovascular biology of purines. Developments in cardiovascular medicine. Vol 209. Springer, pp 21-39

31. Raatikainen MJP, Dennis DM, Belardinelli L (1998) Cardiac and electrophysiology of adenosine: cellular basis and clinical observations. In: Pelleg A, Belardinelli L (eds) Effects of extracellular adenosine and ATP on cardiomyocytes. Landes, Austin, pp 87-132

32. Lasley RD, Smart EJ (2001) Cardiac myocyte adenosine receptors and caveolae. Trends Cardiovasc Med 11:259-263

33. Headrick JP, Peart JN, Reichelt ME, Haseler LJ (2011) Adenosine and its receptors in the heart: regulation, retaliation and adaptation. Biochim Biophys Acta 1808:1413-1428

34. Headrick JP, Ashton KJ, Rose'Meyer RB, Peart JN (2013) Cardiovascular adenosine receptors: expression, actions and interactions. Pharmacol Ther 140:92-111

35. Szentmiklósi AJ, Cseppentö A, Harmati G, Nánási PP (2011) Novel trends in the treatment of cardiovascular disorders: siteand event-selective adenosinergic drugs. Curr Med Chem 18: 1164-1187

36. Mustafa SJ, Morrison RR, Teng B, Pelleg A (2009) Adenosine receptors and the heart: role in regulation of coronary blood flow and cardiac electrophysiology. Handb Exp Pharmacol 161-188

37. Manfredi JP, Holmes EW (1985) Purine salvage pathways in myocardium. Annu Rev Physiol 47:691-705

38. Rovetto MJ (1985) Myocardial nucleotide transport. Annu Rev Physiol 47:605-616

39. Rubino A (1993) Non-adrenergic non-cholinergic (NANC) neural control of the atrial myocardium. Gen Pharmacol 24:539-545

40. Pelleg A (1987) Cardiac electrophysiology and pharmacology of adenosine and ATP: modulation by the autonomic nervous system. J Clin Pharmacol 27:366-372

41. Ashton KJ, Peart JN, Morrison RR, Matherne GP, Blackburn MR, Headrick JP (2007) Genetic modulation of adenosine receptor function and adenosine handling in murine hearts: insights and issues. $\mathrm{J}$ Mol Cell Cardiol 42:693-705

42. Vasileiou E, Montero RM, Turner CM, Vergoulas G (2010) P2X receptor at the heart of disease. Hippokratia 14:155-163

43. Fang YM, Grootenhuijs-Triyasut G, Doevendans PA, Appelman Y (2009) Current status of assessment of fractional flow reserve. Chin Med J (Engl) 122:725-731

44. Sinoway LI, Li J (2005) A perspective on the muscle reflex: implications for congestive heart failure. J Appl Physiol 99:5-22
45. Berne RM, DiMarco JP, Belardinelli L (1984) Dromotropic effects of adenosine and adenosine antagonists in the treatment of cardiac arrhythmias involving the atrioventricular node. Circulation 69: 1195-1197

46. Pelleg A (1993) Mechanisms of action and therapeutic potential of adenosine and its analogues in the treatment of cardiac arrhythmias. Coron Artery Dis 4:109-115

47. Vassort G, Alvarez J (2009) Transient receptor potential: a large family of new channels of which several are involved in cardiac arrhythmia. Can J Physiol Pharmacol 87:100-107

48. Van Belle H (1993) Nucleoside transport inhibition: a therapeutic approach to cardioprotection via adenosine? Cardiovasc Res 27:68-76

49. Kitakaze M, Hori M (1998) It is time to ask what adenosine can do for cardioprotection. Heart Vessels 13:211-228

50. Auchampach JA, Bolli R (1999) Adenosine receptor subtypes in the heart: therapeutic opportunities and challenges. Am J Physiol 276: H1113-H1116

51. Shneyvays V, Safran N, Halili-Rutman I, Shainberg A (2000) Insights into adenosine $A_{1}$ and $A_{3}$ receptors function: cardiotoxicity and cardioprotection. Drug Dev Res 50:324-337

52. Mubagwa K, Flameng W (2001) Adenosine, adenosine receptors and myocardial protection: an updated overview. Cardiovasc Res 52:25-39

53. Willems L, Ashton KJ, Headrick JP (2005) Adenosine-mediated cardioprotection in the aging myocardium. Cardiovasc Res 66:245255

54. Yang G, FitzGerald GA (2012) (Almost) everything is illuminated: adenosine shines a light on cardioprotection. Circ Res 111:965-966

55. Randhawa MP Jr, Lasley RD, Mentzer RM Jr (1993) Adenosine and the stunned heart. J Card Surg 8:332-337

56. Lasley RD (1998) Protective effects of adenosine in reversibly and irreversibly injured ischemic myocardium. In: Pelleg A, Belardinelli L (eds) Effects of extracellular adenosine and ATP on cardiomyocytes. Landes, Austin, pp 133-172

57. Kao RL, Browder W, Li C (2009) Cellular cardiomyoplasty: what have we learned? Asian Cardiovasc Thorac Ann 17:89-101

58. Dohadwala MM, Givertz MM (2008) Role of adenosine antagonism in the cardiorenal syndrome. Cardiovasc Ther 26:276-286

59. Vallon V, Miracle C, Thomson S (2008) Adenosine and kidney function: potential implications in patients with heart failure. Eur J Heart Fail 10:176-187

60. Belhassen B, Pelleg A (1984) Acute management of paroxysmal supraventricular tachycardia: verapamil, adenosine triphosphate or adenosine? Am J Cardiol 54:225-227

61. Belhassen B, Pelleg A (1985) Adenosine triphosphate and adenosine: perspectives in the acute management of paroxysmal supraventricular tachycardia. Clin Cardiol 8:460-464

62. Parker RB, McCollam PL (1990) Adenosine in the episodic treatment of paroxysmal supraventricular tachycardia. Clin Pharm 9: 261-271

63. Innes JA (2008) Review article: adenosine use in the emergency department. Emerg Med Aust 20:209-215

64. Boettge K, Jaeger KH, Mittenzwei H (1957) Das adenylsäuresystem. Neuere ergebnisse und probleme. Arzneimittelforschung 7:24-59

65. Sollevi A (1986) Cardiovascular effects of adenosine in man; possible clinical implications. Prog Neurobiol 27:319-349

66. Stone T (1992) Therapeutic potential of adenosine. Scrip Magazine :41-43

67. Abbracchio MP, Burnstock G (1998) Purinergic signalling: pathophysiological roles. Jpn J Pharmacol 78:113-145

68. Kaiser SM, Quinn RJ (1999) Adenosine receptors as potential therapeutic targets. Drug Discov Today 4:542-551

69. Agteresch HJ, Dagnelie PC, van den Berg JWO, Wilson JH (1999) Adenosine triphosphate: established and potential clinical applications. Drugs 58:211-232 
70. Broadley KJ (2000) Drugs modulating adenosine receptors as potential therapeutic agents for cardiovascular diseases. Exp Opin Ther Patents 10:1169-1692

71. Williams M (2001) Clinical opportunities in purinergic neuromodulation. In: Abbracchio MP, Williams M (eds) Handbook of experimental pharmacology, Volume 151/II. Purinergic and pyrimidinergic signalling II-cardiovascular, respiratory, immune, metabolic and gastrointestinal tract function. Springer, Berlin, pp 407-434

72. Ralevic V, Burnstock G (2003) Involvement of purinergic signalling in cardiovascular diseases. Drug News Perspect 16:133-140

73. Press NJ, Gessi S, Borea PA, Polosa R (2007) Therapeutic potential of adenosine receptor antagonists and agonists. Expert Opin Ther Pat 17:979-991

74. Erlinge D, Burnstock G (2008) P2 receptors in cardiovascular regulation and disease. Purinergic Signal 4:1-20

75. Erlinge D (2011) P2Y receptors in health and disease. Adv Pharmacol 61:417-439

76. Burnstock G, Kennedy C (2011) P2X receptors in health and disease. In: Jacobson KA, Linden J (eds) Purine and pyrimidine receptor pharmacology. Academic, Burlington, pp 333-372

77. Kennedy C, Chootip K, Mitchell C, Syed NI, Tengah A (2013) P2X and $\mathrm{P} 2 \mathrm{Y}$ nucleotide receptors as targets in cardiovascular disease. Future Med Chem 5:431-449

78. Burnstock G, Ralevic V (2014) Purinergic signalling and blood vessels in health and disease. Pharmacol Rev 66:102-192

79. Wedd AM (1931) The action of adenosine and certain related compounds on the coronary flow of the perfused heart of the rabbit. J Pharmacol Exp Ther 41:355-366

80. Jezer A, Oppenheimer BS, Schwartz SP (1933) The effect of adenosine on cardiac irregularities in man. Am Heart J 9:252-258

81. Honey RM, Ritchie WT, Thomson WAR (1930) The action of adenosine upon the human heart. QJM os-23:485-489

82. Drury AN (1936) The physiological activity of nucleic acid and its derivatives. Physiol Rev 16:292-325

83. Gillespie JH (1934) The biological significance of the linkages in adenosine triphosphoric acid. J Physiol 80:345-359

84. Gaddum JH, Holtz P (1933) The localization of the action of drugs on the pulmonary vessels of dog and cats. J Physiol 77:139-158

85. Green HN, Stoner HB (1950) The effect of purine derivatives on the cardiovascular system. Biological actions of the adenine nucleotides. Lewis, London, pp 65-103

86. Heidelmann G (1956) Management of cardiovascular diseases with muscle adenylic acid. Munch Med Wochenschr 98:1631-1633

87. Dinelli CA (1953) The clinical use of adenosinetriphosphate. Minerva Med 44:1338-1344

88. Olivet J, Grund G (1953) Heart therapy with adenylic acid. Munch Med Wochenschr 95:1205-1206

89. Tursi F (1954) The use of A.T.P. in circulatory insufficiency and angina pectoris. Rass Int Clin Ter 34:604-606

90. Cadario F, Porretti F, Re A (1956) Use of adenosinetriphosphate (ATP) in cardiovascular diseases; clinical contribution. Minerva Med 47:2000-2006

91. Kraucher GK (1955) Treatment of circulatory disorders with adenine compounds. Wien Med Wochenschr 105:303-305

92. Berne RM (1963) Cardiac nucleotides in hypoxia: possible role in regulation of coronary blood flow. Am J Physiol 204: 317-322

93. Gerlach E, Deuticke B, Dreisbach RH, Rosarius CW (1963) On the behavior of nucleotides and their dephosphorylation degradation products in the kidney in ischemia and short-term post-ischemic re-establishment of blood circulation. Pflugers Arch Gesamten Physiol Menschen Tiere 278:296-315

94. Burnstock G (1972) Purinergic nerves. Pharmacol Rev 24:509-581

95. Hopkins SV, Goldie RG (1971) A species difference in the uptake of adenosine by heart. Biochem Pharmacol 20:3359-3365
96. Angus JA, Cobbin LB, Einstein R, Maguire MH (1971) Cardiovascular actions of substituted adenosine analogues. $\mathrm{Br} \mathrm{J}$ Pharmacol 41:592-599

97. Minkes MS, Douglas JR Jr, Needleman P (1973) Prostaglandin release by the isolated perfused rabbit heart. Prostaglandins 3:439 445

98. Hopkins SV (1973) The action of ATP in the guinea-pig heart. Biochem Pharmacol 22:335-339

99. Schrader J, Gerlach E (1976) Compartmentation of cardiac adenine nucleotides and formation of adenosine. Pflugers Arch 367:129 135

100. Huang M, Drummond GI (1976) Effect of adenosine on cyclic AMP accumulation in ventricular myocardium. Biochem Pharmacol 25:2713-2719

101. Forrester T, Williams CA (1977) Release of adenosine triphosphate from isolated adult heart cells in response to hypoxia. J Physiol 268: 371-390

102. Juhász-Nagy A, Aviado DM (1977) Inosine as a cardiotonic agent that reverses adrenergic beta blockade. J Pharmacol Exp Ther 202: 683-695

103. Schrader J, Nees S, Gerlach E (1977) Evidence for a cell surface adenosine receptor on coronary myocytes and atrial muscle cells. Studies with an adenosine derivative of high molecular weight. Pflugers Arch 369:251-257

104. Schrader J, Baumann G, Gerlach E (1977) Adenosine as inhibitor of myocardial effects of catecholamines. Pflugers Arch 372:29-35

105. Burnstock G (1993) Hypoxia, endothelium and purines. Drug Dev Res 28:301-305

106. Olsson RA (2004) Cardiovascular ecto-5'-nucleotidase: an end to 40 years in the wilderness? Circ Res 95:752-753

107. Fredholm BB, Hedqvist P, Lindstrom K, Wennmalm M (1982) Release of nucleosides and nucleotides from the rabbit heart by sympathetic nerve stimulation. Acta Physiol Scand 116:285-295

108. Wennmalm M, Fredholm BB, Hedqvist P (1988) Adenosine as a modulator of sympathetic nerve-stimulation-induced release of noradrenaline from the isolated rabbit heart. Acta Physiol Scand 132: 487-494

109. Furshpan EJ, Potter DD, Matsumoto SG (1986) Synaptic functions in rat sympathetic neurons in microcultures. III. A purinergic effect on cardiac myocytes. J Neurosci 6:1099-1107

110. Bramich NJ, Edwards FR, Hirst GD (1990) Sympathetic nerve stimulation and applied transmitters on the sinus venosus of the toad. J Physiol 429:349-375

111. Ogawa S, Barnett JV, Sen L, Galper JB, Smith TW, Marsh JD (1992) Direct contact between sympathetic neurons and rat cardiac myocytes in vitro increases expression of functional calcium channels. J Clin Invest 89:1085-1093

112. von Kügelgen I, Stoffel D, Starke K (1995) $\mathrm{P}_{2}$-purinoceptor-mediated inhibition of noradrenaline release in rat atria. Br J Pharmacol $115: 247-254$

113. Tokunaga T, Katsuragi T, Sato C, Furukawa T (1995) ATP release evoked by isoprenaline from adrenergic nerves of guinea pig atrium. Neurosci Lett 186:95-98

114. Sperlágh B, Erdelyi F, Szabo G, Vizi ES (2000) Local regulation of $\left[{ }^{3} \mathrm{H}\right]$-noradrenaline release from the isolated guinea-pig right atrium by $\mathrm{P}_{2 \mathrm{X}}$-receptors located on axon terminals. $\mathrm{Br} \mathrm{J}$ Pharmacol 131: 1775-1783

115. Svíglerová J, Kuncová J, Nalos L, Slavíkova J, Stengl M (2008) Depressed cardiac contractility and its postnatal development in rats after chemical sympathectomy. Physiol Res 57:507-515

116. Rücker B, Almeida ME, Libermann TA, Zerbini LF, Wink MR, Sarkis JJ (2008) E-NTPDases and ecto-5'-nucleotidase expression profile in rat heart left ventricle and the extracellular nucleotide hydrolysis by their nerve terminal endings. Life Sci 82 : $477-486$ 
117. Mantelli L, Amerini S, Ledda F (1990) Opioid agonists, prostaglandin $\mathrm{E}_{1}$ and clonidine modulate non-adrenergic, non-cholinergic transmission in the mammalian heart. J Auton Nerv Syst 30(Suppl):S113-S115

118. Rubino A, Mantelli L, Amerini S, Ledda F (1990) Adenosine modulation of non-adrenergic non-cholinergic neurotransmission in isolated guinea-pig atria. Naunyn Schmiedeberg's Arch Pharmacol 342:520-522

119. Rubino A, Amerini S, Mantelli L, Ledda F (1991) Adenosine receptors involved in the inhibitory control of non-adrenergic noncholinergic neurotransmission in guinea-pig atria belong to the $\mathrm{A}_{1}$ subtype. Naunyn Schmiedeberg's Arch Pharmacol 344:464-470

120. Huang MH, Sylven C, Horackova M, Armour JA (1995) Ventricular sensory neurons in canine dorsal root ganglia: effects of adenosine and substance P. Am J Physiol 269:R318-R324

121. Garcia-Guzman M, Stühmer W, Soto F (1997) Molecular characterization and pharmacological properties of the human $\mathrm{P}_{2} \mathrm{X}_{3}$ purinoceptor. Brain Res Mol Brain Res 47:59-66

122. Xu J, Kussmaul W, Kurnik PB, Al-Ahdav M, Pelleg A (2005) Electrophysiological-anatomic correlates of ATP-triggered vagal reflex in the dog. V. Role of purinergic receptors. Am J Physiol Regul Integr Comp Physiol 288:R651-R655

123. Crowe R, Burnstock G (1982) Fluorescent histochemical localisation of quinacrine-positive neurones in the guinea-pig and rabbit atrium. Cardiovasc Res 16:384-390

124. Allen TGJ, Burnstock G (1987) Intracellular studies of the electrophysiological properties of cultured intracardiac neurones of the guinea-pig. J Physiol 388:349-366

125. Allen TGJ, Burnstock G (1990) The actions of adenosine 5'-triphosphate on guinea-pig intracardiac neurones in culture. Br J Pharmacol 100:269-276

126. Fieber LA, Adams DJ (1991) Adenosine triphosphate-evoked currents in cultured neurones dissociated from rat parasympathetic cardiac ganglia. J Physiol 434:239-256

127. Huang MH, Sylvén C, Pelleg A, Smith FM, Armour JA (1993) Modulation of in situ canine intrinsic cardiac neuronal activity by locally applied adenosine, ATP, or analogues. Am J Physiol 265: R914-R922

128. Horackova M, Huang MH, Armour JA (1994) Purinergic modulation of adult guinea pig cardiomyocytes in long term cultures and co-cultures with extracardiac or intrinsic cardiac neurones. Cardiovasc Res 28:673-679

129. Saffrey MJ, Hassall CJS, Allen TGJ, Burnstock G (1992) Ganglia within the gut, heart, urinary bladder and airways: studies in tissue culture. Int Rev Cytol 136:93-144

130. Armour JA, Huang MH, Pelleg A, Sylven C (1994) Responsiveness of in situ canine nodose ganglion afferent neurones to epicardial mechanical or chemical stimuli. Cardiovasc Res 28:1218-1225

131. Liu DM, Katnik C, Stafford M, Adams DJ (2000) P2Y purinoceptor activation mobilizes intracellular $\mathrm{Ca}^{2+}$ and induces a membrane current in rat intracardiac neurones. J Physiol 526:287-298

132. Machida T, Heerdt PM, Reid AC, Schafer U, Silver RB, Broekman MJ, Marcus AJ, Levi R (2005) Ectonucleoside triphosphate diphosphohydrolase $1 / \mathrm{CD} 39$, localized in neurons of human and porcine heart, modulates ATP-induced norepinephrine exocytosis. J Pharmacol Exp Ther 313:570-577

133. Schindler CW, Karcz-Kubicha M, Thorndike EB, Müller CE, Tella SR, Ferré S, Goldberg SR (2005) Role of central and peripheral adenosine receptors in the cardiovascular responses to intraperitoneal injections of adenosine $A_{1}$ and $A_{2 A}$ subtype receptor agonists. Br J Pharmacol 144:642-650

134. Belhassen B, Ilia R, Pelleg A, Greenspan A, Horowitz L (1985) A comparative study of the electrophysiologic effects of Striadyne, adenosine triphosphate and adenosine in the canine heart. Cardiology 72:113-122
135. Pelleg A, Mitamura H, Michelson EL (1985) Evidence for vagal involvement in the electrophysiologic actions of exogenous adenosine and adenosine triphosphate in the canine heart. J Auton Pharmacol 5:207-212

136. Bishop VS, Hasser EM (1987) Physiological role of ventricular receptors. In: McWilliam PN, Mary DA (eds) Cardiogenic reflexes. Oxford, Oxford, pp 62-73

137. Pelleg A, Hurt CM, Soler-Baillo JM, Polansky M (1993) Electrophysiological-anatomic correlates of ATP-triggered vagal reflex in dogs. Am J Physiol 265:H681-H690

138. Katchanov G, Xu J, Hurt CM, Pelleg A (1996) Electrophysiological-anatomic correlates of ATP-triggered vagal reflex in the dog. III. Role of cardiac afferents. Am J Physiol 270: H1785-H1790

139. Katchanov G, Xu J, Clay A, Pelleg A (1997) Electrophysiologicalanatomic correlates of ATP-triggered vagal reflex in the dog. IV. Role of LV vagal afferents. Am J Physiol 272:H1898-H1903

140. Flammang D, Church T, Waynberger M, Chassing A, Antiel M (1997) Can adenosine 5'-triphosphate be used to select treatment in severe vasovagal syndrome? Circulation 96:1201-1208

141. Flammang D, Pelleg A, Benditt DG (2005) The adenosine triphospate (ATP) test for evaluation of syncope of unknown origin. J Cardiovasc Electrophysiol 16:1388-1389

142. Flammang D, Chassing A, Donal E, Hamani D, Erickson M, McCarville S (1998) Reproducibility of the adenosine-5'-triphosphate test in vasovagal syndrome. J Cardiovasc Electrophysiol 9: 1161-1166

143. Brignole M, Alboni P, Benditt DG, Bergfeldt L, Blanc JJ, Thomsen PE, van Gert DJ, Fitzpatrick A, Hohnloser S, Janousek J, Kapoor W, Kenny RA, Kulakowski P, Masotti G, Moya A, Raviele A, Sutton R, Theodorakis G, Ungar A, Wieling W, Priori SG, Garcia MA, Budaj A, Cowie M, Deckers J, Burgos EF, Lekakis J, Lindhal B, Mazzotta G, Morais J, Oto A, Smiseth O, Menozzi C, Ector H, Vardas P (2004) Guidelines on management (diagnosis and treatment) of syncope-update 2004. Executive Summary. Eur Heart J 25: 2054-2072

144. Taneyama C, Benson KT, Hild PG, Goto H (1997) Adenosine triphosphate attenuates renal sympathetic nerve activity through left ventricular chemosensitive receptors. J Pharmacol Exp Ther 280: $570-575$

145. Shen WK, Hammill SC, Munger TM, Stanton MS, Packer DL, Osborn MJ, Wood DL, Bailey KR, Low PA, Gersh BJ (1996) Adenosine: potential modulator for vasovagal syncope. J Am Coll Cardiol 28:146-154

146. Minic Z, O'Leary DS, Goshgarian HG, Scislo TJ (2013) Immunohistochemistry confirms the functional evidence that the cardiopulmonary chemoreflex (CCR) pathways in the caudal nucleus of the solitary tract (cNTS) are directly inhibited by $A_{1}$ adenosine receptors and indirectly inhibited by $\mathrm{A}_{2 \mathrm{a}}$ receptors via GABA release. FASEB J 27:1118

147. Belardinelli L, Lerman BB (1991) Adenosine: cardiac electrophysiology. Pacing Clin Electrophysiol 14:1672-1680

148. Dhalla AK, Shryock JC, Shreeniwas R, Belardinelli L (2003) Pharmacology and therapeutic applications of A1 adenosine receptor ligands. Curr Top Med Chem 3:369-385

149. Zhan E, McIntosh VJ, Lasley RD (2011) Adenosine $A_{2 A}$ and $A_{2 B}$ receptors are both required for adenosine $A_{1}$ receptor-mediated cardioprotection. Am J Physiol Heart Circ Physiol 301:H1183H1189

150. Leung E, Johnston CI, Woodcock EA (1983) Demonstration of adenylate cyclase coupled adenosine receptors in guinea pig ventricular membranes. Biochem Biophys Res Commun 110:208-215

151. Collis MG (1983) Evidence for an $A_{1}$-adenosine receptor in the guinea-pig atrium. Br J Pharmacol 78:207-212

152. Martens D, Lohse MJ, Rauch B, Schwabe U (1987) Pharmacological characterization of $\mathrm{A}_{1}$ adenosine receptors in 
isolated rat ventricular myocytes. Naunyn Schmiedeberg's Arch Pharmacol 336:342-348

153. Leung E, Woodcock EA (1986) Effect of temperature on atrial and ventricular adenosine $A_{1}$ receptors of the guinea pig. Can J Physiol Pharmacol 64:1497-1502

154. Evoniuk G, Jacobson KA, Shamim MT, Daly JW, Wurtman RJ (1987) A1- and A2-selective adenosine antagonists: in vivo characterization of cardiovascular effects. J Pharmacol Exp Ther 242:882887

155. Dobson JG Jr (1978) Reduction by adenosine of the isoproterenolinduced increase in cyclic adenosine $3^{\prime}, 5^{\prime}$-monophosphate formation and glycogen phosphorylase activity in rat heart muscle. Circ Res 43:785-792

156. Endoh M, Yamashita S (1980) Adenosine antagonizes the positive inotropic action mediated via $\beta$-, but not $\alpha$-adrenoceptors in the rabbit papillary muscle. Eur J Pharmacol 65:445-448

157. Dobson JG Jr (1983) Mechanism of adenosine inhibition of catecholamine-induced responses in heart. Circ Res 52:151-160

158. Song Y, Thedford S, Lerman BB, Belardinelli L (1992) Adenosinesensitive afterdepolarizations and triggered activity in guinea pig ventricular myocytes. Circ Res 70:743-753

159. Huang M, Drummond GI (1978) Interaction between adenosine and catecholamines on cyclic AMP accumulation in guinea pig ventricular myocardium. Biochem Pharmacol 27:187-191

160. Lee HT, Thompson CI, Linden J, Belloni FL (1993) Differential sensitization of cardiac actions of adenosine in rats after chronic theophylline treatment. Am J Physiol 264:H1634-H1643

161. Liang BT, Morley JF (1996) A new cyclic AMP-independent, $\mathrm{G}_{\mathrm{s}^{-}}$ mediated stimulatory mechanism via the adenosine $\mathrm{A}_{2 \mathrm{a}}$ receptor in the intact cardiac cell. J Biol Chem 271:18678-18685

162. Norton GR, Woodiwiss AJ, McGinn RJ, Lorbar M, Chung ES, Honeyman TW, Fenton RA, Dobson JG Jr, Meyer TE (1999) Adenosine $\mathrm{A}_{1}$ receptor-mediated antiadrenergic effects are modulated by $\mathrm{A}_{2 \mathrm{a}}$ receptor activation in rat heart. Am J Physiol 276: H341-H349

163. Srinivas M, Shryock JC, Dennis DM, Baker SP, Belardinelli L (1997) Differential A1 adenosine receptor reserve for two actions of adenosine on guinea pig atrial myocytes. Mol Pharmacol 52:683691

164. Lokhandwala MF (1979) Inhibition of cardiac sympathetic neurotransmission by adenosine. Eur J Pharmacol 60:353-357

165. Hedqvist P, Fredholm BB (1979) Inhibitory effect of adenosine on adrenergic neuroeffector transmission in the rabbit heart. Acta Physiol Scand 105:120-122

166. Szentmiklósi AJ, Németh M, Szegi J, Papp JG, Szekeres L (1980) Effect of adenosine on sinoatrial and ventricular automaticity of the guinea pig. Naunyn Schmiedeberg's Arch Pharmacol 311:147-149

167. Fredholm BB, Hedqvist P, Vernet L (1979) Release of adenosine from the rabbit heart by sympathetic nerve stimulation. Acta Physiol Scand 106:381-382

168. Wakade AR, Wakade TD (1982) Mechanism of presynaptic actions of adenosine and acetylcholine on noradrenaline release in the guinea-pig heart. Neuroscience 7:2267-2276

169. Ford DA, Rovetto MJ (1987) Rat cardiac myocyte adenosine transport and metabolism. Am J Physiol 252:H54-H63

170. Clanachan AS, Marshall RJ (1980) Potentiation of the effects of adenosine on isolated cardiac and smooth muscle by diazepam. Br J Pharmacol 71:459-466

171. Szentmiklósi AJ, Németh M, Cseppentö A, Szegi J, Papp JG, Szekeres L (1982) Potentiation of the myocardial actions of adenosine in the presence of coformycin, a specific inhibitor of adenosine deaminase. Arch Int Pharmacodyn Ther 256:236-252

172. de Garavilla L, Valentine HL, Schenden JS, Kinnier WJ, Hanson RC (1993) Cardiovascular effects of adenosine and the adenosine $\mathrm{A}_{1}$ receptor antagonist NPC 205 are altered with age in guinea pigs. Drug Dev Res 28:496-502
173. Bullough DA, Magill MJ, Firestein GS, Mullane KM (1995) Adenosine activates $A_{2}$ receptors to inhibit neutrophil adhesion and injury to isolated cardiac myocytes. J Immunol 155:2579-2586

174. Gao E, Snyder DL, Johnson MD, Friedman E, Roberts J, Horwitz J (1997) The effect of age on adenosine $A_{1}$ receptor function in the rat heart. J Mol Cell Cardiol 29:593-602

175. Xu J, Gao F, Ma XL, Gao E, Friedman E, Snyder DL, Horwitz J, Pelleg A (1999) Effect of aging on the negative chronotropic and anti-beta-adrenergic actions of adenosine in the rat heart. J Cardiovasc Pharmacol 34:904-912

176. Kennedy I, Gurden M, Strong P (1992) Do adenosine $A_{3}$ receptors exist? Gen Pharmacol 23:303-307

177. Gurden MF, Coates J, Ellis F, Evans B, Foster M, Hornby E, Kennedy I, Martin DP, Strong P, Vardey CJ (1993) Functional characterization of three adenosine receptor types. Br J Pharmacol 109:693-698

178. Meester BJ, Shankley NP, Welsh NJ, Wood J, Meijler FL, Black JW (1998) Pharmacological classification of adenosine receptors in the sinoatrial and atrioventricular nodes of the guinea-pig. Br J Pharmacol 124:685-692

179. Shneyvays V, Nawrath H, Jacobson KA, Shainberg A (1998) Induction of apoptosis in cardiac myocytes by an $\mathrm{A}_{3}$ adenosine receptor agonist. Exp Cell Res 243:383-397

180. Henry P, Demolombe S, Pucéat M, Escande D (1996) Adenosine $A_{1}$ stimulation activates delta-protein kinase $\mathrm{C}$ in rat ventricular myocytes. Circ Res 78:161-165

181. Ikeda U, Kurosaki K, Shimpo M, Okada K, Saito T, Shimada K (1997) Adenosine stimulates nitric oxide synthesis in rat cardiac myocytes. Am J Physiol 273:H59-H65

182. Salman H, Bergman M, Schlesinger H, Zahavi I, KesslerIcekson G (1999) Adenosine stimulates ANP expression in cultured ventricular cardiomyocytes. J Cardiovasc Pharmacol $34: 7-9$

183. Neumann J, Vahlensieck U, Boknik P, Linck B, Lüss H, Müller FU, Matherne GP, Schmitz W (1999) Functional studies in atrium overexpressing $\mathrm{A}_{1}$-adenosine receptors. Br J Pharmacol 128:1623-1629

184. Woodiwiss AJ, Honeyman TW, Fenton RA, Dobson JG Jr (1999) Adenosine $\mathrm{A}_{2 \mathrm{a}}$-receptor activation enhances cardiomyocyte shortening via $\mathrm{Ca}^{2+}$-independent and -dependent mechanisms. Am J Physiol 276:H1434-H1441

185. Flitney FW, Singh J (1980) Inotropic responses of the frog ventricle to adenosine triphosphate and related changes in endogenous cyclic nucleotides. J Physiol 304:21-42

186. Niedergerke R, Page S (1981) Two physiological agents that appear to facilitate calcium discharge from the sarcoplasmic reticulum in frog heart cells: adrenalin an ATP. Proc R Soc Lond B Biol Sci 213: 325-344

187. Burnstock G, Meghji P (1983) The effect of adenyl compounds on the rat heart. Br J Pharmacol 79:211-218

188. Lundberg JM, Hua Y, Fredholm BB (1984) Capsaicin-induced stimulation of the guinea-pig atrium. Involvement of a novel sensory transmitter or a direct action on myocytes? Naunyn Schmiedeberg's Arch Pharmacol 325:176-182

189. Sugiura H, Toyama J, Tsuboi N, Kamiya K, Kodama I (1990) ATP directly affects junctional conductance between paired ventricular myocytes isolated from guinea pig heart. Circ Res 66:1095-1102

190. Williams CA, Forrester T (1983) Possible source of adenosine triphosphate released from rat myocytes in response to hypoxia and acidosis. Cardiovasc Res 17:301-312

191. De Young MB, Scarpa A (1989) ATP receptor-induced $\mathrm{Ca}^{2+}$ transients in cardiac myocytes: sources of mobilized $\mathrm{Ca}^{2+}$. Am J Physiol 257:C750-C758

192. Vial C, Owen P, Opie LH, Posel D (1987) Significance of release of adenosine triphosphate and adenosine induced by hypoxia or adrenaline in perfused rat heart. J Mol Cell Cardiol 19:187-197 
193. Danziger RS, Raffaeli S, Moreno-Sanchez R, Sakai M, Capogrossi MC, Spurgeon HA, Hansford RG, Lakatta EG (1988) Extracellular ATP has a potent effect to enhance cytosolic calcium and contractility in single ventricular myocytes. Cell Calcium 9:193-199

194. Pucéat M, Clément O, Scamps F, Vassort G (1991) Extracellular ATP-induced acidification leads to cytosolic calcium transient rise in single rat cardiac myocytes. Biochem J 274:55-62

195. Christie A, Sharma VK, Sheu SS (1992) Mechanism of extracellular ATP-induced increase of cytosolic $\mathrm{Ca}^{2+}$ concentration in isolated rat ventricular myocytes. J Physiol 445:369-388

196. Hirano Y, Abe S, Sawanobori T, Hiraoka M (1991) External ATPinduced changes in $\left[\mathrm{Ca}^{2+}\right]_{\mathrm{i}}$ and membrane currents in mammalian atrial myocytes. Am J Physiol 260:C673-C680

197. Zheng JS, Christie A, Levy MN, Scarpa A (1992) $\mathrm{Ca}^{2+}$ mobilization by extracellular ATP in rat cardiac myocytes: regulation by protein kinase C and A. Am J Physiol 263:C933-C940

198. Legssyer A, Poggioli J, Renard D, Vassort G (1988) ATP and other adenine compounds increase mechanical activity and inositol trisphosphate production in rat heart. J Physiol 401:185-199

199. Yamada M, Hamamori Y, Akita H, Yokoyama M (1992) $P_{2}-$ purinoceptor activation stimulates phosphoinositide hydrolysis and inhibits accumulation of cAMP in cultured ventricular myocytes. Circ Res 70:477-485

200. Mantelli L, Amerini S, Filippi S, Ledda F (1993) Blockade of adenosine receptors unmasks a stimulatory effect of ATP on cardiac contractility. Br J Pharmacol 109:1268-1271

201. Pucéat M, Vassort G (1996) Purinergic stimulation of rat cardiomyocytes induces tyrosine phosphorylation and membrane association of phospholipase $\mathrm{C} \gamma$ : a major mechanism for $\operatorname{Ins} P_{3}$ generation. Biochem J 318:723-728

202. Vulchanova L, Arvidsson U, Riedl M, Wang J, Buell G, Surprenant A, North RA, Elde R (1996) Differential distribution of two ATPgated channels $\left(\mathrm{P}_{2 \mathrm{X}}\right.$ receptors) determined by immunocytochemistry. Proc Natl Acad Sci U S A 93:8063-8067

203. Garcia-Guzman M, Soto F, Gomez-Hernandez JM, Lund PE, Stühmer W (1997) Characterization of recombinant human P2X receptor reveals pharmacological differences to the rat homologue. Mol Pharmacol 51:109-118

204. Bogdanov Y, Rubino A, Burnstock G (1998) Characterisation of subtypes of the P2X and P2Y families of receptors in the foetal human heart. Life Sci 62:697-703

205. Hansen MA, Bennett MR, Barden JA (1999) Distribution of purinergic $\mathrm{P} 2 \mathrm{X}$ receptors in the rat heart. J Auton Nerv Syst 78:1-9

206. Giannattasio B, Powers K, Scarpa A (1992) Photoaffinity labeling and expression cloning of extracellular ATP receptors of cardiac myocytes. Ann N Y Acad Sci 671:471-477

207. Giannattasio B, Powers K, Scarpa A (1992) Characterization of myocardial extracellular ATP receptors by photoaffinity labelling and functional assays. FEBS Lett 308:327-331

208. Scamps F, Legssyer A, Mayoux E, Vassort G (1990) The mechanism of positive inotropy induced by adenosine triphosphate in rat heart. Circ Res 67:1007-1016

209. Friel DD, Bean BP (1990) Dual control by ATP and acetylcholine of inwardly rectifying $\mathrm{K}^{+}$channels in bovine atrial cells. Pflugers Arch 415:651-657

210. Matsuura H, Ehara T (1992) Activation of chloride current by purinergic stimulation in guinea pig heart cells. Circ Res $70: 851-855$

211. Kaneda M, Fukui K, Doi K (1994) Activation of chloride current by $\mathrm{P}_{2}$-purinoceptors in rat ventricular myocytes. Br J Pharmacol 111: $1355-1360$

212. Levesque PC, Hume JR (1995) $\mathrm{ATP}_{\mathrm{o}}$ but not cAMPi activates a chloride conductance in mouse ventricular myocytes. Cardiovasc Res 29:336-343
213. Dakshinamurti K, Wang X, Musat S, Dandekar M, Dhalla NS (1998) Alterations of $\mathrm{KCl}^{-}$and ATP-induced increase in $\left[\mathrm{Ca}^{2+}\right]_{\mathrm{i}}$ in cardiomyocytes from vitamin $\mathrm{B}_{6}$ deficient rats. Can J Physiol Pharmacol 76:837-842

214. Duan D, Ye L, Britton F, Miller LJ, Yamazaki J, Horowitz B, Hume JR (1999) Purinoceptor-coupled $\mathrm{Cl}^{-}$channels in mouse heart: a novel, alternative pathway for CFTR regulation. J Physiol 521:4356

215. Qu Y, Campbell DL, Strauss HC (1993) Modulation of L-type $\mathrm{Ca}^{2+}$ current by extracellular ATP in ferret isolated right ventricular myocytes. J Physiol 471:295-317

216. Scamps F, Nilius B, Alvarez J, Vassort G (1993) Modulation of Ltype $\mathrm{Ca}$ channel activity by $\mathrm{P}_{2}$-purinergic agonist in cardiac cells. Pflugers Arch 422:465-471

217. Qi AD, Kwan YW (1996) Modulation by extracellular ATP of Ltype calcium channels in guinea-pig single sinoatrial nodal cell. Br J Pharmacol 119:1454-1462

218. Scamps F, Vassort G (1994) Pharmacological profile of the ATPmediated increase in L-type calcium current amplitude and activation of a non-specific cationic current in rat ventricular cells. $\mathrm{Br} \mathrm{J}$ Pharmacol 113:982-986

219. Yamamoto T, Habuchi Y, Nishio M, Morikawa J, Tanaka H (1999) $\mathrm{P}_{2}$ purinoceptors contribute to ATP-induced inhibition of L-type $\mathrm{Ca}^{2+}$ current in rabbit atrial myocytes. Cardiovasc Res 41:166-174

220. Liu QY, Rosenberg RL (2001) Stimulation of cardiac L-type calcium channels by extracellular ATP. Am J Physiol Cell Physiol 280: C1107-C1113

221. Froldi G, Pandolfo L, Chinellato A, Ragazzi E, Caparrotta L, Fassina G (1994) Dual effect of ATP and UTP on rat atria: which types of receptors are involved? Naunyn Schmiedeberg's Arch Pharmacol 349:381-386

222. Matsuura H, Tsuruhara Y, Sakaguchi M, Ehara T (1996) Enhancement of delayed rectifier $\mathrm{K}^{+}$current by $\mathrm{P}_{2}$-purinoceptor stimulation in guinea-pig atrial cells. J Physiol 490:647-658

223. Matsubayashi T, Matsuura H, Ehara T (1999) On the mechanism of the enhancement of delayed rectifier $\mathrm{K}^{+}$current by extracellular ATP in guinea-pig ventricular myocytes. Pflugers Arch 437:635642

224. Hoyle CHV, Ziganshin AU, Pintor J, Burnstock G (1996) The activation of $\mathrm{P}_{1}$ - and $\mathrm{P}_{2}$-purinoceptors in the guinea-pig left atrium by diadenosine polyphosphates. Br J Pharmacol 118:1294-1300

225. Zhang BX, Ma X, McConnell BK, Damron DS, Bond M (1996) Activation of purinergic receptors triggers oscillatory contractions in adult rat ventricular myocytes. Circ Res 79:94-102

226. Matsuura H, Sakaguchi M, Tsuruhara Y, Ehara T (1996) Activation of the muscarinic $\mathrm{K}^{+}$channel by $\mathrm{P}_{2}$-purinoceptors via pertussis toxin-sensitive $\mathrm{G}$ proteins in guinea-pig atrial cells. J Physiol 490: 659-671

227. Hara Y, Nakaya H (1997) Dual effects of extracellular ATP on the muscarinic acetylcholine receptor-operated $\mathrm{K}^{+}$current in guinea-pig atrial cells. Eur J Pharmacol 324:295-303

228. Pelleg A, Hurt CM, Hewlett EL (1996) ATP shortens atrial action potential duration in the dog: role of adenosine, the vagus nerve, and G protein. Can J Physiol Pharmacol 74:15-22

229. Wu SN, Liu SI, Hwang TL (1998) Activation of muscarinic $\mathrm{K}^{+}$ channels by extracellular ATP and UTP in rat atrial myocytes. J Cardiovasc Pharmacol 31:203-211

230. Avkiran M, Yokoyama H (2000) Adenosine $A_{1}$ receptor stimulation inhibits $\alpha_{1}$-adrenergic activation of the cardiac sarcolemmal $\mathrm{Na}^{+} / \mathrm{H}^{+}$ exchanger. Br J Pharmacol 131:659-662

231. Sterin-Borda L, Gómez RM, Borda E (2002) Role of nitric oxide/ cyclic GMP in myocardial adenosine $A_{1}$ receptor-inotropic response. Br J Pharmacol 135:444-450

232. Xu Z, Park SS, Mueller RA, Bagnell RC, Patterson C, Boysen PG (2005) Adenosine produces nitric oxide and prevents mitochondrial oxidant damage in rat cardiomyocytes. Cardiovasc Res 65:803-812 
233. White PJ, Nguyen TT (2002) Chronic caffeine treatment causes changes in cardiac adenosine receptor function in rats. Pharmacology 65:129-135

234. Neumann J, Boknik P, Begrow F, Hanske G, Justus I, Mat'us M, Reinke U, Matherne GP, Schmitz W (2003) Altered signal transduction in cardiac ventricle overexpressing $\mathrm{A}_{1}$-adenosine receptors. Cardiovasc Res 60:529-537

235. Goldenberg I, Shainberg A, Jacobson KA, Shneyvays V, Grossman E (2003) Adenosine protects against angiotensin II-induced apoptosis in rat cardiocyte cultures. Mol Cell Biochem 252:133-139

236. Monahan TS, Sawmiller DR, Fenton RA, Dobson JG Jr (2000) Adenosine $\mathrm{A}_{2 \mathrm{a}}$-receptor activation increases contractility in isolated perfused hearts. Am J Physiol Heart Circ Physiol 279:H1472H1481

237. Teng B, Ledent $C$, Mustafa SJ (2008) Up-regulation of $A_{2 B}$ adenosine receptor in $\mathrm{A}_{2 \mathrm{~A}}$ adenosine receptor knockout mouse coronary artery. J Mol Cell Cardiol 44:905-914

238. Stavrou BM, Lawrence C, Blackburn GM, Cohen T, Sheridan DJ, Flores NA (2001) Coronary vasomotor and cardiac electrophysiologic effects of diadenosine polyphosphates and nonhydrolyzable analogs in the guinea pig a. J Cardiovasc Pharmacol 37:571-584

239. Brandts B, Borchard R, Dirkmann D, Wickenbrock I, Sievers B, Van BM, Prull MW, Trappe HJ (2003) Diadenosine-5-phosphate exerts A1-receptor-mediated proarrhythmic effects in rabbit atrial myocardium. Br J Pharmacol 139:1265-1272

240. Zimmermann N, Nacke PR, Neumann J, Winter J, Gams E (2000) Inotropic effects of diadenosine monophosphate $\left(\mathrm{AP}_{1} \mathrm{~A}\right)$ in isolated human cardiac preparations. J Cardiovasc Pharmacol 35:881-886

241. Westhoff T, Jankowski J, Schmidt S, Luo J, Giebing G, Schlüter H, Tepel M, Zidek W, van der Giet M (2003) Identification and characterization of adenosine 5'-tetraphosphate in human myocardial tissue. J Biol Chem 278:17735-17740

242. Luo J, Jankowski V, Güngä N, Neumann J, Schmitz W, Zidek W, Schlüter H, Jankowski J (2004) Endogenous diadenosine tetraphosphate, diadenosine pentaphosphate, and diadenosine hexaphosphate in human myocardial tissue. Hypertension 43: $1055-1059$

243. Arvola L, Bertelsen G, Hassaf D, Ytrehus K (2004) Positive inotropic and sustained anti- $\beta$-adrenergic effect of diadenosine pentaphosphate in human and guinea pig hearts. Role of dinucleotide receptors and adenosine receptors. Acta Physiol Scand 182:277-285

244. Song L, Carter SM, Chen Y, Sitsapesan R (2009) Diadenosine pentaphosphate is a potent activator of cardiac ryanodine receptors revealing a novel high-affinity binding site for adenine nucleotides. Br J Pharmacol 156:857-867

245. Rajasekaran S, Morey TE, Martynyuk AE, Dennis DM (2003) Free radicals potentiate the negative dromotropic effect of adenosine in guinea pig isolated heart. Acta Cardiol 58:191-197

246. Liu Q, Hofmann PA (2003) Modulation of protein phosphatase 2a by adenosine $\mathrm{A}_{1}$ receptors in cardiomyocytes: role for $\mathrm{p} 38 \mathrm{MAPK}$. Am J Physiol Heart Circ Physiol 285:H97-H103

247. Germack R, Griffin M, Dickenson JM (2004) Activation of protein kinase $B$ by adenosine $A_{1}$ and $A_{3}$ receptors in newborn rat cardiomyocytes. J Mol Cell Cardiol 37:989-999

248. Gardner NM, Yates L, Broadley KJ (2004) Effects of endogenous adenosine and adenosine receptor agonists on hypoxia-induced myocardial stunning in Guinea-pig atria and papillary muscles. J Cardiovasc Pharmacol 43:358-368

249. Jenner TL, Mellick AS, Harrison GJ, Griffiths LR, Rose'Meyer RB (2004) Age-related changes in cardiac adenosine receptor expression. Mech Ageing Dev 125:211-217

250. Pousti A, Deemyad T, Malihi G, Brumand K (2006) Involvement of adenosine in the effect of fluoxetine on isolated guinea-pig atria. Pharmacol Res 53:44-48
251. Yang JN, Tiselius C, Darée E, Johansson B, Valen G, Fredholm BB (2007) Sex differences in mouse heart rate and body temperature and in their regulation by adenosine A1 receptors. Acta Physiol (Oxf) 190:63-75

252. Kemeny-Beke A, Jakab A, Zsuga J, Vecsernyes M, Karsai D, Pasztor F, Grenczer M, Szentmiklosi AJ, Berta A, Gesztelyi R (2007) Adenosine deaminase inhibition enhances the inotropic response mediated by A1 adenosine receptor in hyperthyroid guinea pig atrium. Pharmacol Res 56:124-131

253. Yang JN, Chen JF, Fredholm BB (2009) Physiological roles of $A_{1}$ and $\mathrm{A}_{2 \mathrm{~A}}$ adenosine receptors in regulating heart rate, body temperature, and locomotion as revealed using knockout mice and caffeine. Am J Physiol Heart Circ Physiol 296:H1141-H1149

254. Koeppen M, Eckle T, Eltzschig HK (2009) Selective deletion of the A1 adenosine receptor abolishes heart-rate slowing effects of intravascular adenosine in vivo. PLoS One 4:e6784

255. Keene AM, Balasubramanian R, Lloyd J, Shainberg A, Jacobson KA (2010) Multivalent dendrimeric and monomeric adenosine agonists attenuate cell death in HL-1 mouse cardiomyocytes expressing the $\mathrm{A}_{3}$ receptor. Biochem Pharmacol 80:188-196

256. Fassett JT, Hu X, Xu X, Lu Z, Zhang P, Chen Y, Bache RJ (2011) Adenosine kinase regulation of cardiomyocyte hypertrophy. Am J Physiol Heart Circ Physiol 300:H1722-H1732

257. Chandrasekera PC, McIntosh VJ, Cao FX, Lasley RD (2010) Differential effects of adenosine A2a and A2b receptors on cardiac contractility. Am J Physiol Heart Circ Physiol 299: H2082-H2089

258. Buscariollo DL, Breuer GA, Wendler CC, Rivkees SA (2011) Caffeine acts via $\mathrm{A} 1$ adenosine receptors to disrupt embryonic cardiac function. PLoS One 6:e28296

259. Bott-Flügel L, Bernshausen A, Schneider H, Luppa P, Zimmermann K, Albrecht-Küpper B, Kast R, Laugwitz KL, Ehmke H, Knorr A, Seyfarth M (2011) Selective attenuation of norepinephrine release and stress-induced heart rate increase by partial adenosine A1 agonism. PLoS One 6:e18048

260. Fenton RA, Dobson JG Jr (2012) Reduced adenosine release from the aged mammalian heart. J Cell Physiol 227:3709-3714

261. Ryzhov S, Goldstein AE, Novitskiy SV, Blackburn MR, Biaggioni I, Feoktistov I (2012) Role of A2B adenosine receptors in regulation of paracrine functions of stem cell antigen 1-positive cardiac stromal cells. J Pharmacol Exp Ther 341:764-774

262. Robin E, Sabourin J, Marcillac F, Raddatz E (2013) Involvement of CD73, equilibrative nucleoside transporters and inosine in rhythm and conduction disturbances mediated by adenosine $\mathrm{A} 1$ and $\mathrm{A} 2 \mathrm{~A}$ receptors in the developing heart. J Mol Cell Cardiol 63:14-25

263. Joulia F, Coulange M, Lemaitre F, Costalat G, Franceschi F, Gariboldi V, Nee L, Fromonot J, Bruzzese L, Gravier G, Kipson N, Jammes Y, Boussuges A, Brignole M, Deharo JC, Guieu R (2013) Plasma adenosine release is associated with bradycardia and transient loss of consciousness during experimental breathhold diving. Int J Cardiol 168:e138-e141

264. Kalkan S, Oransay K, Bal I, Ertunc M, Sara Y, Iskit A (2013) The role of adenosine receptors on amitriptylineinduced electrophysiological changes on rat atrium. Hum Exp Toxicol 32:62-69

265. Buscariollo DL, Fang X, Greenwood V, Xue H, Rivkees SA, Wendler CC (2014) Embryonic caffeine exposure acts via A1 adenosine receptors to alter adult cardiac function and DNA methylation in mice. PLoS One 9:e87547

266. Nakai T, Watanabe I, Kunimoto S, Kojima T, Kondo K, Saito S, Ozawa Y, Kanmatsuse K (2000) Electrophysiological effect of adenosine triphosphate and adenosine on atrial and ventricular action potential duration in humans. Jpn Circ J 64:430-435

267. Yasuda Y, Matsuura H, Ito M, Matsumoto T, Ding WG, Horie M (2005) Regulation of the muscarinic $\mathrm{K}^{+}$channel by extracellular 
ATP through membrane phosphatidylinositol 4,5-bisphosphate in guinea-pig atrial myocytes. Br J Pharmacol 145:156-165

268. Musa H, Jones SA, Deuchars J, Boyett MR (2000) Expression of P2X ATP-actvated non-specific cation channels in the rat heart. J Physiol 526:114P-115P

269. Zhang YH, Youm JB, Sung HK, Lee SH, Ryu SY, Ho WK, Earm YE (2000) Stretch-activated and background non-selective cation channels in rat atrial myocytes. J Physiol 523:607-619

270. Liao X, Wang X, Gu Y, Chen Q, Chen LY (2005) Involvement of death receptor signaling in mechanical stretch-induced cardiomyocyte apoptosis. Life Sci 77:160-174

271. Mei Q, Liang BT (2001) P2 purinergic receptor activation enhances cardiac contractility in isolated rat and mouse hearts. Am J Physiol Heart Circ Physiol 281:H334-H341

272. Hu B, Mei QB, Yao XJ, Smith E, Barry WH, Liang BT (2001) A novel contractile phenotype with cardiac transgenic expression of the human $\mathrm{P}_{2} \mathrm{X}_{4}$ receptor. FASEB J 15:2739-2741

273. Hu B, Senkler C, Yang A, Soto F, Liang BT (2002) P2X ${ }_{4}$ receptor is a glycosylated cardiac receptor mediating a positive inotropic response to ATP. J Biol Chem 277:15752-15757

274. Shen JB, Pappano AJ, Liang BT (2006) Extracellular ATPstimulated current in wild-type and $\mathrm{P} 2 \mathrm{X} 4$ receptor transgenic mouse ventricular myocytes: implications for a cardiac physiologic role of P2X4 receptors. FASEB J 20:277-284

275. Shen JB, Shutt R, Werner B, Pappano A, Liang B (2007) Mechanism of P2X receptor-mediated increase in cardiac myocyte contractility: importance of augmentation of SR $\mathrm{Ca}^{2+}$ loading. FASEB J 21:A1157

276. Balogh J, Wihlborg AK, Isackson H, Joshi BV, Jacobson KA, Arner A, Erlinge D (2005) Phospholipase C and cAMP-dependent positive inotropic effects of ATP in mouse cardiomyocytes via $\mathrm{P}_{2} \mathrm{Y}_{11}$ like receptors. J Mol Cell Cardiol 39:223-230

277. Gergs U, Boknik P, Schmitz W, Simm A, Silber RE, Neumann J (2008) A positive inotropic effect of ATP in the human cardiac atrium. Am J Physiol Heart Circ Physiol 294:H1716-H1723

278. Anikina TA, Zverev AA, Sitdikov FG, Anisimova IN (2013) Interaction of adrenergic and purinergic receptors in the regulation of rat myocardial contractility in postnatal ontogeny. Russ J Dev Biol 44:296-301

279. Anikina TA, Anisimova IN, Zverev AA, Sitdikov FG, Zefirov TL (2014) Involvement of $\mathrm{P} 2 \mathrm{Y}_{2,4}$ receptors in the regulation of myocardial contractility in growing rats. Bull Exp Biol Med 156:299-302

280. Cao C, Piao FL, Han JH, Kim SZ, Kim SH (2005) ATPstimulated ANP release through P1 receptor subtype. Regul Pept 127:37-43

281. Yuan K, Bai GY, Park WH, Kim SZ, Kim SH (2008) Stimulation of ANP secretion by 2-Cl-IB-MECA through $\mathrm{A}_{3}$ receptor and CaMKII. Peptides 29:2216-2224

282. Yamamoto-Mizuma S, Wang GX, Hume JR (2004) P2Y purinergic receptor regulation of CFTR chloride channels in mouse cardiac myocytes. J Physiol 556:727-737

283. Yamamoto S, Ichishima K, Ehara T (2007) Regulation of extracellular UTP-activated $\mathrm{Cl}^{-}$current by P2Y-PLC-PKC signaling and ATP hydrolysis in mouse ventricular myocytes. J Physiol Sci 57: 85-94

284. Liu GX, Vepa S, Artman M, Coetzee WA (2007) Modulation of human cardiovascular outward rectifying chloride channel by intraand extracellular ATP. Am J Physiol Heart Circ Physiol 293: H3471-H3479

285. Oketani N, Kakei M, Ichinari K, Okamura M, Miyamura A, Nakazaki M, Ito S, Tei C (2002) Regulation of $\mathrm{K}_{\mathrm{ATP}}$ channels by $\mathrm{P}_{2 \mathrm{Y}}$ purinoceptors coupled to $\mathrm{PIP}_{2}$ metabolism in guinea pig ventricular cells. Am J Physiol Heart Circ Physiol 282:H757-H765

286. Jiang L, Bardini M, Keogh A, dos Remedios CG, Burnstock G (2005) $\mathrm{P} 2 \mathrm{X}_{1}$ receptors are closely associated with connexin 43 in human ventricular myocardium. Int J Cardiol 98:291-297
287. Nakayama Y, Kawahara K, Hachiro T, Yamauchi Y, Yoneyama M (2007) Possible involvement of ATP-purinoceptor signalling in the intercellular synchronization of intracellular $\mathrm{Ca}^{2+}$ oscillation in cultured cardiac myocytes. Biosystems 90:179-187

288. Dutta AK, Korchev YE, Shevchuk AI, Hayashi S, Okada Y, Sabirov RZ (2008) Spatial distribution of maxi-anion channel on cardiomyocytes detected by smart-patch technique. Biophys J 94: $1646-1655$

289. Liang W, McDonald P, McManus B, van Breemen C, Wang X (2008) $\mathrm{P}_{2} \mathrm{Y} 2$ receptor-mediated $\mathrm{Ca}^{2+}$ signaling and spontaneous $\mathrm{Ca}^{2+}$ releases in human valvular myofibroblasts. Int Heart J 49:221-236

290. Alvarez J, Coulombe A, Cazorla O, Ugur M, Rauzier JM, Magyar J, Mathieu EL, Boulay G, Souto R, Bideaux P, Salazar G, Rassendren F, Lacampagne A, Fauconnier J, Vassort G (2008) ATP/UTP activate cation-permeable channels with TRPC $3 / 7$ properties in rat cardiomyocytes. Am J Physiol Heart Circ Physiol 295:H21-H28

291. Talasila A, Germack R, Dickenson JM (2009) Characterization of $\mathrm{P} 2 \mathrm{Y}$ receptor subtypes functionally expressed on neonatal rat cardiac myofibroblasts. Br J Pharmacol 158:339-353

292. Barth K, Pfleger C, Linge A, Sim JA, Surprenant A, Steinbronn N, Strasser RH, Kasper M (2010) Increased P2X7R expression in atrial cardiomyocytes of caveolin-1 deficient mice. Histochem Cell Biol 134:31-38

293. Oishi S, Sasano T, Tateishi Y, Tamura N, Isobe M, Furukawa T (2012) Stretch of atrial myocytes stimulates recruitment of macrophages via ATP released through gap-junction channels. J Pharmacol Sci 120:296-304

294. Wayne EJ, Goodwin JF, Stoner HB (1949) The effect of adenosine triphosphate on the electrocardiogram of man and animals. Br Heart J 11:55-67

295. Belardinelli L, Shryock J, West GA, Clemo HF, DiMarco JP, Berne RM (1984) Effects of adenosine and adenine nucleotides on the atrioventricular node of isolated guinea pig hearts. Circulation 70: 1083-1091

296. Clemo HF, Belardinelli L (1986) Effect of adenosine on atrioventricular conduction. II: modulation of atrioventricular node transmission by adenosine in hypoxic isolated guinea pig hearts. Circ Res 59:437-446

297. Xu J, Tong H, Wang L, Hurt CM, Pelleg A (1993) Endogenous adenosine, $\mathrm{A} 1$ adenosine receptor, and pertussis toxin sensitive guanine nucleotide binding protein mediate hypoxia induced AV nodal conduction block in guinea pig heart in vivo. Cardiovasc Res 27:134-140

298. Clemo HF, Belardinelli L (1986) Effect of adenosine on atrioventricular conduction. I: Site and characterization of adenosine action in the guinea pig atrioventricular node. Circ Res 59:427-436

299. Froldi G, Belardinelli L (1990) Species-dependent effects of adenosine on heart rate and atrioventricular nodal conduction. Mechanism and physiological implications. Circ Res 67:960-978

300. Dennis DM, Shryock JC, Belardinelli L (1995) Homologous desensitization of the A1-adenosine receptor system in the guinea pig atrioventricular node. J Pharmacol Exp Ther 272:1024-1035

301. Pelleg A, Belhassen B, Ilia R, Laniado S (1985) Comparative electrophysiologic effects of adenosine triphosphate and adenosine in the canine heart: influence of atropine, propranolol, vagotomy, dipyridamole and aminophylline. Am J Cardiol 55:571-576

302. Favale S, Di Biase M, Rizzo U, Belardinelli L, Rizzon P (1985) Effect of adenosine and adenosine-5'-triphosphate on atrioventricular conduction in patients. J Am Coll Cardiol 5:1212-1219

303. Pelleg A, Mitsuoka T, Mazgalev T, Michelson EL (1987) Vagal component in the chronotropic and dromotropic actions of adenosine and ATP. Prog Clin Biol Res 230:375-384

304. Sharma AD, Klein GJ (1988) Comparative quantitative electrophysiologic effects of adenosine triphosphate on the sinus node and atrioventricular node. Am J Cardiol 61:330-335

305. Kirchhof P, Fabritz L, Fortmuller L, Matherne GP, Lankford A, Baba HA, Schmitz W, Breithardt G, Neumann J, Boknik P (2003) 
Altered sinus nodal and atrioventricular nodal function in freely moving mice overexpressing the $\mathrm{A}_{1}$ adenosine receptor. Am J Physiol Heart Circ Physiol 285:H145-H153

306. Pelleg A, Hurt C, Miyagawa A, Michelson EL, Dreifus LS (1990) Differential sensitivity of cardiac pacemakers to exogenous adenosine in vivo. Am J Physiol 258:H1815-H1822

307. Hartzell HC (1979) Adenosine receptors in frog sinus venosus: slow inhibitory potentials produced by adenine compounds and acetylcholine. J Physiol 293:23-49

308. West GA, Belardinelli L (1985) Sinus slowing and pacemaker shift caused by adenosine in rabbit SA node. Pflugers Arch 403:66-74

309. Belardinelli L, Giles WR, West A (1988) Ionic mechanisms of adenosine actions in pacemaker cells from rabbit heart. J Physiol 405:615-633

310. Wesley RC Jr, Belardinelli L (1985) Role of adenosine on ventricular overdrive suppression in isolated guinea pig hearts and Purkinje fibers. Circ Res 57:517-531

311. Kobayashi M, Shimotori M, Chiba S (1983) The effects of aminophylline on adenosine and ATP actions on sinoatrial conduction in the isolated, blood-perfused dog atrium. Eur J Pharmacol 91:261265

312. Musa H, Tellez JO, Chandler NJ, Greener ID, Maczewski M, Mackiewicz U, Beresewicz A, Molenaar P, Boyett MR, Dobrzynski H (2009) P2 purinergic receptor mRNA in rat and human sinoatrial node and other heart regions. Naunyn Schmiedeberg's Arch Pharmacol 379:541-549

313. Ren LM, Li JX, Shi CX, Zhao D (2003) Electrophysiologic effects of adenosine triphosphate on rabbit sinoatrial node pacemaker cells via P1 receptors. Acta Pharmacol Sin 24:943-947

314. Yaniv Y, Spurgeon HA, Ziman BD, Lyashkov AE, Lakatta EG (2013) Mechanisms that match ATP supply to demand in cardiac pacemaker cells during high ATP demand. Am J Physiol Heart Circ Physiol 304:H1428-H1438

315. Pelzmann B, Schaffer P, Mäachler H, Rigler B, Koidl B (1995) Adenosine inhibits the L-type calcium current in human atrial myocytes. Naunyn Schmiedeberg's Arch Pharmacol 351:293297

316. Szegi J, Szentmiklósi AJ, Cseppentö Á (1989) Adenosine decreases the fibrillation threshold in atrial myocardium. Pol J Pharmacol Pharm 41:511-518

317. Pelleg A, Hurt CM, Michelson EL (1990) Cardiac effects of adenosine and ATP. Ann N Y Acad Sci 603:19-30

318. Rosen MR, Danilo P Jr, Weiss RM (1983) Actions of adenosine on normal and abnormal impulse initiation in canine ventricle. Am $\mathrm{J}$ Physiol 244:H715-H721

319. Belardinelli L, Fenton RA, West A, Linden J, Althaus JS, Berne RM (1982) Extracellular action of adenosine and the antagonism by aminophylline on the atrioventricular conduction of isolated perfused guinea pig and rat hearts. Circ Res 51:569-579

320. Rardon DP, Bailey JC (1984) Adenosine attenuation of the electrophysiological effects of isoproterenol on canine cardiac Purkinje fibers. J Pharmacol Exp Ther 228:792-798

321. Boachie-Ansah G, Kane KA, Parratt JR (1989) Electrophysiological effects of adenosine and adenosine triphosphate on sheep Purkinje fibres under normal and simulated ischaemic conditions. Br J Pharmacol 97:240-246

322. Qin K, Ren LM, Zhao D (2001) Uridine triphosphate prolongs action potential duration of guinea pig papillary muscles via $\mathrm{P}_{2} \mathrm{Y}_{2}$ purinoceptors. Acta Pharmacol Sin 22:21-25

323. Manabe K, Ito H, Matsuda H, Noma A (1995) Hyperpolarization induced by vasoactive substances in intact guinea-pig endocardial endothelial cells. J Physiol 484:25-40

324. Burnstock G, Knight GE (2004) Cellular distribution and functions of P2 receptor subtypes in different systems. Int Rev Cytol 240:31304
325. Erlinge D, Harnek J, van Heusden C, Olivecrona G, Jern S, Lazarowski E (2005) Uridine triphosphate (UTP) is released during cardiac ischemia. Int J Cardiol 100:427-433

326. Yitzhaki S, Shneyvays V, Jacobson KA, Shainberg A (2005) Involvement of uracil nucleotides in protection of cardiomyocytes from hypoxic stress. Biochem Pharmacol 69:1215-1223

327. Burnstock G (1999) Release of vasoactive substances from endothelial cells by shear stress and purinergic mechanosensory transduction. J Anat 194:335-342

328. Bodin P, Burnstock G (2001) Evidence that release of ATP from endothelial cells during increased shear stress is vesicular. J Cardiovasc Pharmacol 38:900-908

329. Bodin P, Burnstock G (2001) Purinergic signalling: ATP release. Neurochem Res 26:959-969

330. Wan J, Forsyth AM, Stone HA (2011) Red blood cell dynamics: from cell deformation to ATP release. Integr Biol (Camb) 3:972981

331. Borst MM, Schrader J (1991) Adenine nucleotide release from isolated perfused guinea pig hearts and extracellular formation of adenosine. Circ Res 68:797-806

332. Kuzmin AI, Lakomkin VL, Kapelko VI, Vassort G (1998) Interstitial ATP level and degradation in control and postmyocardial infarcted rats. Am J Physiol Cell Physiol 275:C766-C771

333. Paddle BM, Burnstock G (1974) Release of ATP from perfused heart during coronary vasodilatation. Blood Vessels 11:110-119

334. Darius H, Stahl GL, Lefer AM (1987) Pharmacologic modulation of ATP release from isolated rat hearts in response to vasoconstrictor stimuli using a continuous flow technique. J Pharmacol Exp Ther 240:542-547

335. Vials A, Burnstock G (1996) ATP release from the isolated perfused guinea pig heart in response to increased flow. J Vasc Res 33:1-4

336. Burnstock G (1990) Noradrenaline and ATP as cotransmitters in sympathetic nerves. Neurochem Int 17:357-368

337. Burnstock G (2014) The Erasmus Lecture 2012. The concept of cotransmission: focus on ATP as a cotransmitter and its significance in health and disease. Eur Rev 22:1-17

338. Lu D, Soleymani S, Madakshire R, Insel PA (2012) ATP released from cardiac fibroblasts via connexin hemichannels activates profibrotic $\mathrm{P}_{2} \mathrm{Y}_{2}$ receptors. FASEB J 26:2580-2591

339. Sprague RS, Stephenson AH, Ellsworth ML (2007) Red not dead: signaling in and from erythrocytes. Trends Endocrinol Metab 18: 350-355

340. Baroja-Mazo A, Barberà-Cremades M, Pelegrín P (2013) The participation of plasma membrane hemichannels to purinergic signaling. Biochim Biophys Acta 1828:79-93

341. Jorgensen S (1956) Breakdown of adenine and hypoxanthine nucleotides and nucleosides in human plasma. Acta Pharmacol Toxicol (Copenh) 12:294-302

342. Fleetwood G, Coade SB, Gordon JL, Pearson JD (1989) Kinetics of adenine nucleotide catabolism in coronary circulation of rats. Am J Physiol Heart Circ Physiol 256:H1565-H1572

343. Bowditch J, Nigdikar S, Brown AK, Dow JW (1985) 5'Nucleotidase activity of isolated mature rat cardiac myocytes. Biochim Biophys Acta 845:21-26

344. Choong YS, Armiger LC (1986) Relative activities of 5'-nucleotidase and adenosine deaminase in atrial and ventricular myocardium - the enzyme paradox. Exp Pathol 30:151-155

345. Nees S (1989) Coronary flow increases induced by adenosine and adenine nucleotides are mediated by the coronary endothelium: a new principle of the regulation of coronary flow. Eur Heart J 10(Suppl F):28-35

346. Ely SW, Berne RM (1992) Protective effects of adenosine in myocardial ischemia. Circulation 85:893-904

347. Meghji P, Middleton K, Hassall CJ, Phillips MI, Newby AC (1988) Evidence for extracellular deamination of adenosine in the rat heart. Int J Biochem 20:1335-1341 
348. Schrader WP, West CA (1990) Localization of adenosine deaminase and adenosine deaminase complexing protein in rabbit heart. Implications for adenosine metabolism. Circ Res 66:754-762

349. Tuana BS, Dhalla NS (1988) Purification and characterization of a $\mathrm{Ca}^{2+} / \mathrm{Mg}^{2+}$ ecto-ATPase from rat heart sarcolemma. Mol Cell Biochem 81:75-88

350. Darvish A, Postlewaite JJ, Metting PJ (1993) Immunogold localization of adenosine 5'-monophosphate-specific cytosolic 5'-nucleotidase in dog heart. Hypertension 21:906-910

351. Langfort J, Czarnowski D, Pilis W, Wójcik B, Górski J (1996) Effect of various types of exercise training on 5'-nucleotidase and adenosine deaminase activities in rat heart: influence of a single bout of endurance exercise. Biochem Mol Med 59:28-32

352. Carneiro-Ramos MS, da Silva V, Coutinho MB Jr, Battastini AM, Sarkis JJ, Barreto-Chaves ML (2004) Thyroid hormone stimulates 5 '-ecto-nucleotidase of neonatal rat ventricular myocytes. Mol Cell Biochem 265:195-201

353. Meghji P, Pearson JD, Slakey LL (1992) Regulation of extracellular adenosine production by ectonucleotidases of adult rat ventricular myocytes. Am J Physiol Heart Circ Physiol 263:H40-H47

354. Al-Rashida M, Iqbal J (2014) Therapeutic potentials of ectonucleoside triphosphate diphosphohydrolase, ecto-nucleotide pyrophosphatase/phosphodiesterase, ecto-5'-nucleotidase, and alkaline phosphatase inhibitors. Med Res Rev 34:703-743

355. Espinosa V, Galleguillos M, Mancilla M, Garrido J, Kettlun AM, Collados L, Chayet L, Garcia L, Traverso-Cori A, Valenzuela MA (1996) ATP-diphosphophydrolase activity in rat heart tissue. Biochem Mol Biol Int 39:905-915

356. Beaudoin AR, Sévigny J, Grondin G, Daoud S, Levesque FP (1997) Purification, characterization, and localization of two ATP diphosphohydrolase isoforms in bovine heart. Am J Physiol 273: H673-H681

357. Menezes de Oliveira E, Oliveira Battastini AM, Meirelles MN, Menezes Moreira C, Dutra Dias R, Freitas Sarkis JJ (1997) Characterization and localization of an ATP diphosphohydrolase activity (EC 3.6.1.5) in sarcolemmal membrane from rat heart. Mol Cell Biochem 170:115-123

358. Zinchuk VS, Okada T, Kobayashi T (1999) Ecto-ATPase activity in the rat cardiac muscle: biochemical characteristics and histocytochemical localization. Cell Tissue Res 298:499-509

359. Sesti C, Broekman MJ, Drosopoulos JH, Islam N, Marcus AJ, Levi R (2002) EctoNucleotidase in cardiac sympathetic nerve endings modulates ATP-mediated feedback of norepinephrine release. J Pharmacol Exp Ther 300:605-611

360. Dubey RK, Gillespie DG, Jackson EK (1998) Adenosine inhibits collagen and protein synthesis in cardiac fibroblasts: role of $A_{2 B}$ receptors. Hypertension 31:943-948

361. Dubey RK, Gillespie DG, Zacharia LC, Mi Z, Jackson EK (2001) $\mathrm{A}_{2 \mathrm{~B}}$ receptors mediate the antimitogenic effects of adenosine in cardiac fibroblasts. Hypertension 37:716-721

362. Chen Y, Epperson S, Makhsudova L, Ito B, Suarez J, Dillmann W, Villarreal F (2004) Functional effects of enhancing or silencing adenosine A2b receptors in cardiac fibroblasts. Am J Physiol Heart Circ Physiol 287:H2478-H2486

363. Grden M, Podgorska M, Kocbuch K, Szutowicz A, Pawelczyk T (2006) Expression of adenosine receptors in cardiac fibroblasts as a function of insulin and glucose level. Arch Biochem Biophys 455: $10-17$

364. Epperson SA, Brunton LL, Ramirez-Sanchez I, Villarreal F (2009) Adenosine receptors and second messenger signaling pathways in rat cardiac fibroblasts. Am J Physiol Cell Physiol 296:C1171C1177

365. Villarreal F, Epperson SA, Ramirez-Sanchez I, Yamazaki KG, Brunton LL (2009) Regulation of cardiac fibroblast collagen synthesis by adenosine: roles for Epac and PI3K. Am J Physiol Cell Physiol 296:C1178-C1184
366. Zhan E, McIntosh V, Wang F, Maruthi R, Kadi B, DeMerle M, Lasley R (2013) Adenosine A2A and A2B receptors differentially modulate signal transduction and collagen production in murine cardiac fibroblasts. FASEB J 27:1188

367. Zheng JS, O'Neill L, Long X, Webb TE, Barnard EA, Lakatta EG, Boluyt MO (1998) Stimulation of P2Y receptors activates $c$-fos gene expression and inhibits DNA synthesis in cultured cardiac fibroblasts. Cardiovasc Res 37:718-728

368. Braun OÖ, Lu D, Aroonsakool N, Insel PA (2010) Uridine triphosphate (UTP) induces profibrotic responses in cardiac fibroblasts by activation of P2Y2 receptors. J Mol Cell Cardiol 49:362-369

369. Nishida M, Sato Y, Uemura A, Narita Y, Tozaki-Saitoh H, Nakaya M, Ide T, Suzuki K, Inoue K, Nagao T, Kurose H (2008) P2 $\mathrm{Y}_{6}$ receptor-G $\alpha_{12 / 13}$ signalling in cardiomyocytes triggers pressure overload-induced cardiac fibrosis. EMBO J 27:3104-3115

370. Chen JB, Liu WJ, Che H, Liu J, Sun HY, Li GR (2012) Adenosine5 '-triphosphate up-regulates proliferation of human cardiac fibroblasts. Br J Pharmacol 166:1140-1150

371. Lu D, Insel PA (2013) Hydrolysis of extracellular ATP by ectonucleoside triphosphate diphosphohydrolase (ENTPD) establishes the set point for fibrotic activity of cardiac fibroblasts. J Biol Chem 288:19040-19049

372. Toda N, Okunishi H, Taniyama K, Miyazaki M (1982) Responses to adenine nucleotides and related compounds of isolated dog cerebral, coronary and mesenteric arteries. Blood Vessel 19:226-236

373. Nees S, Böck M, Herzog V, Becker BF, Des Rosiers C, Gerlach E (1985) The adenine nucleotide metabolism of the coronary endothelium: implications for the regulation of coronary flow by adenosine. In: Stefanovich V, Rudolphi K, Schubert P (eds) Adenosine: receptors and modulation of cell function. IRL, Oxford, pp 419-436

374. Zucchi R, Limbruno U, Poddighe R, Mariani M, Ronca G (1989) The adenosine hypothesis revisited: relationship between purine release and coronary flow in isolated rat heart. Cardiovasc Res 23: 125-131

375. Yang S, Cheek DJ, Westfall DP, Buxton IL (1994) Purinergic axis in cardiac blood vessels. Agonist-mediated release of ATP from cardiac endothelial cells. Circ Res 74:401-407

376. Houston DS, Shepherd JT, Vanhoutte PM (1985) Adenine nucleotides, serotonin, and endothelium-dependent relaxations to platelets. Am J Physiol 248:H389-H395

377. Ellsworth ML, Ellis CG, Goldman D, Stephenson AH, Dietrich HH, Sprague RS (2009) Erythrocytes: oxygen sensors and modulators of vascular tone. Physiology 24:107-116

378. Kato M, Shiode N, Teragawa H, Hirao H, Yamada T, Yamagata T, Matsuura H, Kajiyama G (1999) Adenosine 5'-triphosphate induced dilation of human coronary microvessels in vivo. Intern Med 38: 324-329

379. Wilson RF, Wyche K, Christensen BV, Zimmer S, Laxson DD (1990) Effects of adenosine on human coronary arterial circulation. Circulation 82:1595-1606

380. Hoffman WE, Satinover I, Miletich DJ, Albrecht RF, Gans BJ (1982) Cardiovascular changes during sodium nitroprusside or adenosine triphosphate infusion in the rat. Anesth Analg 61:99-103

381. Mehrke G, Daut J (1990) The electrical response of cultured guineapig coronary endothelial cells to endothelium-dependent vasodilators. J Physiol 430:251-272

382. Keef KD, Pasco JS, Eckman DM (1992) Purinergic relaxation and hyperpolarization in guinea pig and rabbit coronary artery: role of the endothelium. J Pharmacol Exp Ther 260:592-600

383. White TD, Angus JA (1987) Relaxant effects of ATP and adenosine on canine large and small coronary arteries in vitro. Eur J Pharmacol 143:119-126

384. Hansmann G, Ihling C, Pieske B, Bültmann R (1998) Nucleotideevoked relaxation of human coronary artery. Eur J Pharmacol 359: $59-67$ 
385. Saetrum Opgaard O, Edvinsson L (1997) Mechanical properties and effects of sympathetic co-transmitters on human coronary arteries and veins. Basic Res Cardiol 92:168-180

386. Takata Y, Kuriyama H (1980) ATP-induced hyperpolarization of smooth muscle cells of the guinea-pig coronary artery. J Pharmacol Exp Ther 212:519-526

387. Vials A, Burnstock G (1994) Differential effects of ATP- and 2methylthioATP-induced relaxation in guinea pig coronary vasculature. J Cardiovasc Pharmacol 23:757-764

388. Matsumoto T, Nakane T, Chiba S (1997) UTP induces vascular responses in the isolated and perfused canine epicardial coronary artery via UTP-preferring P2Y receptors. Br J Pharmacol 122:16251632

389. Brown IP, Thompson CI, Belloni FL (1992) Mechanisms of coronary vasodilatation produced by ATP in guinea-pig isolated perfused heart. Br J Pharmacol 105:211-215

390. Gorman MW, Ogimoto K, Savage MV, Jacobson KA, Feigl EO (2003) Nucleotide coronary vasodilation in guinea pig hearts. Am J Physiol Heart Circ Physiol 285:H1040-H1047

391. Vials AJ, Burnstock G (1994) The effect of suramin on vasodilator responses to ATP and 2-methylthio-ATP in the Sprague-Dawley rat coronary vasculature. Eur J Pharmacol 251:299-302

392. Korchazhkina O, Wright G, Exley C (1999) Intravascular ATP and coronary vasodilation in the isolated working rat heart. $\mathrm{Br} \mathrm{J}$ Pharmacol 127:701-708

393. Bender SB, Berwick ZC, Laughlin MH, Tune JD (2011) Functional contribution of $\mathrm{P}_{2} \mathrm{Y}_{1}$ receptors to the control of coronary blood flow. J Appl Physiol 111:1744-1750

394. Moccia F, Baruffi S, Spaggiari S, Coltrini D, Berra-Romani R, Signorelli S, Castelli L, Taglietti V, Tanzi F (2001) $\mathrm{P}_{2 \mathrm{Y} 1}$ and $\mathrm{P}_{2 \mathrm{Y} 2}$ receptor-operated $\mathrm{Ca}^{2+}$ signals in primary cultures of cardiac microvascular endothelial cells. Microvasc Res 61:240-252

395. Yang S, Buxton IL, Probert CB, Talbot JN, Bradley ME (1996) Evidence for a discrete UTP receptor in cardiac endothelial cells. Br J Pharmacol 117:1572-1578

396. Zünkler BJ, Gräfe M, Henning B, Kühne S, Ott T, Fleck E, Hildebrandt AG (1999) Effects of P2 purinoceptor agonists on membrane potential and intracellular $\mathrm{Ca}^{2+}$ of human cardiac endothelial cells. Pharmacol Toxicol 85:7-15

397. Gündüz D, Aslam M, Krieger U, Becker L, Grebe M, Arshad M, Sedding DG, Hartel FV, Abdallah Y, Piper HM, Voss RK, Noll $\mathrm{T}$ (2012) Opposing effects of ATP and adenosine on barrier function of rat coronary microvasculature. J Mol Cell Cardiol 52:962-970

398. Fleetwood G, Gordon JL (1987) Purinoceptors in the rat heart. Br J Pharmacol 90:219-227

399. Hopwood AM, Burnstock G (1987) ATP mediates coronary vasoconstriction via $\mathrm{P}_{2 \mathrm{x}}$-purinoceptors and coronary vasodilatation via $\mathrm{P}_{2 \mathrm{y}}$-purinoceptors in the isolated perfused rat heart. Eur J Pharmacol 136:49-54

400. Corr L, Burnstock G (1994) Analysis of $P_{2}$-purinoceptor subtypes on the smooth muscle and endothelium of rabbit coronary artery. J Cardiovasc Pharmacol 23:709-715

401. Malmsjö M, Hou M, Harden TK, Pendergast W, Pantev E, Edvinsson L, Erlinge D (2000) Characterization of contractile P2 receptors in human coronary arteries by use of the stable pyrimidines uridine $5^{\prime}-O$-thiodiphosphate and uridine $5^{\prime}-O-3$ thiotriphosphate. J Pharmacol Exp Ther 293:755-760

402. Rayment SJ, Latif ML, Ralevic V, Alexander SP (2007) Evidence for the expression of multiple uracil nucleotide-stimulated $\mathrm{P} 2$ receptors coupled to smooth muscle contraction in porcine isolated arteries. Br J Pharmacol 150:604-612

403. Strøbæk D, Olesen SP, Christophersen P, Dissing S (1996) P2purinoceptor-mediated formation of inositol phosphates and intracellular $\mathrm{Ca}^{2+}$ transients in human coronary artery smooth muscle cells. Br J Pharmacol 118:1645-1652
404. Nori S, Fumagalli L, Bo X, Bogdanov Y, Burnstock G (1998) Coexpression of mRNAs for $\mathrm{P} 2 \mathrm{X}_{1}, \mathrm{P} 2 \mathrm{X}_{2}$ and $\mathrm{P} 2 \mathrm{X}_{4}$ receptors in rat vascular smooth muscle: an in situ hybridization and RT-PCR study. J Vasc Res 35:179-185

405. Welsh DG, Brayden JE (2001) Mechanisms of coronary artery depolarization by uridine triphosphate. Am J Physiol Heart Circ Physiol 280:H2545-H2553

406. van der Giet M, Schmidt S, Tolle M, Jankowski J, Schluter H, Zidek W, Tepel M (2002) Effects of dinucleoside polyphosphates on regulation of coronary vascular tone. Eur J Pharmacol 448:207-213

407. Zhou Z, Merkus D, Cheng C, Duckers HJ, Jan Danser AH, Duncker DJ (2013) Uridine adenosine tetraphosphate is a novel vasodilator in the coronary microcirculation which acts through purinergic $\mathrm{P} 1$ but not $\mathrm{P} 2$ receptors. Pharmacol Res 67:10-17

408. Simonsen U, García-Sacristán A, Prieto D (1997) Involvement of ATP in the non-adrenergic non-cholinergic inhibitory neurotransmission of lamb isolated coronary small arteries. Br J Pharmacol 120:411-420

409. Farias M III, Gorman MW, Savage MV, Feigl EO (2005) Plasma ATP during exercise: possible role in regulation of coronary blood flow. Am J Physiol Heart Circ Physiol 288: H1586-H1590

410. Gorman MW, Rooke GA, Savage MV, Jayasekara MP, Jacobson KA, Feigl EO (2010) Adenine nucleotide control of coronary blood flow during exercise. Am J Physiol Heart Circ Physiol 299:H1981H1989

411. Gorman MW, Feigl EO (2012) Control of coronary blood flow during exercise. Exerc Sport Sci Rev 40:37-42

412. Agazie YM, Bagot JC, Trickey E, Halenda SP, Wilden PA (2001) Molecular mechanisms of ATP and insulin synergistic stimulation of coronary artery smooth muscle growth. Am J Physiol Heart Circ Physiol 280:H795-H801

413. Hinze AV, Mayer P, Harst A, von Kügelgen I (2013) P2X $X_{1}$ receptormediated inhibition of the proliferation of human coronary smooth muscle cells involving the transcription factor NR4A1. Purinergic Signal 9:677-686

414. Afonso S, O'Brien GS, Berndt TB, Ansfield TJ, Rowe GG (1971) Enhancement of coronary vasodilator action of nicotinamide adenine dinucleotide by lidoflazine. J Pharmacol Exp Ther 179:573579

415. Cobbin LB, Einstein R, Maguire MH (1974) Studies on the coronary dilator actions of some adenosine analogues. Br J Pharmacol 50:25-33

416. Olsson RA, Khouri EM, Bedynek JL Jr, McLean J (1979) Coronary vasoactivity of adenosine in the conscious dog. Circ Res 45:468478

417. Watt AH, Penny WJ, Singh H, Routledge PA, Henderson AH (1987) Adenosine causes transient dilatation of coronary arteries in man. Br J Clin Pharmacol 24:665-668

418. Leung E, Johnston CI, Woodcock EA (1985) An investigation of the receptors involved in the coronary vasodilatory effect of adenosine analogues. Clin Exp Pharmacol Physiol 12:515-519

419. Daly JW, Padgett W, Thompson RD, Kusachi S, Bugni WJ, Olsson RA (1986) Structure-activity relationships for $N^{6}$-substituted adenosines at a brain $\mathrm{A}_{1}$-adenosine receptor with a comparison to an $\mathrm{A}_{2-}$ adenosine receptor regulating coronary blood flow. Biochem Pharmacol 35:2467-2481

420. Odawara S, Kurahashi K, Usui H, Taniguchi T, Fujiwara M (1986) Relaxations of isolated rabbit coronary artery by purine derivatives: $\mathrm{A}_{2}$-adenosine receptors. J Cardiovasc Pharmacol 8:567-573

421. Ramagopal MV, Rash VA, Mustafa SJ (1988) Antagonism of adenosine-induced relaxation by methylxanthines in coronary artery. Arch Int Pharmacodyn Ther 295:174-180

422. Des Rosiers C, Nees S (1987) Functional evidence for the presence of adenosine $\mathrm{A}_{2}$-receptors in cultured coronary endothelial cells. Naunyn Schmiedeberg's Arch Pharmacol 336:94-98 
423. Kroll K, Schrader J, Möllmann D (1987) Endothelial activation by adenosine and coronary flow regulation in the guinea pig heart. In: Gerlach E, Becker BF (eds) Topics and perspectives in adenosine research. Springer, Berlin, pp 470-479

424. Ramagopal MV, Chitwood RW Jr, Mustafa SJ (1988) Evidence for an $\mathrm{A}_{2}$ adenosine receptor in human coronary arteries. Eur $\mathrm{J}$ Pharmacol 151:483-486

425. King AD, Milavec-Krizman M, Müller-Schweinitzer E (1990) Characterization of the adenosine receptor in porcine coronary arteries. Br J Pharmacol 100:483-486

426. Balcells E, Suarez J, Rubio R (1992) Functional role of intravascular coronary endothelial adenosine receptors. Eur $\mathrm{J}$ Pharmacol 210:1-9

427. Pekka Raatikainen MJ, Peuhkurinen KJ, Hassinen IE (1991) Cellular source and role of adenosine in isoproterenol-induced coronary vasodilatation. J Mol Cell Cardiol 23:1137-1148

428. Sabouni MH, Hargittai PT, Lieberman EM, Mustafa SJ (1989) Evidence for adenosine receptor-mediated hyperpolarization in coronary smooth muscle. Am J Physiol 257:H1750-H1752

429. Olanrewaju HA, Hargittai PT, Lieberman EA, Mustafa SJ (1995) Role of endothelium in hyperpolarization of coronary smooth muscle by adenosine and its analogues. J Cardiovasc Pharmacol 25: 234-239

430. Seiss-Geuder M, Mehrke G, Daut J (1992) Sustained hyperpolarization of cultured guinea pig coronary endothelial cells induced by adenosine. J Cardiovasc Pharmacol 20(Suppl 12):S97-S100

431. Nees S, Des Rosiers C, Böck M (1987) Adenosine receptors at the coronary endothelium: functional implications. In: Gerlach E, Becker BF (eds) Topics and perspectives in adenosine research. Springer, Berlin, pp 454-468

432. Cox BF, Greenland BD, Perrone MH, Merkel LA (1994) Ischaemia/ reperfusion selectively attenuates coronary vasodilatation to an adenosine $\mathrm{A}_{2}$ - but not to an $\mathrm{A}_{1}$-agonist in the dog. $\mathrm{Br} \mathrm{J}$ Pharmacol 111:1233-1239

433. Merkel LA, Lappe RW, Rivera LM, Cox BF, Perrone MH (1992) Demonstration of vasorelaxant activity with an $\mathrm{A}_{1}$-selective adenosine agonist in porcine coronary artery: involvement of potassium channels. J Pharmacol Exp Ther 260:437-443

434. Dart C, Standen NB (1993) Adenosine-activated potassium current in smooth muscle cells isolated from the pig coronary artery. $\mathrm{J}$ Physiol 471:767-786

435. Abebe W, Makujina SR, Mustafa SJ (1994) Adenosine receptormediated relaxation of porcine coronary artery in presence and absence of endothelium. Am J Physiol 266:H2018-H2025

436. Kemp BK, Cocks TM (1999) Adenosine mediates relaxation of human small resistance-like coronary arteries via $\mathrm{A}_{2 \mathrm{~B}}$ receptors. Br J Pharmacol 126:1796-1800

437. Sato A, Terata K, Miura H, Toyama K, Loberiza FR Jr, Hatoum OA, Saito T, Sakuma I, Gutterman DD (2005) Mechanism of vasodilation to adenosine in coronary arterioles from patients with heart disease. Am J Physiol Heart Circ Physiol 288:H1633-H1640

438. Olanrewaju HA, Mustafa SJ (2000) Adenosine $A_{2 A}$ and $A_{2 B}$ receptors mediated nitric oxide production in coronary artery endothelial cells. Gen Pharmacol 35:171-177

439. Teng B, Qin W, Ansari HR, Mustafa SJ (2005) Involvement of p38mitogen-activated protein kinase in adenosine receptor-mediated relaxation of coronary artery. Am J Physiol Heart Circ Physiol 288:H2574-H2580

440. Rayment SJ, Ralevic V, Barrett DA, Cordell R, Alexander SP (2007) A novel mechanism of vasoregulation: ADP-induced relaxation of the porcine isolated coronary artery is mediated via adenosine release. FASEB J 21:577-585

441. Rubio R, Ceballos G (2003) Sole activation of three luminal adenosine receptor subtypes in different parts of coronary vasculature. Am J Physiol Heart Circ Physiol 284:H204-H214
442. Hinschen AK, Rose'Meyer RB, Headrick JP (2003) Adenosine receptor subtypes mediating coronary vasodilation in rat hearts. $J$ Cardiovasc Pharmacol 41:73-80

443. Flood A, Headrick JP (2001) Functional characterization of coronary vascular adenosine receptors in the mouse. $\mathrm{Br} \mathrm{J}$ Pharmacol 133:1063-1072

444. Talukder MA, Morrison RR, Ledent C, Mustafa SJ (2003) Endogenous adenosine increases coronary flow by activation of both $\mathrm{A}_{2 \mathrm{~A}}$ and $\mathrm{A}_{2 \mathrm{~B}}$ receptors in mice. J Cardiovasc Pharmacol 41: $562-570$

445. Sanjani MS, Teng B, Krahn T, Tilley S, Ledent C, Mustafa SJ (2011) Contributions of $A_{2 A}$ and $A_{2 B}$ adenosine receptors in coronary flow responses in relation to the $\mathrm{K}_{\mathrm{ATP}}$ channel using $\mathrm{A}_{2 \mathrm{~B}}$ and $\mathrm{A}_{2 \mathrm{~A} / 2 \mathrm{~B}}$ double-knockout mice. Am J Physiol Heart Circ Physiol 301:H2322-H2333

446. van der Meer P, de Jong JW (1990) Inosine transiently decreases coronary flow but potentiates vasodilation by adenosine. Am J Physiol 259:H759-H765

447. Nakae I, Takahashi M, Takaoka A, Liu Q, Matsumoto T, Amano M, Sekine A, Nakajima H, Kinoshita M (1996) Coronary effects of diadenosine tetraphosphate resemble those of adenosine in anesthetized pigs: involvement of ATP-sensitive potassium channels. J Cardiovasc Pharmacol 28:124-133

448. Conant AR, Theologou T, Dihmis WC, Simpson AW (2008) Diadenosine polyphosphates are selective vasoconstrictors in human coronary artery bypass grafts. Vasc Pharmacol 48: $157-164$

449. Heusch G (2010) Adenosine and maximum coronary vasodilation in humans: myth and misconceptions in the assessment of coronary reserve. Basic Res Cardiol 105:1-5

450. Wittfeldt A, Emanuelsson H, Brandrup-Wognsen G, van Giezen JJ, Jonasson J, Nylander S, Gan LM (2013) Ticagrelor enhances adenosine-induced coronary vasodilatory responses in humans. J Am Coll Cardiol 61:723-727

451. Buss DD, Hennemann WW III, Posner P (1987) Maturation of coronary responsiveness to exogenous adenosine in the rabbit. Basic Res Cardiol 82:290-296

452. Rose'Meyer RB, Harden FA, Varela JI, Harrison GJ, Willis RJ (1999) Age-related changes in adenosine in rat coronary resistance vessels. Gen Pharmacol 32:35-40

453. Hinschen AK, Rose'Meyer RB, Headrick JP (2001) Age-related changes in adenosine-mediated relaxation of coronary and aortic smooth muscle. Am J Physiol Heart Circ Physiol 280:H2380 H2389

454. Jenner TL, Rose'Meyer RB (2006) Adenosine $A_{3}$ receptor mediated coronary vasodilation in the rat heart: changes that occur with maturation. Mech Ageing Dev 127:264-273

455. Ryzhov S, Solenkova NV, Goldstein AE, Lamparter M, Fleenor T, Young PP, Greelish JP, Byrne JG, Vaughan DE, Biaggioni I, Hatzopoulos AK, Feoktistov I (2008) Adenosine receptormediated adhesion of endothelial progenitors to cardiac microvascular endothelial cells. Circ Res 102:356-363

456. Heinonen I, Nesterov SV, Liukko K, Kemppainen J, Någren K, Luotolahti M, Virsu P, Oikonen V, Nuutila P, Kujala UM, Kainulainen H, Boushel R, Knuuti J, Kalliokoski KK (2008) Myocardial blood flow and adenosine $\mathrm{A}_{2 \mathrm{~A}}$ receptor density in endurance athletes and untrained men. J Physiol 586:5193-5202

457. Huxley VH, Wang J, Whitt SP (2005) Sexual dimorphism in the permeability response of coronary microvessels to adenosine. Am J Physiol Heart Circ Physiol 288:H2006-H2013

458. Pelleg A, Belardinelli L (2008) The first second-generation adenosine drug enters the US market. Purinergic Signal 4:407-408

459. Cortigiani L, Baroni M, Picano E, Palmieri C, Boni A, Ravani M, Biagini A, Nannini E (1998) Acute hemodynamic effects of endogenous adenosine in patients with chronic heart failure. Am Heart $\mathrm{J}$ $136: 37-42$ 
460. Sanada S, Asanuma H, Koretsune Y, Watanabe K, Nanto S, Awata N, Hoki N, Fukunami M, Kitakaze M, Hori M (2007) Long-term oral administration of dipyridamole improves both cardiac and physical status in patients with mild to moderate chronic heart failure: a prospective open-randomized study. Hypertens Res 30: 913-919

461. Funakoshi H, Zacharia LC, Tang Z, Zhang J, Lee LL, Good JC, Herrmann DE, Higuchi Y, Koch WJ, Jackson EK, Chan TO, Feldman AM (2007) A1 adenosine receptor upregulation accompanies decreasing myocardial adenosine levels in mice with left ventricular dysfunction. Circulation 115:2307-2315

462. Kitakaze M, Minamino T, Node K, Takashima S, Funaya H, Kuzuya T, Hori M (1999) Adenosine and cardioprotection in the diseased heart. Jpn Circ J 63:231-243

463. Lee JE, Bokoch G, Liang BT (2001) A novel cardioprotective role of RhoA: new signaling mechanism for adenosine. FASEB J 15: 1886-1894

464. Asakura M, Asanuma H, Kim J, Liao Y, Nakamaru K, Fujita M, Komamura K, Isomura T, Furukawa H, Tomoike H, Kitakaze M (2007) Impact of adenosine receptor signaling and metabolism on pathophysiology in patients with chronic heart failure. Hypertens Res 30:781-787

465. Cabiati M, Martino A, Mattii L, Caselli C, Prescimone T, Lionetti V, Morales MA, Del Ry S (2014) Adenosine receptor expression in an experimental animal model of myocardial infarction with preserved left ventricular ejection fraction. Heart Vessel 29:513-519

466. Mitrovic V, Seferovic P, Dodic S, Krotin M, Neskovic A, Dickstein K, de Voogd H, Böcker C, Ziegler D, Godes M, Nakov R, Essers H, Verboom C, Hocher B (2009) Cardio-renal effects of the A1 adenosine receptor antagonist SLV320 in patients with heart failure. Circ Heart Fail 2:523-531

467. Slawsky MT, Givertz MM (2009) Rolofylline: a selective adenosine 1 receptor antagonist for the treatment of heart failure. Expert Opin Pharmacother 10:311-322

468. Ensor CR, Russell SD (2010) Tonapofylline: a selective adenosine1 receptor antagonist for the treatment of heart failure. Expert Opin Pharmacother 11:2405-2415

469. Givertz MM (2009) Adenosine $A_{1}$ receptor antagonists at a fork in the road. Circ Heart Fail 2:519-522

470. Massie BM, O'Connor CM, Metra M, Ponikowski P, Teerlink JR, Cotter G, Weatherley BD, Cleland JG, Givertz MM, Voors A, Delucca P, Mansoor GA, Salerno CM, Bloomfield DM, Dittrich HC (2010) Rolofylline, an adenosine A1receptor antagonist, in acute heart failure. $\mathrm{N}$ Engl $\mathrm{J}$ Med 363:1419-1428

471. Teerlink JR, Iragui VJ, Mohr JP, Carson PE, Hauptman PJ, Lovett DH, Miller AB, Piña IL, Thomson S, Varosy PD, Zile MR, Cleland JG, Givertz MM, Metra M, Ponikowski P, Voors AA, Davison BA, Cotter G, Wolko D, Delucca P, Salerno CM, Mansoor GA, Dittrich H, O'Connor CM, Massie BM (2012) The safety of an adenosine $\mathrm{A}_{1}$-receptor antagonist, rolofylline, in patients with acute heart failure and renal impairment: findings from PROTECT. Drug Saf 35:233-244

472. Gottlieb SS, Givertz MM, Metra M, Gergich K, Bird S, JonesBurton C, Massie B, Cotter G, Ponikowski P, Weatherley B, O' Connor C, Dittrich H (2010) The effects of adenosine $A_{1}$ receptor antagonism in patients with acute decompensated heart failure and worsening renal function: the REACH UP study. J Card Fail 16: 714-719

473. Carrega L, Fenouillet E, Giaime P, Charavil A, Mercier L, Gerolami V, Berge-Lefranc JL, Berland Y, Ruf J, Saadjian A, Dussol B, Guieu $R$ (2007) Influence of haemodialysis and left ventricular failure on peripheral $\mathrm{A}_{2 \mathrm{~A}}$ adenosine receptor expression. Nephrol Dial Transplant 22:851-856

474. Wang M, Gupta RC, Rastogi S, Kohli S, Zhang K, Lanfear DE, Sabbah HN (2013) Acute intravenous infusion of an adenosine regulating agent improves left ventricular function in dogs with advanced heart failure. Cardiovasc Drugs Ther 27:489-498

475. Del Ry S, Cabiati M, Martino A, Simioniuc A, Morales MA, Picano E (2011) Adenosine receptor mRNA expression in normal and failing minipig hearts. J Cardiovasc Pharmacol 58:149-156

476. Franceschi F, Deharo JC, Giorgi R, By Y, Monserrat C, Condo J, Ibrahim Z, Saadjian A, Guieu R (2009) Peripheral plasma adenosine release in patients with chronic heart failure. Heart 95:651-655

477. Kinugawa T, Fujita M, Ogino K, Kato M, Osaki S, Igawa O, Shigemasa C, Hisatome I, Kitakaze M (2006) Catabolism of adenine nucleotides favors adenosine production following exercise in patients with chronic heart failure. J Card Fail 12:720-725

478. Hisatome I (2007) Adenosine and cardioprotection in chronic heart failure: genes and protein expression. Hypertens Res 30:757-758

479. Berry D, Yao M, Barden JA, Balcar VJ, Hansen MA, Bennett MR, Keogh A, dos Remedios CG (1998) Alterations in the expression of $\mathrm{P} 2 \mathrm{X} 1$ receptors in failing and nondiseased human atria. Electrophoresis 19:856-859

480. Banfi C, Ferrario S, De Vincenti O, Ceruti S, Fumagalli M, Mazzola A, D'Ambrosi N, Volontè C, Fratto P, Vitali E, Burnstock G, Beltrami E, Parolari A, Polvani G, Biglioli P, Tremoli E, Abbracchio MP (2005) P2 receptors in human heart: upregulation of $\mathrm{P} 2 \mathrm{X}_{6}$ in patients undergoing heart transplantation, interaction with $\mathrm{TNF} \alpha$ and potential role in myocardial cell death. J Mol Cell Cardiol 39:929-939

481. Kumar TS, Zhou SY, Joshi BV, Balasubramanian R, Yang T, Liang BT, Jacobson KA (2010) Structure-activity relationship of $(N)$ Methanocarba phosphonate analogues of $5^{\prime}$-AMP as cardioprotective agents acting through a cardiac P2X receptor. J Med Chem 53:2562-2576

482. Patel N, Yang T, Qanud K, Khan R, Hintze T, Recchia F, Liang B (2011) Cardioprotective effects of the P2X receptor agonist MRS2339 in dog and mouse models of heart failure. FASEB J 25: 1085

483. Zhou SY, Mamdani M, Qanud K, Shen JB, Pappano AJ, Kumar TS, Jacobson KA, Hintze T, Recchia FA, Liang BT (2010) Treatment of heart failure by a methanocarba derivative of adenosine monophosphate: implication for a role of cardiac purinergic P2X receptors. J Pharmacol Exp Ther 333:920-928

484. Fujita M, Asakura M, Sanada S, Funaya H, Tsukamoto O, Komamura K, Asanuma H, Taketani S, Isomura T, Nakamaru K, Furukawa H, Sawa Y, Hori M, Kitakaze M (2008) Activation of ecto-5'-nucleotidase in the blood and hearts of patients with chronic heart failure. J Card Fail 14:426-430

485. Furlan-Freguia C, Marchese P, Gruber A, Ruggeri ZM, Ruf W (2011) P2X7 receptor signaling contributes to tissue factordependent thrombosis in mice. J Clin Invest 121:2932-2944

486. Newman WH, Grossman SJ, Frankis MB, Webb JG (1984) Increased myocardial adenosine release in heart failure. J Mol Cell Cardiol 16:577-580

487. Gottlieb SS, Ticho B, Deykin A, Abraham WT, Denofrio D, Russell SD, Chapman D, Smith W, Goldman S, Thomas I (2011) Effects of BG9928, an adenosine $A_{1}$ receptor antagonist, in patients with congestive heart failure. J Clin Pharmacol 51:899-907

488. Hou M, Malmsjö M, Möller S, Pantev E, Bergdahl A, Zhao XH, Sun XY, Hedner T, Edvinsson L, Erlinge D (1999) Increase in cardiac $\mathrm{P} 2 \mathrm{X}_{1}$-and $\mathrm{P} 2 \mathrm{Y}_{2}$-receptor mRNA levels in congestive heart failure. Life Sci 65:1195-1206

489. Malmsjö M, Bergdahl A, Möller S, Zhao XH, Sun XY, Hedner T, Edvinsson L, Erlinge D (1999) Congestive heart failure induces downregulation of $\mathrm{P} 2 \mathrm{X}_{1}$-receptors in resistance arteries. Cardiovasc Res 43:219-227

490. Malmsjö M, Bergdahl A, Zhao XH, Sun XY, Hedner T, Edvinsson L, Erlinge D (1999) Enhanced acetylcholine and P2Y-receptor 
stimulated vascular EDHF-dilatation in congestive heart failure. Cardiovasc Res 43:200-209

491. Zhao XH, Sun XY, Erlinge D, Edvinsson L, Hedner T (2000) Downregulation of adenosine and $\mathrm{P} 2 \mathrm{X}$ receptor-mediated cardiovascular responses in heart failure rats. Blood Press 9:152-161

492. Grenz A, Bauerle JD, Dalton JH, Ridyard D, Badulak A, Tak E, McNamee EN, Clambey E, Moldovan R, Reyes G, Klawitter J, Ambler K, Magee K, Christians U, Brodsky KS, Ravid K, Choi DS, Wen J, Lukashev D, Blackburn MR, Osswald H, Coe IR, Nürnberg B, Haase VH, Xia Y, Sitkovsky M, Eltzschig HK (2012) Equilibrative nucleoside transporter 1 (ENT1) regulates postischemic blood flow during acute kidney injury in mice. J Clin Invest 122:693-710

493. Scott JB, Chen WT, Swindall BT, Dabney JM, Haddy FJ (1979) Evidence from bioassay studies indicating a role for adenosine in cardiac ischemic and hypoxic dilation in the dog. Circ Res 45:451459

494. Belardinelli L, Mattos EC, Berne RM (1981) Evidence for adenosine mediation of atrioventricular block in the ischemic canine myocardium. J Clin Invest 68:195-205

495. Afonso S, Ansfield TJ, Berndt TB, Rowe GG (1972) Coronary vasodilator responses to hypoxia before and after aminophylline. J Physiol 221:589-599

496. Bünger R, Haddy FJ, Gerlach E (1975) Coronary responses to dilating substances and competitive inhibition by theophylline in the isolated perfused guinea pig heart. Pflugers Arch 358: 213-224

497. Rehncrona S, Siesjö BK, Westerberg E (1978) Adenosine and cyclic AMP in cerebral cortex of rats in hypoxia, status epilepticus and hypercapnia. Acta Physiol Scand 104:453-463

498. Heistad DD, Marcus ML, Gourley JK, Busija DW (1981) Effect of adenosine and dipyridamole on cerebral blood flow. Am J Physiol 240:H775-H780

499. Pinard E, Puiroud S, Seylaz J (1989) Role of adenosine in cerebral hypoxic hyperemia in the unanesthetized rabbit. Brain Res 481: $124-130$

500. Eikens E, Wilcken DE (1973) Myocardial reactive hyperaemia in conscious dogs: effect of dipyridamole and aminophylline on responses to four- and eight-second coronary artery occlusions. Aust J Exp Biol Med Sci 51:617-630

501. Eikens E, Wilcken DE (1973) The effect of dipyridamole and of aminophyline on responses to sixty-second coronary artery occlusions in dogs. Aust J Exp Biol Med Sci 51:631-642

502. Giles RW, Wilcken DE (1977) Reactive hyperaemia in the dog heart: inter-relations between adenosine, ATP, and aminophylline and the effect of indomethacin. Cardiovasc Res 11:113-121

503. Clemens MG, Chaudry IH, Baue AE (1985) Increased coronary flow and myocardial efficiency with systemic infusion of adenosine triphosphate-magnesium chloride. Surg Forum 36:224-226

504. Clemens MG, Forrester T (1981) Appearance of adenosine triphosphate in the coronary sinus effluent from isolated working rat heart in response to hypoxia. J Physiol 312:143-158

505. Bodin P, Bailey DJ, Burnstock G (1991) Increased flow-induced ATP release from isolated vascular endothelial but not smooth muscle cells. Br J Pharmacol 103:1203-1205

506. Vials A, Burnstock G (1993) $\mathrm{A}_{2}$-purinoceptor-mediated relaxation in the guinea-pig coronary vasculature: a role for nitric oxide. Br J Pharmacol 109:424-429

507. Ishibashi T, Ichihara K, Abiko Y (1985) Difference in the time course between increases in coronary flow and in effluent adenosine concentration during anoxia in the perfused rat heart. Jpn Circ J 49: 1090-1098

508. Meghji P, Burnstock G (1995) Inhibition of extracellular ATP degradation in endothelial cells. Life Sci 57:763-771

509. Urthaler FERD, Woods WT, James TN, Walker AA (1981) Effects of adenosine on mechanical performance and electrical activity in the canine heart. J Pharmacol Exp Ther 216:254-260
510. Burlington RF, Zook MA (1985) Enhancement of hypothermic cardiac performance with adenosine. J Thermal Biol 10: $109-113$

511. Olafsson B, Forman MB, Puett DW, Pou A, Cates CU, Friesinger GC, Virmani R (1987) Reduction of reperfusion injury in the canine preparation by intracoronary adenosine: importance of the endothelium and the no-reflow phenomenon. Circulation 76:1135-1145

512. Babbitt DG, Virmani R, Forman MB (1989) Intracoronary adenosine administered after reperfusion limits vascular injury after prolonged ischemia in the canine model. Circulation 80:1388-1399

513. Ledingham S, Katayama O, Lachno D, Patel N, Yacoub M (1990) Beneficial effect of adenosine during reperfusion following prolonged cardioplegic arrest. Cardiovasc Res 24:247-253

514. Thornton JD, Liu GS, Olsson RA, Downey JM (1992) Intravenous pretreatment with $\mathrm{A}_{1}$-selective adenosine analogues protects the heart against infarction. Circulation 85:659-665

515. Liu GS, Thornton J, Van Winkle DM, Stanley AW, Olsson RA, Downey JM (1991) Protection against infarction afforded by preconditioning is mediated by $\mathrm{A}_{1}$ adenosine receptors in rabbit heart. Circulation 84:350-356

516. Vanhaecke J, Flameng W, Borgers M, Jang IK, Van de Werf F, De Geest H (1990) Evidence for decreased coronary flow reserve in viable postischemic myocardium. Circ Res 67:1201-1210

517. Zucchi R, Ronca-Testoni S, Galbani P, Yu G, Mariani M, Ronca G (1992) Cardiac $A_{2}$ adenosine receptors - influence of ischaemia. Cardiovasc Res 26:549-554

518. Finegan BA, Lopaschuk GD, Gandhi M, Clanachan AS (1996) Inhibition of glycolysis and enhanced mechanical function of working rat hearts as a result of adenosine $\mathrm{A}_{1}$ receptor stimulation during reperfusion following ischaemia. Br J Pharmacol 118:355-363

519. Schlack W, Schäfer M, Uebing A, Schäfer S, Borchard U, Thämer V (1993) Adenosine $A_{2}$-receptor activation at reperfusion reduces infarct size and improves myocardial wall function in dog heart. $\mathrm{J}$ Cardiovasc Pharmacol 22:89-96

520. Lozza G, Conti A, Ongini E, Monopoli A (1997) Cardioprotective effects of adenosine $A_{1}$ and $A 2 A$ receptor agonists in the isolated rat heart. Pharmacol Res 35:57-64

521. Matherne GP, Linden J, Byford AM, Gauthier NS, Headrick JP (1997) Transgenic $A_{1}$ adenosine receptor overexpression increases myocardial resistance to ischemia. Proc Natl Acad Sci U S A 94: $6541-6546$

522. Lankford AR, Byford AM, Ashton KJ, French BA, Lee JK, Headrick JP, Matherne GP (2002) Gene expression profile of mouse myocardium with transgenic overexpression of A1 adenosine receptors. Physiol Genomics 11:81-89

523. Winter CB, Cleveland JC, Butler KL, Bensard DB, Mitchell MB, Harken AH, Banerjee A (1997) Facilitative interactions between noradrenergic and purinergic signaling during preconditioning of the rat heart. J Mol Cell Cardiol 29:163-173

524. Stambaugh K, Jacobson KA, Jiang JL, Liang BT (1997) A novel cardioprotective function of adenosine $A_{1}$ and $A_{3}$ receptors during prolonged simulated ischemia. Am J Physiol 273: H501-H505

525. Tracey WR, Magee W, Masamune H, Kennedy SP, Knight DR, Buchholz RA, Hill RJ (1997) Selective adenosine A3 receptor stimulation reduces ischemic myocardial injury in the rabbit heart. Cardiovasc Res 33:410-415

526. Liang BT, Jacobson KA (1998) A physiological role of the adenosine $\mathrm{A}_{3}$ receptor: sustained cardioprotection. Proc Natl Acad Sci U S A 95:6995-6999

527. Gao F, Christopher TA, Lopez BL, Friedman E, Cai G, Ma XL (2000) Mechanism of decreased adenosine protection in reperfusion injury of aging rats. Am J Physiol Heart Circ Physiol 279:H329 H338

528. Arosio B, Perlini S, Calabresi C, Tozzi R, Palladini G, Ferrari AU, Vergani C, Annoni G (2003) Adenosine A1 and A2A receptor 
cross-talk during ageing in the rat myocardium. Exp Gerontol 38: 855-861

529. Harrison GJ, Cerniway RJ, Peart J, Berr SS, Ashton K, Regan S, Paul MG, Headrick JP (2002) Effects of $A_{3}$ adenosine receptor activation and gene knock-out in ischemic-reperfused mouse heart. Cardiovasc Res 53:147-155

530. Fabritz L, Kirchhof P, Fortmuller L, Auchampach JA, Baba HA, Breithardt G, Neumann J, Boknik P, Schmitz W (2004) Gene dosedependent atrial arrhythmias, heart block, and bradycardiomyopathy in mice overexpressing $\mathrm{A}_{3}$ adenosine receptors. Cardiovasc Res 62:500-508

531. Ashton KJ, Nilsson U, Willems L, Holmgren K, Headrick JP (2003) Effects of aging and ischemia on adenosine receptor transcription in mouse myocardium. Biochem Biophys Res Commun 312:367-372

532. Glover DK, Riou LM, Ruiz M, Sullivan GW, Linden J, Rieger JM, Macdonald TL, Watson DD, Beller GA (2005) Reduction of infarct size and postischemic inflammation from ATL-146e, a highly selective adenosine $\mathrm{A} 2 \mathrm{~A}$ receptor agonist, in reperfused canine myocardium. Am J Physiol Heart Circ Physiol 288:H1851-H1858

533. Manintveld OC, te Lintel HM, Keijzer E, Verdouw PD, Duncker DJ (2005) Intravenous adenosine protects the myocardium primarily by activation of a neurogenic pathway. Br J Pharmacol 145:703-711

534. Köhler D, Eckle T, Faigle M, Grenz A, Mittelbronn M, Laucher S, Hart ML, Robson SC, Müller CE, Eltzschig HK (2007) CD39/ectonucleoside triphosphate diphosphohydrolase 1 provides myocardial protection during cardiac ischemia/reperfusion injury. Circulation 116:1784-1794

535. Cohen R, Shainberg A, Hochhauser E, Cheporko Y, Tobar A, Birk E, Pinhas L, Leipziger J, Don J, Porat E (2011) UTP reduces infarct size and improves mice heart function after myocardial infarct via $\mathrm{P}_{2} \mathrm{Y}_{2}$ receptor. Biochem Pharmacol 82:1126-1133

536. Hausenloy DJ, Tsang A, Yellon DM (2005) The reperfusion injury salvage kinase pathway: a common target for both ischemic preconditioning and postconditioning. Trends Cardiovasc Med 15:69-75

537. Hausenloy DJ, Yellon DM (2006) Survival kinases in ischemic preconditioning and postconditioning. Cardiovasc Res 70:240-253

538. Murphy E, Steenbergen C (2008) Mechanisms underlying acute protection from cardiac ischemia-reperfusion injury. Physiol Rev 88:581-609

539. Reichelt ME, Willems L, Molina JG, Sun CX, Noble JC, Ashton KJ, Schnermann J, Blackburn MR, Headrick JP (2005) Genetic deletion of the A1 adenosine receptor limits myocardial ischemic tolerance. Circ Res 96:363-367

540. Solenkova NV, Solodushko V, Cohen MV, Downey JM (2006) Endogenous adenosine protects preconditioned heart during early minutes of reperfusion by activating Akt. Am J Physiol Heart Circ Physiol 290:H441-H449

541. Morrison RR, Tan XL, Ledent C, Mustafa SJ, Hofmann PA (2007) Targeted deletion of $\mathrm{A} 2 \mathrm{~A}$ adenosine receptors attenuates the protective effects of myocardial postconditioning. Am J Physiol Heart Circ Physiol 293:H2523-H2529

542. Sadigh B, Shahgaldi K, Sylvén C, Quintana M, Winter R (2009) Preconditioning effects of adenosine in patients with severe coronary artery disease but preserved coronary flow reserve. Coron Artery Dis 20:354-359

543. Yang Z, Day YJ, Toufektsian MC, Xu Y, Ramos SI, Marshall MA, French BA, Linden J (2006) Myocardial infarct-sparing effect of adenosine $\mathrm{A}_{2 \mathrm{~A}}$ receptor activation is due to its action on $\mathrm{CD} 4^{+} \mathrm{T}$ lymphocytes. Circulation 114:2056-2064

544. Xu TR, He G, Rumsby MG (2009) Adenosine triggers the nuclear translocation of protein kinase $\mathrm{C}$ epsilon in $\mathrm{H} 9 \mathrm{c} 2$ cardiomyoblasts with the loss of phosphorylation at Ser729. J Cell Biochem 106: 633-642

545. Dibner-Dunlap ME, Kinugawa T, Thames MD (1993) Activation of cardiac sympathetic afferents: effects of exogenous adenosine and adenosine analogues. Am J Physiol 265:H395-H400
546. Fu LW, Longhurst JC (2010) A new function for ATP: activating cardiac sympathetic afferents during myocardial ischemia. Am J Physiol Heart Circ Physiol 299:H1762-H1771

547. Patel RA, Glover DK, Broisat A, Kabul HK, Ruiz M, Goodman NC, Kramer CM, Meerdink DJ, Linden J, Beller GA (2009) Reduction in myocardial infarct size at 48 hours after brief intravenous infusion of ATL-146e, a highly selective adenosine A2A receptor agonist. Am J Physiol Heart Circ Physiol 297: H637-H642

548. Riksen NP, Wynne A, Yellon DM, Hausenloy DJ (2009) Ischaemic preconditioning and postconditioning do not affect adenosine $A_{1}$ and $\mathrm{A}_{2 \mathrm{~A}}$ receptor sensitivity. Cardiovasc Drugs Ther 23:415-417

549. Xi J, McIntosh R, Shen X, Lee S, Chanoit G, Criswell H, Zvara DA, $\mathrm{Xu} Z \mathrm{Z}$ (2009) Adenosine $\mathrm{A}_{2 \mathrm{~A}}$ and $\mathrm{A}_{2 \mathrm{~B}}$ receptors work in concert to induce a strong protection against reperfusion injury in rat hearts. $\mathrm{J}$ Mol Cell Cardiol 47:684-690

550. Urmaliya VB, Pouton CW, Ledent C, Short JL, White PJ (2010) Cooperative cardioprotection through adenosine $\mathrm{A}_{1}$ and $\mathrm{A}_{2 \mathrm{~A}}$ receptor agonism in ischemia-reperfused isolated mouse heart. $\mathrm{J}$ Cardiovasc Pharmacol 56:379-388

551. Urmaliya VB, Church JE, Coupar IM, Rose'Meyer RB, Pouton CW, White PJ (2009) Cardioprotection induced by adenosine A1 receptor agonists in a cardiac cell ischemia model involves cooperative activation of adenosine A2A and A2B receptors by endogenous adenosine. J Cardiovasc Pharmacol 53:424-433

552. Methner C, Schmidt K, Cohen MV, Downey JM, Krieg T (2010) Both $\mathrm{A} 2 \mathrm{a}$ and $\mathrm{A} 2 \mathrm{~b}$ adenosine receptors at reperfusion are necessary to reduce infarct size in mouse hearts. Am J Physiol Heart Circ Physiol 299:H1262-H1264

553. Leshem-Lev D, Hochhauser E, Chanyshev B, Isak A, Shainberg A (2010) Adenosine $A_{1}$ and $A_{3}$ receptor agonists reduce hypoxic injury through the involvement of P38 MAPK. Mol Cell Biochem 345:153-160

554. Eckle T, Krahn T, Grenz A, Köhler D, Mittelbronn M, Ledent C, Jacobson MA, Osswald H, Thompson LF, Unertl K, Eltzschig HK (2007) Cardioprotection by ecto-5'-nucleotidase (CD73) and A2B adenosine receptors. Circulation 115:1581-1590

555. Aherne CM, Kewley EM, Eltzschig HK (2011) The resurgence of A2B adenosine receptor signaling. Biochim Biophys Acta 1808: $1329-1339$

556. Ge ZD, Peart JN, Kreckler LM, Wan TC, Jacobson MA, Gross GJ, Auchampach JA (2006) Cl-IB-MECA [2-chloro- $N^{6}-(3-$ iodobenzyl)adenosine- $5^{\prime}-N$-methylcarboxamide] reduces ischemia/ reperfusion injury in mice by activating the $\mathrm{A}_{3}$ adenosine receptor. $\mathrm{J}$ Pharmacol Exp Ther 319:1200-1210

557. Wan TC, Tosh DK, Du L, Gizewski ET, Jacobson KA, Auchampach JA (2011) Polyamidoamine (PAMAM) dendrimer conjugate specifically activates the $\mathrm{A}_{3}$ adenosine receptor to improve post-ischemic/reperfusion function in isolated mouse hearts. BMC Pharmacol 11:11

558. Tendera M, Gaszewska-Zurek E, Parma Z, Ponikowski P, Jankowska E, Kawecka-Jaszcz K, Czarnecka D, KrzeminskaPakula M, Bednarkiewicz Z, Sosnowski M, Ochan KM, Agrawal R (2012) The new oral adenosine A1 receptor agonist capadenoson in male patients with stable angina. Clin Res Cardiol 101:585-591

559. Bönner F, Borg N, Jacoby C, Bongardt S, Flögel U, Schrader J (2012) Modulation of immune response by CD73-derived adenosine during myocardial remodelling after ischemia/reperfusion. Purinergic Signal 8:162

560. Goretti E, Bousquenaud M, Rolland-Turner M, Nicolas C, Maskali F, Marie PY, Devaux Y, Wagner DR (2012) Asenosine stimulates the recruitment of endothelial progenitor cells to the ischemic heart. Involvement of the microRNA-150-CXCR4-SDF-1alpha pathway. Eur Heart J 33:197 
561. Eltzschig HK, Bonney SK, Eckle T (2013) Attenuating myocardial ischemia by targeting A2B adenosine receptors. Trends Mol Med 19:345-354

562. de Jong JW, de Jonge R, Keijzer E, Bradamante S (2000) The role of adenosine in preconditioning. Pharmacol Ther 87:141-149

563. Ganote CE, Armstrong SC (2000) Adenosine and preconditioning in the rat heart. Cardiovasc Res 45:134-140

564. Sommerschild HT, Kirkeboen KA (2000) Adenosine and cardioprotection during ischaemia and reperfusion-an overview. Acta Anaesthesiol Scand 44:1038-1055

565. Lasley RD, Narayan P, Mentzer RM (2001) New insights into adenosine receptor modulation of myocardial ischaemiareperfusion injuryaveolae. Drug Dev Res 52:357-365

566. Przyklenk K, Whittaker P (2005) Cardioprotection with adenosine: 'a riddle wrapped in a mystery'. Br J Pharmacol 145: 699-700

567. Cohen MV, Downey JM (2008) Adenosine: trigger and mediator of cardioprotection. Basic Res Cardiol 103:203-215

568. Drew BG, Kingwell BA (2008) Acadesine, an adenosine-regulating agent with the potential for widespread indications. Expert Opin Pharmacother 9:2137-2144

569. Laubach VE, French BA, Okusa MD (2011) Targeting of adenosine receptors in ischemia-reperfusion injury. Expert Opin Ther Targets 15:103-118

570. McIntosh VJ, Lasley RD (2012) Adenosine receptor-mediated cardioprotection: are all 4 subtypes required or redundant? J Cardiovasc Pharmacol Ther 17:21-33

571. Stoner HB, Green HN, Threlfall CJ (1948) Bodily reactions to trauma; a possible role of nucleotides in cardiac ischaemia. Br J Exp Pathol 29:419-446

572. Kaul TK, Bain WH, Watson DA (1977) Local of infusion of ATP, creatine phosphate and methylprednisolone in acute myocardial infarction. Br Heart J 39:325

573. Reimer KA, Hill ML, Jennings RB (1981) Prolonged depletion of ATP and of the adenine nucleotide pool due to delayed resynthesis of adenine nucleotides following reversible myocardial ischemic injury in dogs. J Mol Cell Cardiol 13:229-239

574. Chaudry IH (1983) Cellular mechanisms in shock and ischemia and their correction. Am J Physiol 245:R117-R134

575. McDonagh PF, Laks H, Chaudry IH, Baue AE (1984) Improved myocardial recovery from ischemia. Treatment with low-dose adenosine triphosphate-magnesium chloride. Arch Surg 119: $1379-1384$

576. Kopf GS, Chaudry I, Condos S, Baue AE (1987) Reperfusion with ATP- $\mathrm{MgCl}_{2}$ following prolonged ischemia improves myocardial performance. J Surg Res 43:114-117

577. Ninomiya H, Otani H, Lu K, Uchiyama T, Kido M, Imamura H (2002) Complementary role of extracellular ATP and adenosine in ischemic preconditioning in the rat heart. Am J Physiol Heart Circ Physiol 282:H1810-H1820

578. Yitzhaki S, Shainberg A, Cheporko Y, Vidne BA, Sagie A, Jacobson KA, Hochhauser E (2006) Uridine-5'-triphosphate (UTP) reduces infarct size and improves rat heart function after myocardial infarct. Biochem Pharmacol 72:949-955

579. Lai ZF, Nishi K (2000) Enhancement of intracellular $\mathrm{Cl}^{-}$concentrations induced by extracellular ATP in guinea pig ventricular muscle. Jpn J Pharmacol 84:438-448

580. Sesti C, Koyama M, Broekman MJ, Marcus AJ, Levi R (2003) Ectonucleotidase in sympathetic nerve endings modulates ATP and norepinephrine exocytosis in myocardial ischemia. J Pharmacol Exp Ther 306:238-244

581. Clarke TC, Williams OJ, Martin PE, Evans WH (2009) ATP release by cardiac myocytes in a simulated ischaemia model: inhibition by a connexin mimetic and enhancement by an antiarrhythmic peptide. Eur J Pharmacol 605:9-14
582. Vassort G, Scamps F, Pucéat M, Clément O (1992) Multiple site effects of extracellular ATP in cardiac tissues. Physiology 7:212215

583. Dolmatova E, Spagnol G, Boassa D, Baum JR, Keith K, Ambrosi C, Kontaridis MI, Sorgen PL, Sosinsky GE, Duffy HS (2012) Cardiomyocyte ATP release through pannexin 1 aids in early fibroblast activation. Am J Physiol Heart Circ Physiol 303:H1208H1218

584. Vessey DA, Li L, Kelley M (2011) P2X7 receptor agonists pre- and postcondition the heart against ischemia-reperfusion injury by opening pannexin-1/P2X 7 channels. Am J Physiol Heart Circ Physiol 301:H881-H887

585. Vessey DA, Li L, Kelley M (2010) Pannexin-I/P2X7 purinergic receptor channels mediate the release of cardioprotectants induced by ischemic pre- and postconditioning. J Cardiovasc Pharmacol Ther 15:190-195

586. Kunugi S, Iwabuchi S, Matsuyama D, Okajima T, Kawahara K (2011) Negative-feedback regulation of ATP release: ATP release from cardiomyocytes is strictly regulated during ischemia. Biochem Biophys Res Commun 416:409-415

587. Cosentino S, Banfi C, Burbiel JC, Luo H, Tremoli E, Abbracchio MP (2012) Cardiomyocyte death induced by ischaemic/hypoxic stress is differentially affected by distinct purinergic $\mathrm{P} 2$ receptors. J Cell Mol Med 16:1074-1084

588. Szondy Z, Mastroberardino PG, Varadi J, Farrace MG, Nagy N, Bak I, Viti I, Wieckowski MR, Melino G, Rizzuto R, Tosaki A, Fesus L, Piacentini M (2006) Tissue transglutaminase (TG2) protects cardiomyocytes against ischemia/reperfusion injury by regulating ATP synthesis. Cell Death Differ 13:1827-1829

589. Kong F, Liu S, Xu C, Liu J, Li G, Li G, Gao Y, Lin H, Tu G, Peng H, Qiu S, Fan B, Zhu Q, Yu S, Zheng C, Liang S (2013) Electrophysiological studies of upregulated $\mathrm{P} 2 \mathrm{X}_{7}$ receptors in rat superior cervical ganglia after myocardial ischemic injury. Neurochem Int 63:230-237

590. Liu J, Li G, Peng H, Tu G, Kong F, Liu S, Gao Y, Xu H, Qiu S, Fan B, Zhu Q, Yu S, Zheng C, Wu B, Peng L, Song M, Wu Q, Li G, Liang S (2013) Sensory-sympathetic coupling in superior cervical ganglia after myocardial ischemic injury facilitates sympathoexcitatory action via $\mathrm{P} 2 \mathrm{X}_{7}$ receptor. Purinergic Signal 9: 463-479

591. Tu G, Li G, Peng H, Hu J, Liu J, Kong F, Liu S, Gao Y, Xu C, Xu X, Qiu S, Fan B, Zhu Q, Yu S, Zheng C, Wu B, Peng L, Song M, Wu Q, Liang S (2013) P2X $\mathrm{X}_{7}$ inhibition in stellate ganglia prevents the increased sympathoexcitatory reflex via sensory-sympathetic coupling induced by myocardial ischemic injury. Brain Res Bull 96:71-85

592. Yao D, Liu RG (2010) The protective effect of ATP postconditioning on myocardial ischemia reperfusion injury in rats. Cardiol 117:18

593. Liu S, Zhang C, Shi Q, Li G, Song M, Gao Y, Xu C, Xu H, Fan B, Yu S, Zheng C, Zhu Q, Wu B, Peng L, Xiong H, Wu Q, Liang S (2014) Puerarin blocks the signaling transmission mediated by $\mathrm{P}_{2} \mathrm{X}_{3}$ in $\mathrm{SG}$ and DRG to relieve myocardial ischemic damage. Brain Res Bull 101:57-63

594. Gündüz D, Kasseckert SA, Härtel FV, Aslam M, Abdallah Y, Schäfer M, Piper HM, Noll T, Schäfer C (2006) Accumulation of extracellular ATP protects against acute reperfusion injury in rat heart endothelial cells. Cardiovasc Res 71:764-773

595. Urban D, Hartel F, Gadiraju K, Piper HM, Noll T (2009) Abstract 3675: extracellular ATP protects human endothelial cells from apoptotic death during ischemia by activating a P2Y2-receptor mediated MEK/ERK- and PI3K/Akt-signaling. Circulation 120:S847-S84a

596. Wee S, Peart JN, Headrick JP (2007) P2 purinoceptor-mediated cardioprotection in ischemic-reperfused mouse heart. J Pharmacol Exp Ther 323:861-867

597. Mazzola A, Amoruso E, Beltrami E, Lecca D, Ferrario S, Cosentino S, Tremoli E, Ceruti S, Abbracchio MP (2008) Opposite effects of 
uracil and adenine nucleotides on the survival of murine cardiomyocytes. J Cell Mol Med 12:522-536

598. Hartner WC, Verma DD, Levchenko TS, Bernstein EA, Torchilin VP (2009) ATP-loaded liposomes for treatment of myocardial ischemia. Wiley Interdiscip Rev Nanomedicine Nanobiotechnol 1: 530-539

599. Millart H, Alouane L, Oszust F, Chevallier S, Robinet A (2009) Involvement of P2Y receptors in pyridoxal-5'-phosphate-induced cardiac preconditioning. Fundam Clin Pharmacol 23:279-292

600. Olivecrona GK, Gotberg M, Harnek J, Wang L, Jacobson KA, Erlinge D (2004) Coronary artery reperfusion: the ADP receptor $\mathrm{P}_{2} \mathrm{Y}_{1}$ mediates early reactive hyperemia in vivo in pigs. Purinergic Signal 1:59-65

601. Olivecrona GK, Götberg M, Harnek J, Jacobson KA, Jern S, Erlinge D (2007) The ADP receptor $\mathrm{P}_{2} \mathrm{Y}_{1}$ mediates t-PA release in pigs during cardiac ischemia. $\mathrm{J}$ Thromb Thrombolysis 24:115-122

602. Horckmans M, Robaye B, Léon-Gómez E, Lantz N, Unger P, DolGleizes F, Clouet S, Cammarata D, Schaeffer P, Savi P, Gachet C, Balligand JL, Dessy C, Boeynaems JM, Communi D (2012) P2Y, nucleotide receptor: a novel actor in post-natal cardiac development. Angiogenesis 15:349-360

603. Hochhauser E, Cohen R, Waldman M, Maksin A, Isak A, Aravot D, Jayasekara PS, Müller CE, Jacobson KA, Shainberg A (2013) P2Y receptor agonist with enhanced stability protects the heart from ischemic damage in vitro and in vivo. Purinergic Signal 9:633-642

604. Saini HK, Elimban V, Dhalla NS (2005) Attenuation of extracellular ATP response in cardiomyocytes isolated from hearts subjected to ischemia-reperfusion. Am J Physiol Heart Circ Physiol 289:H614 H623

605. Sonin D, Zheng JG, Cronin C, Sonina T, Liang B (2007) Cardiacspecific overexpression of human $\mathrm{P} 2 \mathrm{X} 4$ purinergic receptors confers a beneficial effect in left anterior descending artery ligation model of ischemic cardiomyopathy. FASEB J 21:A800

606. Sonin D, Zhou SY, Cronin C, Sonina T, Wu J, Jacobson KA, Pappano A, Liang BT (2008) Role of P2X purinergic receptors in the rescue of ischemic heart failure. Am J Physiol Heart Circ Physiol 295:H1191-H1197

607. Yang R, Liang BT (2012) Cardiac $\mathrm{P}_{2} \mathrm{X}_{4}$ receptors: targets in ischemia and heart failure? Circ Res 111:397-401

608. Zhang C, Li G, Liang S, Xu C, Zhu G, Wang Y, Zhang A, Wan F (2008) Myocardial ischemic nociceptive signaling mediated by $\mathrm{P} 2 \mathrm{X}_{3}$ receptor in rat stellate ganglion neurons. Brain Res Bull 75: $77-82$

609. Shao LJ, Liang SD, Li GL, Xu CS, Zhang CP (2007) Exploration of $\mathrm{P} 2 \mathrm{X}_{3}$ in the rat stellate ganglia after myocardial ischemia. Acta Histochem 109:330-337

610. Wang Y, Li G, Liang S, Zhang A, Xu C, Gao Y, Zhang C, Wan F (2008) Role of $\mathrm{P}_{2} \mathrm{X}_{3}$ receptor in myocardial ischemia injury and nociceptive sensory transmission. Auton Neurosci 139:30-37

611. Wang Y, Li G, Yu K, Liang S, Wan F, Xu C, Gao Y, Liu S, Lin J (2009) Expressions of $\mathrm{P} 2 \mathrm{X}_{2}$ and $\mathrm{P} 2 \mathrm{X}_{3}$ receptors in rat nodose neurons after myocardial ischemia injury. Auton Neurosci 145:7175

612. Li G, Liu S, Yang Y, Xie J, Liu J, Kong F, Tu G, Wu R, Li G, Liang S (2011) Effects of oxymatrine on sympathoexcitatory reflex induced by myocardial ischemic signaling mediated by $\mathrm{P} 2 \mathrm{X}$ receptors in rat SCG and DRG. Brain Res Bull 84:419-424

613. Björkman JA, Kirk I, van Giezen JJ (2007) Abstract 245: AZD6140 inhibits adenosine uptake into erythrocytes and enhances coronary blood flow after local ischemia or intracoronary adenosine infusion. Circulation 116:245

614. García-Villalón AL, Fernández N, Monge L, Diéguez G (2011) Coronary response to diadenosine tetraphosphate after ischemia-reperfusion in the isolated rat heart. Eur J Pharmacol 660:394-401
615. Golan O, Issan Y, Isak A, Leipziger J, Robaye B, Shainberg A (2011) Extracellular nucleotide derivatives protect cardiomyocytes against hypoxic stress. Biochem Pharmacol 81:1219-1227

616. García-Villalón AL, Fernández N, Monge L, Granado M, CarreñoTarragona G, Figueras JC, Dieguez G (2012) Coronary response to diadenosine triphosphate after ischemia-reperfusion in the isolated rat heart. Exp Biol Med (Maywood) 237:966-972

617. Wheeler DG, Joseph ME, Mahamud SD, Aurand WL, Mohler PJ, Pompili VJ, Dwyer KM, Nottle MB, Harrison SJ, d'Apice AJ, Robson SC, Cowan PJ, Gumina RJ (2012) Transgenic swine: expression of human CD39 protects against myocardial injury. J Mol Cell Cardiol 52:958-961

618. Corti F, Olson KE, Marcus AJ, Levi R (2011) The expression level of ecto-NTP diphosphohydrolase1/CD39 modulates exocytotic and ischemic release of neurotransmitters in a cellular model of sympathetic neurons. J Pharmacol Exp Ther 337:524-532

619. Cai M, Huttinger ZM, He H, Zhang W, Li F, Goodman LA, Wheeler DG, Druhan LJ, Zweier JL, Dwyer KM, He G, d'Apice AJ, Robson SC, Cowan PJ, Gumina RJ (2011) Transgenic over expression of ectonucleotide triphosphate diphosphohydrolase-1 protects against murine myocardial ischemic injury. J Mol Cell Cardiol 51:927-935

620. Schaefer U, Machida T, Broekman MJ, Marcus AJ, Levi R (2007) Targeted deletion of ectonucleoside triphosphate diphosphohydrolase 1/CD39 leads to desensitization of pre- and postsynaptic purinergic P2 receptors. J Pharmacol Exp Ther 322: $1269-1277$

621. Takahashi-Sato K, Murakawa M, Kimura J, Ito MA, Matsuoka I (2013) Loss of ectonucleotidases from the coronary vascular bed after ischemia-reperfusion in isolated rat heart. BMC Cardiovasc Disord 13:53

622. Kitakaze M, Hori M, Takashima S, Sato H, Inoue M, Kamada T (1993) Ischemic preconditioning increases adenosine release and 5'nucleotidase activity during myocardial ischemia and reperfusion in dogs. Implications for myocardial salvage. Circulation 87:208-215

623. Liu GS, Richards SC, Olsson RA, Mullane K, Walsh RS, Downey JM (1994) Evidence that the adenosine $A_{3}$ receptor may mediate the protection afforded by preconditioning in the isolated rabbit heart. Cardiovasc Res 28:1057-1061

624. Woolfson RG, Patel VC, Neild GH, Yellon DM (1995) Inhibition of nitric oxide synthesis reduces infarct size by an adenosinedependent mechanism. Circulation 91:1545-1551

625. Matsusaka T, Hasebe N, Jin YT, Kawabe J, Kikuchi K (2002) Magnesium reduces myocardial infarct size via enhancement of adenosine mechanism in rabbits. Cardiovasc Res 54:568-575

626. Yang Z, Cerniway RJ, Byford AM, Berr SS, French BA, Matherne GP (2002) Cardiac overexpression of $A_{1}$-adenosine receptor protects intact mice against myocardial infarction. Am J Physiol Heart Circ Physiol 282:H949-H955

627. Micari A, Belcik TA, Balcells EA, Powers E, Wei K, Kaul S, Lindner JR (2005) Improvement in microvascular reflow and reduction of infarct size with adenosine in patients undergoing primary coronary stenting. Am J Cardiol 96:1410-1415

628. Ross AM, Gibbons RJ, Stone GW, Kloner RA, Alexander RW (2005) A randomized, double-blinded, placebo-controlled multicenter trial of adenosine as an adjunct to reperfusion in the treatment of acute myocardial infarction (AMISTAD-II). J Am Coll Cardiol 45: $1775-1780$

629. Zhang H, Tian NL, Hu ZY, Wang F, Chen L, Zhang YJ, Chen SL (2012) Three hours continuous injection of adenosine improved left ventricular function and infarct size in patients with ST-segment elevation myocardial infarction. Chin Med J (Engl) 125:1713-1719

630. Grygier M, Araszkiewicz A, Lesiak M, Grajek S (2013) Role of adenosine as an adjunct therapy in the prevention and treatment of no-reflow phenomenon in acute myocardial infarction with ST segment elevation: review of the current data. Kardiol Pol 71:115-120 
631. Forman MB, Stone GW, Jackson EK (2006) Role of adenosine as adjunctive therapy in acute myocardial infarction. Cardiovasc Drug Rev 24:116-147

632. Wakeno M, Minamino T, Seguchi O, Okazaki H, Tsukamoto O, Okada K, Hirata A, Fujita M, Asanuma H, Kim J, Komamura K, Takashima S, Mochizuki N, Kitakaze M (2006) Long-term stimulation of adenosine A2b receptors begun after myocardial infarction prevents cardiac remodeling in rats. Circulation 114:1923-1932

633. Maas JE, Koupenova M, Ravid K, Auchampach JA (2008) Abstract 4831: the A2B adenosine receptor contributes to post-infarction heart failure. Circulation 118:S946

634. Toldo S, Zhong H, Mezzaroma E, Van Tassell BW, Kannan H, Zeng D, Belardinelli L, Voelkel NF, Abbate A (2012) GS-6201, a selective blocker of the $\mathrm{A} 2 \mathrm{~B}$ adenosine receptor, attenuates cardiac remodeling after acute myocardial infarction in the mouse. $\mathrm{J}$ Pharmacol Exp Ther 343:587-595

635. Simonis G, Wiedemann S, Joachim D, Weinbrenner C, Marquetant R, Strasser RH (2009) Stimulation of adenosine A2b receptors blocks apoptosis in the non-infarcted myocardium even when administered after the onset of infarction. Mol Cell Biochem 328:119-126

636. Ryzhov S, Zhang Q, Biaggioni I, Feoktistov I (2013) Adenosine $\mathrm{A}_{2 \mathrm{~B}}$ receptors on cardiac stem cell antigen (Sca)-1-positive stromal cells play a protective role in myocardial infarction. Am J Pathol 183:665-672

637. Tian F, Chen YD, Lu SZ, Song XT, Yuan F, Fang F, Li ZA (2008) Intracoronary adenosine improves myocardial perfusion in late reperfused myocardial infarction. Chin Med J (Engl) 121:195-199

638. Fokkema ML, Vlaar PJ, Vogelzang M, Gu YL, Kampinga MA, de Smet BJ, Jessurun GA, Anthonio RL, van den Heuvel AF, Tan ES, Zijlstra F (2009) Effect of high-dose intracoronary adenosine administration during primary percutaneous coronary intervention in acute myocardial infarction: a randomized controlled trial. Circ Cardiovasc Interv 2:323-329

639. Wang J, Chen YD, Zhi G, Xu Y, Chen L, Liu HB, Zhou X, Tian F (2012) Beneficial effect of adenosine on myocardial perfusion in patients treated with primary percutaneous coronary intervention for acute myocardial infarction. Clin Exp Pharmacol Physiol 39:247252

640. Niccoli G, Rigattieri S, De Vita MR, Valgimigli M, Corvo P, Fabbiocchi F, Romagnoli E, De Caterina AR, La Torre G, Lo Schiavo P, Tarantino F, Ferrari R, Tomai F, Olivares P, Cosentino N, D'Amario D, Leone AM, Porto I, Burzotta F, Trani C, Crea F (2013) Open-label, randomized, placebo-controlled evaluation of intracoronary adenosine or nitroprusside after thrombus aspiration during primary percutaneous coronary intervention for the prevention of microvascular obstruction in acute myocardial infarction: the REOPEN-AMI study (Intracoronary Nitroprusside Versus Adenosine in Acute Myocardial Infarction). JACC Cardiovasc Interv 6:580-589

641. Saini HK, Shao Q, Musat S, Takeda N, Tappia PS, Dhalla NS (2005) Imidapril treatment improves the attenuated inotropic and intracellular calcium responses to ATP in heart failure due to myocardial infarction. Br $\mathrm{J}$ Pharmacol 144: 202-211

642. Wihlborg AK, Balogh J, Wang L, Borna C, Dou Y, Joshi BV, Lazarowski E, Jacobson KA, Arner A, Erlinge D (2006) Positive inotropic effects by uridine triphosphate (UTP) and uridine diphosphate (UDP) via $\mathrm{P} 2 \mathrm{Y}_{2}$ and $\mathrm{P} 2 \mathrm{Y}_{6}$ receptors on cardiomyocytes and release of UTP in man during myocardial infarction. Circ Res 98: 970-976

643. Gao Z, Xing J, Sinoway L, Li J (2007) P2X receptor-mediated muscle pressor reflex in myocardial infarction. Am J Physiol Heart Circ Physiol 292:H939-H945

644. Amisten S, Melander O, Wihlborg AK, Berglund G, Erlinge D (2007) Increased risk of acute myocardial infarction and elevated levels of C-reactive protein in carriers of the Thr-87 variant of the ATP receptor $\mathrm{P}_{2} \mathrm{Y}_{11}$. Eur Heart J 28:13-18

645. Tokuyama T, Sakuma T, Motoda C, Kawase T, Takeda R, Mito S, Tamekiyo H, Otsuka M, Okimoto T, Toyofuku M, Hirao H, Muraoka Y, Ueda H, Masaoka Y, Hayashi Y (2009) Intravenous administration of adenosine triphosphate disodium during primary percutaneous coronary intervention attenuates the transient rapid improvement of myocardial wall motion, not myocardial stunning, shortly after recanalization in acute anterior myocardial infarction. J Cardiol 54:289-296

646. Sakuma T, Motoda C, Tokuyama T, Oka T, Tamekiyo H, Okada T, Otsuka M, Okimoto T, Toyofuku M, Hirao H, Muraoka Y, Ueda H, Masaoka Y, Hayashi Y (2010) Exogenous adenosine triphosphate disodium administration during primary percutaneous coronary intervention reduces no-reflow and preserves left ventricular function in patients with acute anterior myocardial infarction: a study using myocardial contrast echocardiography. Int J Cardiol 140:200-209

647. Wang ZX, Nakayama T, Sato N, Izumi Y, Kasamaki Y, Ohta M, Soma M, Aoi N, Matsumoto K, Ozawa Y, Ma YT, Doba N, Hinohara S (2009) Association of the purinergic receptor P2Y, Gprotein coupled, 2 (P2RY2) gene with myocardial infarction in Japanese men. Circ J 73:2322-2329

648. Pelzmann B, Zorn-Pauly K, Hallström S, Mächler H, Jakubowski A, Lang P, Koidl B (2010) Effects of thienopyridines and thienopyrimidinones on L-type calcium current in isolated cardiomyocytes. Naunyn Schmiedeberg's Arch Pharmacol 382: $433-440$

649. Marina N, Tang F, Figueiredo M, Mastitskaya S, Kasimov V, Mohamed-Ali V, Roloff E, Teschemacher AG, Gourine AV, Kasparov S (2013) Purinergic signalling in the rostral ventrolateral medulla controls sympathetic drive and contributes to the progression of heart failure following myocardial infarction in rats. Basic Res Cardiol 108:317

650. Yeung PK (2013) ATP metabolism as biomarker target for cardiovascular protection. Cardiol Pharmacol 2:e118

651. Somló ERN (1955) Adenosine triphosphate in paroxysmal tachycardia. Lancet 265:1125

652. Komor K, Garas ZS (1955) Adenosine triphosphate in paroxysmal tachycardia. Lancet 266:93-94

653. Latour H, Puech P, Grolleau R, Sat M, Balmes P (1968) L' utilisation de l'adénosine-5'-triphosphate dans le diagnostic et traitement des tachycardies paroxystiques nodales. Arch Mal Coeur Vaiss 61:293

654. Motté G, Waynberger M, Lebards A, Bouvrain Y (1972) Adenosine triphosphate in paroxysmal tachycardia. Diagnostic and therapeutic volue. Nouv Press Med 1:3057-3061

655. Chimienti M, Salerno JA, Tavazzi L, Ray M (1975) Utilita dell' acido adenosin trifosforico (ATP) nella terapia delle tachicardie reciprocanti. ANMCO, Rome, 331

656. Greco R, Musto B, Arienzo V, Alborino A, Garofalo S, Marsico F (1982) Treatment of paroxysmal supraventricular tachycardia in infancy with digitalis, adenosine-5'-triphosphate, and verapamil: a comparative study. Circulation 66:504-508

657. Belhassen B, Pelleg A, Shoshani D, Geva B, Laniado S (1983) Electrophysiologic effects of adenosine-5'-triphosphate on atrioventricular reentrant tachycardia. Circulation 68:827-833

658. Saito D, Ueeda M, Abe Y, Tani H, Nakatsu T, Yoshida H, Haraoka S, Nagashima H (1986) Treatment of paroxysmal supraventricular tachycardia with intravenous injection of adenosine triphosphate. $\mathrm{Br}$ Heart J 55:291-294

659. Stoner HB, Green HN (1945) Experimental limb ischaemia in man with especial reference to the role of adenosine triphosphate. Clin Sci 5:159-175

660. Hollander PB, Webb LEYD (1957) Effects of adenine nucleotides on the contractility and membrane potentials of rat atrium. Circ Res $5: 349-353$ 
661. DiMarco JP, Sellers TD, Berne RM, West GA, Belardinelli L (1983) Adenosine: electrophysiologic effects and therapeutic use for terminating paroxysmal supraventricular tachycardia. Circulation 68 : $1254-1263$

662. Watt AH, Bernard MS, Webster J, Passani SL, Stephens MR, Routledge PA (1986) Intravenous adenosine in the treatment of supraventricular tachycardia: a dose-ranging study and interaction with dipyridamole. Br J Clin Pharmacol 21:227-230

663. Rossi AF, Burton DA (1989) Adenosine in altering short- and longterm treatment of supraventricular tachycardia in infants. Am J Cardiol 64:685-686

664. Till J, Shinebourne EA, Rigby ML, Clarke B, Ward DE, Rowland E (1989) Efficacy and safety of adenosine in the treatment of supraventricular tachycardia in infants and children. Br Heart J 62:204211

665. Litman RS, Keon TP, Campbell FW (1991) Termination of supraventricular tachycardia with adenosine in a healthy child undergoing anesthesia. Anesth Analg 73:665-667

666. Domanovits H, Laske H, Stark G, Sterz F, Schmidinger H, Schreiber W, Mullner M, Laggner AN (1994) Adenosine for the management of patients with tachycardias - a new protocol. Eur Heart J 15:589-593

667. Lerman BB, Wesley RC, Belardinelli L (1989) Electrophysiologic effects of dipyridamole on atrioventricular nodal conduction and supraventricular tachycardia. Role of endogenous adenosine. Circulation 80:1536-1543

668. Cabalag MS, Taylor DM, Knott JC, Buntine P, Smit D, Meyer A (2010) Recent caffeine ingestion reduces adenosine efficacy in the treatment of paroxysmal supraventricular tachycardia. Acad Emerg Med 17:44-49

669. Karydes HC, Bryant SM (2010) Adenosine and caffeine-induced paroxysmal supraventricular tachycardia. Acad Emerg Med 17:570

670. Dhalla AK, Wong MY, Wang WQ, Biaggioni I, Belardinelli L (2006) Tachycardia caused by $\mathrm{A}_{2 \mathrm{~A}}$ adenosine receptor agonists is mediated by direct sympathoexcitation in awake rats. J Pharmacol Exp Ther 316:695-702

671. Lim SH, Anantharaman V, Teo WS, Chan YH (2009) Slow infusion of calcium channel blockers compared with intravenous adenosine in the emergency treatment of supraventricular tachycardia. Resuscitation 80:523-528

672. Delaney B, Loy J, Kelly AM (2011) The relative efficacy of adenosine versus verapamil for the treatment of stable paroxysmal supraventricular tachycardia in adults: a meta-analysis. Eur J Emerg Med 18:148-152

673. Belhassen B, Glick A, Laniado S (1988) Comparative clinical and electrophysiologic effects of adenosine triphosphate and verapamil on paroxysmal reciprocating junctional tachycardia. Circulation 77 : 795-805

674. Moro C, Lorio N, Nuñez A, Martinez J, Novo L, Aguilera M, Madrid AH (1989) Dose related efficacy of adenosine triphosphate in spontaneous supraventricular tachyarrhythmias. Int J Cardiol 25: 207-212

675. Rankin AC, Oldroyd KG, Chong E, Dow JW, Rae AP, Cobbe SM (1990) Adenosine or adenosine triphosphate for supraventricular tachycardias? Comparative double-blind randomized study in patients with spontaneous or inducible arrhythmias. Am Heart J 119: 316-323

676. Hina K, Kusachi S, Takaishi A, Yamasaki S, Sakuragi S, Murakami T, Kita T (1996) Effects of adenosine triphosphate on wide QRS tachycardia. Analysis in 18 patients. Jpn Heart J 37:463-470

677. Okumura Y, Watanabe I, Oshikawa N, Masaki R, Okubo K, Hashimoto K, Kofune T, Yamada T, Wakita R, Takagi Y, Saito S, Ozawa Y, Kanmatsuse K (2003) Noninvasive diagnosis of dual AV nodal physiology in patients with AV nodal reentrant tachycardia by adenosine triphosphate test. Jpn Heart J 44:655-666
678. Belhassen B, Fish R, Glikson M, Glick A, Eldar M, Laniado S, Viskin S (1998) Noninvasive diagnosis of dual AV node physiology in patients with AV nodal reentrant tachycardia by administration of adenosine-5'-triphosphate during sinus rhythm. Circulation 98:4753

679. Belhassen B, Fish R, Eldar M, Glick A, Glikson M, Viskin S (2000) Simplified "ATP test" for noninvasive diagnosis of dual AV nodal physiology and assessment of results of slow pathway ablation in patients with AV nodal reentrant tachycardia. J Cardiovasc Electrophysiol 11:255-261

680. Camm AJ, Garratt CJ (1991) Adenosine and supraventricular tachycardia. N Engl J Med 325:1621-1629

681. Takikawa R, Kurachi Y, Mashima S, Sugimoto T (1990) Adenosine-5'-triphosphate-induced sinus tachycardia mediated by prostaglandin synthesis via phospholipase $\mathrm{C}$ in the rabbit heart. Pflugers Arch 417:13-20

682. Dipalma JR (1991) Adenosine for paroxysmal supraventricular tachycardia. Am Fam Physician 44:929-931

683. Rankin AC, Brooks R, Ruskin JN, McGovern BA (1992) Adenosine and the treatment of supraventricular tachycardia. Am J Med 92:655-664

684. Belhassen B, Viskin S (1993) What is the drug of choice for the acute termination of paroxysmal supraventricular tachycardia: verapamil, adenosine triphosphate, or adenosine? Pacing Clin Electrophysiol 16:1735-1741

685. Dixon J, Foster K, Wyllie J, Wren C (2005) Guidelines and adenosine dosing in supraventricular tachycardia. Arch Dis Child 90: $1190-1191$

686. Riccardi A, Arboscello E, Ghinatti M, Minuto P, Lerza R (2008) Adenosine in the treatment of supraventricular tachycardia: 5 years of experience (2002-2006). Am J Emerg Med 26:879-882

687. Connor S (2009) Treatment of supraventricular tachycardia with adenosine in children: size does matter. Emerg Med J 26:911-912

688. Schuller JL, Varosy PD, Nguyen DT (2013) Wide complex tachycardia and adenosine. JAMA Intern Med 173:1644-1646

689. Laorden ML, Hernandez J, Ribeiro JA (1986) The effects of adenosine, ATP and ADP on ventricular automaticity induced by a local injury in the isolated right ventricle of the rat. Arch Int Pharmacodyn Ther 279:258-267

690. Overholt ED, Rheuban KS, Gutgesell HP, Lerman BB, DiMarco JP (1988) Usefulness of adenosine for arrhythmias in infants and children. Am J Cardiol 61:336-340

691. Rossi AF, Steinberg LG, Kipel G, Golinko RJ, Griepp RB (1992) Use of adenosine in the management of perioperative arrhythmias in the pediatric cardiac intensive care unit. Crit Care Med 20:1107-1111

692. Wilbur SL, Marchlinski FE (1997) Adenosine as an antiarrhythmic agent. Am J Cardiol 79:30-37

693. Pelleg A, Pennock RS, Kutalek SP (2002) Proarrhythmic effects of adenosine: one decade of clinical data. Am J Ther 9:141-147

694. Mallet ML (2004) Proarrhythmic effects of adenosine: a review of the literature. Emerg Med J 21:408-410

695. Huang MH, Wolf SG, Armour JA (1994) Ventricular arrhythmias induced by chemically modified intrinsic cardiac neurones. Cardiovasc Res 28:636-642

696. Zhang H, Zhong H, Everett TH, Wilson E, Chang R, Zeng D, Belardinelli L, Olgin JE (2014) Blockade of $\mathrm{A}_{2 \mathrm{~B}}$ adenosine receptor reduces left ventricular dysfunction and ventricular arrhythmias 1 week after myocardial infarction in the rat model. Heart Rhythm 11:101-109

697. da Silva V, Gnecchi-Ruscone T, Bellina V, Oliveira M, Maciel L, de Carvalho AC, Salgado HC, Bergamaschi CM, Tobaldini E, Porta A, Montano N (2012) Acute adenosine increases cardiac vagal and reduces sympathetic efferent nerve activities in rats. Exp Physiol 97:719-729

698. Mazgalev T, Dreifus LS, Michelson EL, Pelleg A (1987) Adenosine-vagus interaction at the cellular level. Prog Clin Biol Res 230:195-219 
699. Iwasaki YK, Nishida K, Kato T, Nattel S (2011) Atrial fibrillation pathophysiology: implications for management. Circulation 124: 2264-2274

700. Nattel S (2012) Adenosine and atrial arrhythmias: exploring electrophysiological mechanisms in vivo. Pacing Clin Electrophysiol 35:553-555

701. Scamps F, Vassort G (1990) Mechanism of extracellular ATPinduced depolarization in rat isolated ventricular cardiomyocytes. Pflugers Arch 417:309-316

702. Song Y, Belardinelli L (1994) ATP promotes development of afterdepolarizations and triggered activity in cardiac myocytes. Am J Physiol 267:H2005-H2011

703. Zhang BX, Desnoyer RW, Bond M (2001) Extracellular adenosine triphosphate triggers arrhythmias and elemental redistribution in electrically stimulated rat cardiac myocytes. Microsc Microanal 7: $48-55$

704. Verrecchia F, Duthe F, Duval S, Duchatelle I, Sarrouilhe D, Herve JC (1999) ATP counteracts the rundown of gap junctional channels of rat ventricular myocytes by promoting protein phosphorylation. J Physiol 516:447-459

705. Waghabi MC, Coutinho-Silva R, Feige J-J, Higuchi ML, Becker DL, Burnstock G, Araújo-Jorge TC (2009) Gap junction reduction in cardiomyocytes following transforming growth factor- $\beta$ treatment and Trypanosoma cruzi infection. Mem Inst Oswaldo Cruz 104:1083-1090

706. Gurung IS, Kalin A, Grace AA, Huang CL (2009) Activation of purinergic receptors by ATP induces ventricular tachycardia by membrane depolarization and modifications of $\mathrm{Ca}^{2+}$ homeostasis. J Mol Cell Cardiol 47:622-633

707. Cummings M, Raza J, Movahed A (2006) Atrial fibrillation during adenosine pharmacologic stress testing. J Nucl Cardiol 13:576-581

708. Kaltman JR, Tanel RE, Shah MJ, Vetter VL, Rhodes LA (2006) Induction of atrial fibrillation after the routine use of adenosine. Pediatr Emerg Care 22:113-115

709. Llach A, Molina CE, Prat-Vidal C, Fernandes J, Casadó V, Ciruela F, Lluís C, Franco R, Cinca J, Hove-Madsen L (2011) Abnormal calcium handling in atrial fibrillation is linked to up-regulation of adenosine $\mathrm{A}_{2 \mathrm{~A}}$ receptors. Eur Heart J 32:721-729

710. Nee L, Franceschi F, Resseguier N, Gravier G, Giorgi R, Gariboldi V, Collart F, Michelet P, Deharo JC, Guieu R, Kerbaul F (2013) High endogenous adenosine plasma concentration is associated with atrial fibrillation during cardiac surgery with cardiopulmonary bypass. Int J Cardiol 165:201-204

711. Jakobsen Ø, Naesheim T, Aas KN, Sørlie D, Steensrud T (2013) Adenosine instead of supranormal potassium in cardioplegia: it is safe, efficient, and reduces the incidence of postoperative atrial fibrillation. A randomized clinical trial. J Thorac Cardiovasc Surg $145: 812-818$

712. Jiang CY, Jiang RH, Matsuo S, Liu Q, Fan YQ, Zhang ZW, Fu GS (2009) Early detection of pulmonary vein reconnection after isolation in patients with paroxysmal atrial fibrillation: a comparison of ATP-induction and reassessment at 30 minutes postisolation. J Cardiovasc Electrophysiol 20:1382-1387

713. Jiang CY, Jiang RH, Matsuo S, Fu GS (2010) ATP revealed extra pulmonary vein source of atrial fibrillation after circumferential pulmonary vein isolation. Pacing Clin Electrophysiol 33:248-251

714. Cheung JW, Lin FS, Ip JE, Bender SR, Siddiqi FK, Liu CF, Thomas G, Markowitz SM, Lerman BB (2013) Adenosineinduced pulmonary vein ectopy as a predictor of recurrent atrial fibrillation after pulmonary vein isolation. Circ Arrhythm Electrophysiol 6:1066-1073

715. McLellan AJ, Kumar S, Smith C, Morton JB, Kalman JM, Kistler PM (2013) The role of adenosine following pulmonary vein isolation in patients undergoing catheter ablation for atrial fibrillation: a systematic review. J Cardiovasc Electrophysiol 24:742-751
716. Miyazaki S, Kobori A, Kuwahara T, Takahashi A (2010) Adenosine triphosphate exposes dormant superior vena cava conduction responsible for recurrent atrial fibrillation. J Cardiovasc Electrophysiol 21:464-465

717. Miyazaki S, Kobori A, Hocini M, Shah AJ, Komatsu Y, Taniguchi H, Kusa S, Uchiyama T, Nakamura H, Hachiya H, Isobe M, Hirao K, Haissaguerre M, Takahashi A, Iesaka Y (2013) Clinical utility of adenosine-infusion test at a repeat atrial fibrillation ablation procedure. Heart Rhythm 10:629-635

718. Miyazaki S, Taniguchi H, Komatsu Y, Uchiyama T, Kusa S, Nakamura H, Hachiya H, Hirao K, Iesaka Y (2013) Clinical impact of adenosine triphosphate injection on arrhythmogenic superior vena cava in the context of atrial fibrillation ablation. Circ Arrhythm Electrophysiol 6:497-503

719. Böhm M, Mende U, Schmitz W, Scholz H (1986) Does an impaired adenosine mediated feedback control play a role in the development of hereditary dystrophic cardiomyopathy? Cardiovasc Res 20:568-573

720. Del Ry S, Cabiati M, Lionetti V, Aquaro GD, Martino A, Mattii L, Morales MA (2012) Pacing-induced regional differences in adenosine receptors mRNA expression in a swine model of dilated cardiomyopathy. PLoS One 7:e47011

721. Berry DA, Barden JA, Balcar VJ, Keogh A, dos Remedios CG (1999) Increase in expression of $P_{2 X 1}$ receptors in the atria of patients suffering from dilated cardiomyopathy. Electrophoresis 20:2059-2064

722. Yang A, Sonin D, Jones L, Barry WH, Liang BT (2004) A beneficial role of cardiac $\mathrm{P}_{2} \mathrm{X}_{4}$ receptors in heart failure: rescue of the calsequestrin overexpression model of cardiomyopathy. Am J Physiol Heart Circ Physiol 287:H1096-H1103

723. Shen JB, Cronin C, Sonin D, Joshi BV, Gongora NM, Harrison D, Jacobson KA, Liang BT (2007) P2X purinergic receptor-mediated ionic current in cardiac myocytes of calsequestrin model of cardiomyopathy: implications for the treatment of heart failure. Am J Physiol Heart Circ Physiol 292:H1077-H1084

724. Brignole M, Donateo P, Menozzi C (2003) The diagnostic value of ATP testing in patients with unexplained syncope. Europace 5:425428

725. Perennes A, Fatemi M, Borel ML, Lebras Y, L'Her C, Blanc JJ (2006) Epidemiology, clinical features, and follow-up of patients with syncope and a positive adenosine triphosphate test result. J Am Coll Cardiol 47:594-597

726. Pérez-Paredes M, Picó Aracil F, Sánchez Villanueva JG, Expósito Oróñez E, Gonzálvez Ortega M, González Caballero E, Iñigo García L, Espinosa García MD, Florenciano Sánchez R, Ruipérez Abizanda JA (1998) Role of adenosine triphosphate (ATP) in headup tilt-induced syncope. Rev Esp Cardiol 51:129-135

727. Mittal S, Stein KM, Markowitz SM, Slotwiner DJ, Rohatgi S, Lerman BB (1999) Induction of neurally mediated syncope with adenosine. Circulation 99:1318-1324

728. Carrega L, Saadjian AY, Mercier L, Zouher I, Bergé-Lefranc JL, Gerolami V, Giaime P, Sbragia P, Paganelli F, Fenouillet E, Levy S, Guieu RP (2007) Increased expression of adenosine A2A receptors in patients with spontaneous and head-up-tilt-induced syncope. Heart Rhythm 4:870-876

729. Deharo JC, Jego C, Lanteaume A, Djiane P (2006) An implantable loop recorder study of highly symptomatic vasovagal patients: the heart rhythm observed during a spontaneous syncope is identical to the recurrent syncope but not correlated with the head-up tilt test or adenosine triphosphate test. J Am Coll Cardiol 47:587-593

730. Liao Y, Takashima S, Asano Y, Asakura M, Ogai A, Shintani Y, Minamino T, Asanuma H, Sanada S, Kim J, Ogita H, Tomoike H, Hori M, Kitakaze M (2003) Activation of adenosine $A_{1}$ receptor attenuates cardiac hypertrophy and prevents heart failure in murine left ventricular pressure-overload model. Circ Res 93:759-766

731. Gan XT, Rajapurohitam V, Haist JV, Chidiac P, Cook MA, Karmazyn M (2005) Inhibition of phenylephrine-induced 
cardiomyocyte hypertrophy by activation of multiple adenosine receptor subtypes. J Pharmacol Exp Ther 312:27-34

732. Pang T, Gan XT, Freeman DJ, Cook MA, Karmazyn M (2010) Compensatory upregulation of the adenosine system following phenylephrine-induced hypertrophy in cultured rat ventricular myocytes. Am J Physiol Heart Circ Physiol 298:H545-H553

733. Gan TX, Taniai S, Zhao G, Huang C, Velenosi TJ, Urquhart BL, Karmazyn M (2013) Phenylephrine-induced cardiomyocyte hypertrophy and calcification are regulated by CD73-TNAP interaction and inhibited by adenosine receptor activation. FASEB J 27:386

734. Zheng JS, Boluyt MO, O'Neill L, Crow MT, Lakatta EG (1994) Extracellular ATP induces immediate-early gene expression but not cellular hypertrophy in neonatal cardiac myocytes. Circ Res 74: 1034-1041

735. Zheng JS, Boluyt MO, Long X, O'Neill L, Lakatta EG, Crow MT (1996) Extracellular ATP inhibits adrenergic agonist-induced hypertrophy of neonatal cardiac myocytes. Circ Res 78:525-535

736. Pham TM, Morris JB, Arthur JF, Post GR, Brown JH, Woodcock EA (2003) UTP but not ATP causes hypertrophic growth in neonatal rat cardiomyocytes. J Mol Cell Cardiol 35:287-292

737. Horckmans M, Léon-Gómez E, Robaye B, Balligand JL, Boeynaems JM, Dessy C, Communi D (2012) Gene deletion of $\mathrm{P}_{2} \mathrm{Y}_{4}$ receptor lowers exercise capacity and reduces myocardial hypertrophy with swimming exercise. Am J Physiol Heart Circ Physiol 303:H835-H843

738. Benedini G, Cuccia C, Bolognesi R, Affatato A, Gallo G, Renaldini E, Visioli O (1984) Value of purinic compounds in assessing sinus node dysfunction in man: a new diagnostic method. Eur Heart J 5: 394-403

739. Yoshimura H (1986) Diagnosis of sick sinus syndrome by rapid intravenous injection of adenosine triphosphate. Yokohama Igaku $38: 223-230$

740. Harada T (1991) Effect of adenosine triphosphate on sino- atrioventricular node and changes in plasma levels of nucleic acid-related substances. St Marianna Med J 19:117-119

741. Resh W, Feuer J, Wesley RC Jr (1992) Intravenous adenosine: a noninvasive diagnostic test for sick sinus syndrome. Pacing Clin Electrophysiol 15:2068-2073

742. Saito D, Yamanari H, Matsubara K, Maekawa K, Mizuo K, Sato T, Kobayashi H, Morita H, Haraoka S (1993) Intravenous injection of adenosine triphosphate for assessing sinus node dysfunction in patients with sick sinus syndrome. Arzneimittelforschung 43: 1313-1316

743. Brignole M, Menozzi C, Alboni P, Oddone D, Gianfranchi L, Gaggioli G, Lolli G, Paparella N (1994) The effect of exogenous adenosine in patients with neurally-mediated syncope and sick sinus syndrome. Pacing Clin Electrophysiol 17:2211-2216

744. Burnett D, Abi-Samra F, Vacek JL (1999) Use of intravenous adenosine as a noninvasive diagnostic test for sick sinus syndrome. Am Heart J 137:435-438

745. Fragakis N, Iliadis I, Sidopoulos E, Lambrou A, Tsaritsaniotis E, Katsaris G (2007) The value of adenosine test in the diagnosis of sick sinus syndrome: susceptibility of sinus and atrioventricular node to adenosine in patients with sick sinus syndrome and unexplained syncope. Europace 9:559-562

746. Miyagawa M, Kumano S, Sekiya M, Watanabe K, Akutzu H, Imachi T, Tanada S, Hamamoto K (1995) Thallium-201 myocardial tomography with intravenous infusion of adenosine triphosphate in diagnosis of coronary artery disease. J Am Coll Cardiol 26:11961201

747. Cuocolo A, Sullo P, Pace L, Nappi A, Gisonni P, Nicolai E, Trimarco B, Salvatore M (1997) Adenosine coronary vasodilation in coronary artery disease: technetium- $99 \mathrm{~m}$ tetrofosmin myocardial tomography versus echocardiography. J Nucl Med 38:1089-1094

748. Amanullah AM, Berman DS, Hachamovitch R, Kiat H, Kang X, Friedman JD (1997) Identification of severe or extensive coronary artery disease in women by adenosine technetium- $99 \mathrm{~m}$ sestamibi SPECT. Am J Cardiol 80:132-137

749. He Q, Yao Z, Yu X, Qu W, Sun F, Ji F, Xu F, Qian Y (2002) Evaluation of $(99 \mathrm{~m})$ Tc-MIBI myocardial perfusion imaging with intravenous infusion of adenosine triphosphate in diagnosis of coronary artery disease. Chin Med J (Engl) 115:1603-1607

750. Mamede M, Tadamura E, Hosokawa R, Ohba M, Kubo S, Yamamuro M, Kimura T, Kita T, Saga T, Togashi K (2005) Comparison of myocardial blood flow induced by adenosine triphosphate and dipyridamole in patients with coronary artery disease. Ann Nucl Med 19:711-717

751. Iskandrian AE, Bateman TM, Belardinelli L, Blackburn B, Cerqueira MD, Hendel RC, Lieu H, Mahmarian JJ, Olmsted A, Underwood SR, Vitola J, Wang W (2007) Adenosine versus regadenoson comparative evaluation in myocardial perfusion imaging: results of the ADVANCE phase 3 multicenter international trial. J Nucl Cardiol 14:645-658

752. Kido T, Kurata A, Higashino H, Inoue Y, Kanza RE, Okayama H, Higaki J, Murase K, Mochizuki T (2008) Quantification of regional myocardial blood flow using first-pass multidetector-row computed tomography and adenosine triphosphate in coronary artery disease. Circ J 72:1086-1091

753. Karamitsos TD, Arnold JR, Pegg TJ, Cheng AS, van Gaal WJ, Francis JM, Banning AP, Neubauer S, Selvanayagam JB (2009) Tolerance and safety of adenosine stress perfusion cardiovascular magnetic resonance imaging in patients with severe coronary artery disease. Int J Cardiovasc Imaging 25:277-283

754. Zoghbi GJ, Iskandrian AE (2012) Selective adenosine agonists and myocardial perfusion imaging. J Nucl Cardiol 19:126-141

755. Korosoglou G, Katus HA (2013) Myocardial perfusion reserve index during adenosine stress magnetic resonance for the detection of coronary artery disease - ready for prime time? J Thorac Dis 5: 362-363

756. Macwar RR, Williams BA, Shirani J (2013) Prognostic value of adenosine cardiac magnetic resonance imaging in patients presenting with chest pain. Am J Cardiol 112:46-50

757. Pereira E, Bettencourt N, Ferreira N, Schuster A, Chiribiri A, Primo J, Teixeira M, Simoes L, Leite-Moreira A, Silva-Cardoso J, Gama V, Nagel E (2013) Incremental value of adenosine stress cardiac magnetic resonance in coronary artery disease detection. Int $\mathrm{J}$ Cardiol 168:4160-4167

758. Sonoda S, Takeuchi M, Nakashima Y, Kuroiwa A (1998) Safety and optimal dose of intracoronary adenosine 5 '-triphosphate for the measurement of coronary flow reserve. Am Heart J 135:621-627

759. El-Omar MM, Islam N, Broekman MJ, Drosopoulos JH, Roa DC, Lorin JD, Sedlis SP, Olson KE, Pulte ED, Marcus AJ (2005) The ratio of ADP- to ATP-ectonucleotidase activity is reduced in patients with coronary artery disease. Thromb Res 116:199-206

760. Fugate SE, Cudd LA (2006) Cangrelor for treatment of coronary thrombosis. Ann Pharmacother 40:925-930

761. Jernberg T, Payne CD, Winters KJ, Darstein C, Brandt JT, Jakubowski JA, Naganuma H, Siegbahn A, Wallentin L (2006) Prasugrel achieves greater inhibition of platelet aggregation and a lower rate of non-responders compared with clopidogrel in aspirintreated patients with stable coronary artery disease. Eur Heart J 27: 1166-1173

762. Zeidner JF, Frishman WH, Lerner RG (2008) Investigational antiplatelet drugs for the treatment and prevention of coronary artery disease. Cardiol Rev 16:250-259

763. Jauregui ME, Umejei OU, Cruz MP (2009) Prasugrel (effient), as adenosine diphosphate receptor antagonist for the treatment of acute coronary syndrome. Pharm Ther 34:417-419

764. Wallentin L (2009) $\mathrm{P}_{2} \mathrm{Y}_{12}$ inhibitors: differences in properties and mechanisms of action and potential consequences for clinical use. Eur Heart J 30:1964-1977 
765. Chandrasekar S, Loomba R, Shah P, Arora R (2013) Ideal antiplatelet therapy for coronary artery disease: focus on adenosine diphosphate receptor inhibitors. Am J Ther 20:337-343

766. Harada K, Matsumoto Y, Umemura K (2011) Adenosine diphosphate receptor $\mathrm{P} 2 \mathrm{Y}_{12}$-mediated migration of host smooth musclelike cells and leukocytes in the development of transplant arteriosclerosis. Transplantation 92:148-154

767. Zoheir N, Abd Elhamid S, Abulata N, El Sobky M, Khafagy D, Mostafa A (2013) P2 $\mathrm{Y}_{12}$ receptor gene polymorphism and antiplatelet effect of clopidogrel in patients with coronary artery disease after coronary stenting. Blood Coagul Fibrinolysis 24:525-531

768. Morici N, Moja L, Rosato V, Oreglia JA, Sacco A, De Marco F, Bruschi G, Klugmann S, La Vecchia C, Savonitto S (2013) Time from adenosine di-phosphate receptor antagonist discontinuation to coronary bypass surgery in patients with acute coronary syndrome: meta-analysis and meta-regression. Int J Cardiol 168:1955-1964

769. Petricevic M, Biocina B, Svetina L, Milicic D (2013) Adenosine diphosphate receptor antagonist discontinuation management prior to coronary artery surgery. Int J Cardiol 168:1678-1679

770. Kern MJ, Deligonul U, Tatineni S, Serota H, Aguirre F, Hilton TC (1991) Intravenous adenosine: continuous infusion and low dose bolus administration for determination of coronary vasodilator reserve in patients with and without coronary artery disease. J Am Coll Cardiol 18:718-729

771. Voigtländer T, Schmermund A, Bramlage P, Elsässer A, Magedanz A, Kauczor HU, Mohrs OK (2011) The adverse events and hemodynamic effects of adenosine-based cardiac MRI. Korean J Radiol $12: 424-430$

772. Feldman MD, Ayers CR, Lehman MR, Taylor HE, Gordon VL, Sabia PJ, Ras D, Skalak TC, Linden J (1992) Improved detection of ischemia-induced increases in coronary sinus adenosine in patients with coronary artery disease. Clin Chem 38:256-262

773. Tarkin JM, Nijjer S, Sen S, Petraco R, Echavarria-Pinto M, Asress $\mathrm{KN}$, Lockie T, Khawaja MZ, Mayet J, Hughes AD, Malik IS, Mikhail GW, Baker CS, Foale RA, Redwood S, Francis DP, Escaned J, Davies JE (2013) Hemodynamic response to intravenous adenosine and its effect on fractional flow reserve assessment: results of the Adenosine for the Functional Evaluation of Coronary Stenosis Severity (AFFECTS) study. Circ Cardiovasc Interv 6:654-661

774. Tang R, Ma C, Dong J, Liu X, Liu X (2006) Does adenosine deaminase play a key role in coronary artery disease. Med Hypotheses 67:371-374

775. Sadigh B, Quintana M, Sylvén C, Berglund M, Brodin LA (2009) The ischemic preconditioning effect of adenosine in patients with ischemic heart disease. Cardiovasc Ultrasound 7:52

776. López-Palop R, Carrillo P, Frutos A, Cordero A, Agudo P, Mashlab S, Bertomeu-Martínez V (2013) Comparison of effectiveness of high-dose intracoronary adenosine versus intravenous administration on the assessment of fractional flow reserve in patients with coronary heart disease. Am J Cardiol 111:1277-1283

777. Ellenbogen KA, Thames MD, DiMarco JP, Sheehan H, Lerman BB (1990) Electrophysiological effects of adenosine in the transplanted human heart. Evidence of supersensitivity. Circulation 81:821-828

778. Soncul H, Gökgöz L, Karasu C, Ayrancioglu K, Ersöz A, Altan M, Yener A (1992) Comparison of potassium and adenosine cardioplegia with or without verapamil in the isolated guinea pig heart. Gen Pharmacol 23:89-93

779. Jakobsen O, Steensrud T, Ytrehus K, Sorlie DG (2010) Adenosine protects against hypoxic injury at hypothermia in guinea pig papillary muscles. Scand Cardiovasc J 44:183-190

780. Lim SH, Lee S, Noda K, Kawamura T, Tanaka Y, Shigemura N, Nakao A, Toyoda Y (2013) Adenosine injection prior to cardioplegia enhances preservation of senescent hearts in rat heterotopic heart transplantation. Eur J Cardiothorac Surg 43:12021208
781. Thelin S, Hultman J, Jakobson S, Juhlin C, Hansson HE, Ronquist G (1987) Functional effects of phosphoenolpyruvate and ATP on pig hearts in cardioplegia and during reperfusion. An in vivo study with cardiopulmonary bypass. Eur Surg Res 19:348-356

782. Bolling SF, Bies LE, Bove EL (1990) Effect of ATP synthesis promoters on postischemic myocardial recovery. J Surg Res 49: 205-211

783. Suviolahti E, Petrosyan A, Mirocha J, Ge S, Karasyov A, Thomas D, Galera O, Lim W, Jimenez AM, Czer LS, Chaux G, De Leon J, Pao A, Jordan SC, Toyoda M (2012) Significant reduction of ATP production in PHA-activated CD4+ cells in 1-day-old blood from transplant patients. Transplantation 94:1243-1249

784. Vergani A, Tezza S, D'Addio F, Fotino C, Liu K, Niewczas M, Bassi R, Molano RD, Kleffel S, Petrelli A, Soleti A, Ammirati E, Frigerio M, Visner G, Grassi F, Ferrero ME, Corradi D, Abdi R, Ricordi C, Sayegh MH, Pileggi A, Fiorina P (2013) Long-term heart transplant survival by targeting the ionotropic purinergic receptor P2X7. Circulation 127:463-475

785. Ray FR, Huang W, Slater M, Barden JA (2002) Purinergic receptor distribution in endothelial cells in blood vessels: a basis for selection of coronary artery grafts. Atherosclerosis 162:55-61

786. Borna C, Wang L, Gudbjartsson T, Karlsson L, Jern S, Malmsjo M, Erlinge D (2003) Contractions in human coronary bypass vessels stimulated by extracellular nucleotides. Ann Thorac Surg 76:50-57

787. Downing SE, Lee JC, Weinstein EM (1982) Coronary dilator actions of adenosine and $\mathrm{CO}_{2}$ in experimental diabetes. Am J Physiol 243:H252-H258

788. Koltai MZ, Jermendy G, Kiss V, Wagner M, Pogátsa G (1984) The effects of sympathetic stimulation and adenosine on coronary circulation and heart function in diabetes mellitus. Acta Physiol Hung 63:119-125

789. Law WR, McLane MP, Raymond RM (1988) Adenosine is required for myocardial insulin responsiveness in vivo. Diabetes 37:842-845

790. Gür S (1997) Effects of adenosine and isoprenaline in left atria from both neonatal and middle-aged noninsulin-dependent diabetic rat models. Gen Pharmacol 29:517-522

791. Usta CK, Adan G, Özdem SS (2001) The effects of adenosine on isolated right atrial preparations from streptozotocin-diabetic rats. J Auton Pharmacol 21:191-195

792. Grden M, Podgórska M, Szutowicz A, Pawelczyk T (2005) Altered expression of adenosine receptors in heart of diabetic rat. J Physiol Pharmacol 56:587-597

793. Podgorska M, Kocbuch K, Grden M, Szutowicz A, Pawelczyk T (2006) Reduced ability to release adenosine by diabetic rat cardiac fibroblasts due to altered expression of nucleoside transporters. J Physiol 576:179-189

794. Bravo PE, Hage FG, Woodham RM, Heo J, Iskandrian AE (2008) Heart rate response to adenosine in patients with diabetes mellitus and normal myocardial perfusion imaging. Am J Cardiol 102:1103-1106

795. Yang Y, Duan W, Zhou J, Yan J, Liu J, Zhang J, Jin Z, Yi D (2012) Protective effects of adenosine on the diabetic myocardium against ischemia-reperfusion injury: role of calpain. Med Hypotheses 79: $462-464$

796. Hage FG, Wackers FJ, Bansal S, Chyun DA, Young LH, Inzucchi SE, Iskandrian AE (2013) The heart rate response to adenosine: a simple predictor of adverse cardiac outcomes in asymptomatic patients with type 2 diabetes. Int J Cardiol 167:2952-2957

797. Higuchi M, Uezu K, Sakanashi M (1993) Ex vivo effect of insulin on normal and diabetic rat hearts hypoperfused with norepinephrine. Eur J Pharmacol 242:293-300

798. Yu JZ, Quamme GA, McNeill JH (1995) Altered $\left[\mathrm{Ca}^{2+}\right]_{\mathrm{i}}$ mobilization in diabetic cardiomyocytes: responses to caffeine, $\mathrm{KCl}$, ouabain, and ATP. Diabetes Res Clin Pract 30:9-20

799. Musial DC, de Magalhães GK, Miranda-Ferreira R, da Silva D, Junior E, Caricati-Neto A, Jurkiewicz NH, Jurkiewicz A, Broetto Biazon AC (2012) Alteration of purinergic neurotransmission in 
isolated atria of streptozotocin-induced diabetic rats. J Cardiovasc Pharmacol 59:158-164

800. Lagerqvist B, Sylvén C, Helmius G, Waldenström A (1990) Effects of exogenous adenosine in a patient with transplanted heart. Evidence for adenosine as a messenger in angina pectoris. Ups $\mathrm{J}$ Med Sci 95:137-145

801. Crea F, Pupita G, Galassi AR, el-Tamimi H, Kaski JC, Davies G, Maseri A (1990) Role of adenosine in pathogenesis of anginal pain. Circulation 81:164-172

802. Crea F, Gaspardone A, Kaski JC, Davies G, Maseri A (1992) Relation between stimulation site of cardiac afferent nerves by adenosine and distribution of cardiac pain: results of a study in patients with stable angina. J Am Coll Cardiol 20:1498-1502

803. Sylvén C (1993) Mechanisms of pain in angina pectoris - a critical review of the adenosine hypothesis. Cardiovasc Drugs Ther 7:745759

804. Mehta AB, Mardikar HM, Hiregoudar NS, Sethi RB, Solanki DR, Mathew R (1997) Adenosine-induced chest pain: is it due to myocardial ischaemia? Clinical, electrocardiographic, haemodynamic and metabolic study. Indian Heart J 49:267-270

805. Tommasi S, Carluccio E, Bentivoglio M, Corea L, Picano E (2000) Low-dose dipyridamole infusion acutely increases exercise capacity in angina pectoris: a double-blind, placebo controlled crossover stress echocardiographic study. J Am Coll Cardiol 35:83-88

806. Sylvén C, Eriksson B, Sheps DS, Maixner B (1996) Beta-endorphin but not metenkephalin counteracts adenosine-provoked angina pectoris-like pain. Neuroreport 7:1982-1984

807. Sadigh-Lindell B, Sylvén C, Berglund M, Eriksson BE (2004) High-dose adenosine infusion provokes oscillations of chest pain without correlation to opioid modulation: a double-blind controlled study. J Pain 5:469-475
808. Elzein E, Zablocki J (2008) A1 adenosine receptor agonists and their potential therapeutic applications. Expert Opin Investig Drugs 17:1901-1910

809. Kugler G (1979) Myocardial release of inosine, hypoxanthine and lactate during pacing-induced angina in humans with coronary artery disease. Eur J Cardiol 9:227-240

810. Kasai T, Yamashina A, Kubo T, Usui Y, Mori Y (1999) Detection of culprit lesion in patients with unstable angina pectoris by using ATP thallium-201 myocardial SPECT. Kaku Igaku 36:819-826

811. Paidas CN, Dudgeon DL, Haller JA Jr, Clemens MG (1988) Adenosine triphosphate: a potential therapy for hypoxic pulmonary hypertension. J Pediatr Surg 23:1154-1160

812. Paidas CN, Dudgeon DL, Haller JA Jr, Clemens MG (1989) Adenosine triphosphate (ATP) treatment of hypoxic pulmonary hypertension (HPH): comparison of dose dependence in pulmonary and renal circulations. J Surg Res 46:374-379

813. Konduri GG, Woodard LL (1991) Selective pulmonary vasodilation by low-dose infusion of adenosine triphosphate in newborn lambs. J Pediatr 119:94-102

814. Konduri GG, Theodorou AA, Mukhopadhyay A, Deshmukh DR (1992) Adenosine triphosphate and adenosine increase the pulmonary blood flow to postnatal levels in fetal lambs. Pediatr Res 31: 451-457

815. Kääpä P, Jahnukainen T, Grönlund J, Rautanen M, Halkola L, Välimäki I (1997) Adenosine triphosphate treatment for meconium aspiration-induced pulmonary hypertension in pigs. Acta Physiol Scand 160:283-289

816. Brook MM, Fineman JR, Bolinger AM, Wong AF, Heymann MA, Soifer SJ (1994) Use of ATP- $\mathrm{MgCl}_{2}$ in the evaluation and treatment of children with pulmonary hypertension secondary to congenital heart defects. Circulation 90:1287-1293 